\title{
7. DESIGN AND PERFORMANCE OF DIAMOND AND ROLLER-CONE BITS ${ }^{1}$
}

\author{
G.L. Holloway ${ }^{2}$
}

\section{EXECUTIVE SUMMARY}

Several new styles of drill bits were designed for the nested drill-in bottom-hole assemblies (DI-BHA) deployed during Ocean Drilling Program (ODP) Leg 142 at the East Pacific Rise (EPR). The nested DI-BHA required the primary stage collars to have a 7-3/8-in. $(18.3 \mathrm{~cm})$ bore and the secondary stage drill collars to have a 4.125 -in. $(10.5 \mathrm{~cm})$ bore. Center bits were designed in conjunction with both bit sizes to remove the core as the outer bits were drilled to depth. Two sizes of primary stage DI-BHA bits were manufactured: a $12-1 / 2$-in. $(31.75 \mathrm{~cm}) 6$-cone roller bit and 11-1/4-in. $(28.6 \mathrm{~cm})$ diamond bits. Both of these bits were run on specially designed 10-3/4-in. $(27.3 \mathrm{~cm})$ drill collars. The second stage of the nested system provided only $7-1 / 4-$ in. $(17.2 \mathrm{~cm})$ diamond bits as the outer bit option. The secondstage bits were run on 6-3/4-in. $(17.2 \mathrm{~cm})$ drill collars with a 4-1/8-in. $(10.5 \mathrm{~cm})$ bore.

The center bits developed were all roller-cone type with the option of either 1- or 2-cone bits. Center-bit latches were used to hold the center bits in position during drilling operations. These latches were not only required to take the full torque of the drilling assemblies but also to be vertically adjustable and wireline retrievable. The large latching system for the 7-1/4-in. $(18.4 \mathrm{~cm})$ roller-cone center bit was designed from a modified casing advancer latch adopted from the mining industry. The smaller size latch for the 4 -in. $(10.2 \mathrm{~cm})$ center bits was a modified version of ODP's extended core barrel (XCB) latch. Several special application bits were also designed for use in the DI-BHA system and diamond coring barrel (DCB). These 7-1/4in. $(18.4 \mathrm{~cm})$ bits included a diamond coring bit for use with the DCB, an impregnated diamond reaming bit with stinger-bit assembly, and a tricone bit.

A considerable amount of information was learned from all the bits run during Leg 142 . The different combinations of center bits run with roller-cone and diamond outer bits provided a considerable amount of insight as to which direction bit design should proceed in the future. The two sizes of tricone bits $(12-1 / 2 \mathrm{in}$. [31.75 cm] and $7-1 / 4 \mathrm{in}$. [18.4 cm] ) proved to be the most robust and performed the majority of work in deepening the boreholes. The large 12-1/2-in. $(31.75 \mathrm{~cm}) 6$-cone roller bits proved effective at cutting the material; however, impact loading from heave with relatively light bit weight resulted in premature demolition of the bits. The smaller 7-1/4-in. $(18.4 \mathrm{~cm})$ tricone bits provided similar penetration rates to those obtained by the larger tricone bits, but did not withstand long hours of rotation in the abrasive basalt and rubble. Probably the most promising of all the bits tried were the impregnated and surface-set diamond bits. Both types of diamond bits showed little wear after drilling through substantial rubble zones and massive flow units. Regardless of the bit size or type, longevity in the hard, abrasive basalt was considerably shorter than expected. Both sizes of the 1-cone center bit were also tried, with poor results reported each time.

\footnotetext{
${ }^{1}$ Storms, M.A., Batiza, R., et al., 1993. Proc. ODP, Init. Repts., 142: College Station, TX (Ocean Drilling Program).

${ }^{2}$ Ocean Drilling Program, Texas A\&M University, College Station, TX 77845 9547, U.S.A.
}

Five different manufacturers contributed to developing drill bits for Leg 142. Even though a considerable amount of effort was put into the design of the new bits, it was recognized that the drill bits were possibly the weakest link of the DI-BHA hardware. Experience from Legs 106 and 109 provided some guidance; however, the bits designed for Leg 142 presented an added complexity in that they not only needed to hold up to the rigors of hard-rock drilling but had to be designed with large open centers to allow a nested casing string clearance to pass. Discussion of the characteristics of each bit, along with field performance information, is provided in the following sections of this chapter. A bit-testing program is also outlined to supplement the field data gathered during the occupation of Holes $864 \mathrm{~A}, 864 \mathrm{~B}$, and $864 \mathrm{C}$. Also included are recommendations for future bit improvements and enhancements for longevity.

\section{INTRODUCTION}

The location selected for Leg 142, the East Pacific Rise, has been studied extensively with multiple seismic surveys and manned submersible dives in the past few years. Previous and ongoing petrologic studies have shed some light on the question of magmatic plumbing systems and magma chamber processes in the area. The dives made by the submersible Alvin have further advanced the understanding of the hydrothermal flow pattern and fluid/rock interaction. However, a considerable amount of information is still unknown, since only shallow surface samples have been collected. Leg 142 was planned to help provide definitive answers to these questions about the origin of ocean-generated crust. The coordinates of the primary drilling location (EPR-2) were $9^{\circ} 30.85^{\prime} \mathrm{N}$ latitude, $104^{\circ} 14.66^{\prime} \mathrm{W}$ longitude. The site is located in approximately $8430 \mathrm{ft}(2570 \mathrm{~m})$ of water.

This chapter describes and discusses the drill bits deployed at EPR during the course of Leg 142. The drill bits were designed to be used in conjunction with the new nested DI-BHA in order to allow the deployment of both the 7-1/4-in. $(18.4 \mathrm{~cm})$ DCB and the 4-in. $(10.2 \mathrm{~cm})$ diamond coring system (DCS). The DCB is a slimhole diamond core barrel compatible with ODP's rotary core barrel (RCB), which cuts a 2.312 -in. ( $58.7 \mathrm{~mm}$ ) core. The DCS is a mini-drilling rig suspended within the main derrick of the JOIDES Resolution. The slimhole DCS core barrel takes a 2.20-in. ( $55.8 \mathrm{~mm})$ core. A schematic of the DCS platform and supporting subsea hardware is illustrated in Figure 1. Figures 2 and 3 provide the different coring and spudding options available for Leg 142 .

Several styles, types, and quantities of bits were designed for the leg since it was unknown exactly what percentages of the formation would be massive or fractured basalts and how much rubble would be found. Hole diameter was a major concern since the zone of disturbance produced by a drill bit is in proportion to the bit's diameter. Typically, the smaller the bit diameter the less likely downhole stability problems would arise, causing drilling difficulties. The amount of material removed from the formation is also a function of hole diameter, as is the time required to drill.

The upper limit placed on the large-diameter bits designed for Leg 142 was held in check by the size of the DI-BHA hardware and the stabilization scheme to keep the hole centered in the landing seat. The inner diameter (ID) of the bore of the bit had to be opened as large as possible so that the secondary DI-BHA would have adequate clearance 


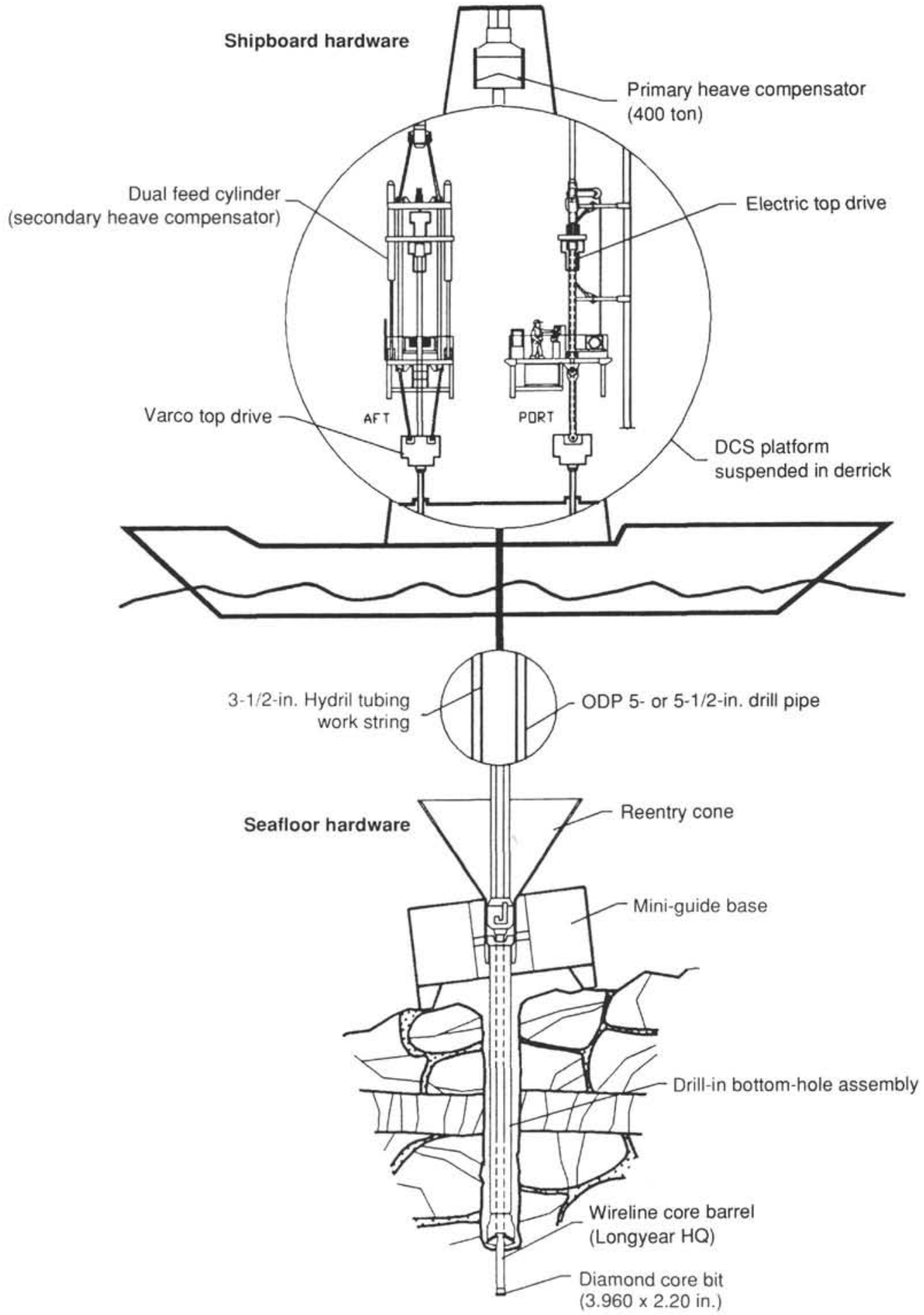

Figure 1. Diamond coring system, Phase II (4500 m depth capacity).

in which to pass. This combination produced a large-diameter rollercone bit with small exterior cones. We hoped that the combination of the center bit used with the 6 -cone outer bit would produce a cutting surface that would aggressively penetrate the massive basalt expected at EPR. Because we feared that either the formation or environmental conditions might be detrimental to the life of roller-cone-style bits, a similar concept was pursued with large-diameter diamond bits. In addition to the new sizes of roller-cone and diamond bits produced for Leg 142, several hybrid design concepts were tried as well, based on the recommendations from Legs 106 and 109. These concepts are discussed in detail in the appropriate sections describing the bits.

Three holes were drilled during Leg 142, in which a total of 15 bits were run and tested. Hole $864 \mathrm{~A}$ was the only hole in which DCS operations were conducted. Highlights of operations in Hole 864A were setting both a 10-3/4-in. $(27.3 \mathrm{~cm})$ and 6-3/4-in. $(17.2 \mathrm{~cm})$ DI-BHA. Coring with the DCS was attempted after each stage of the DI-BHA was installed. However, problems with the secondary compensation system prevented its effective use. The two other holes 


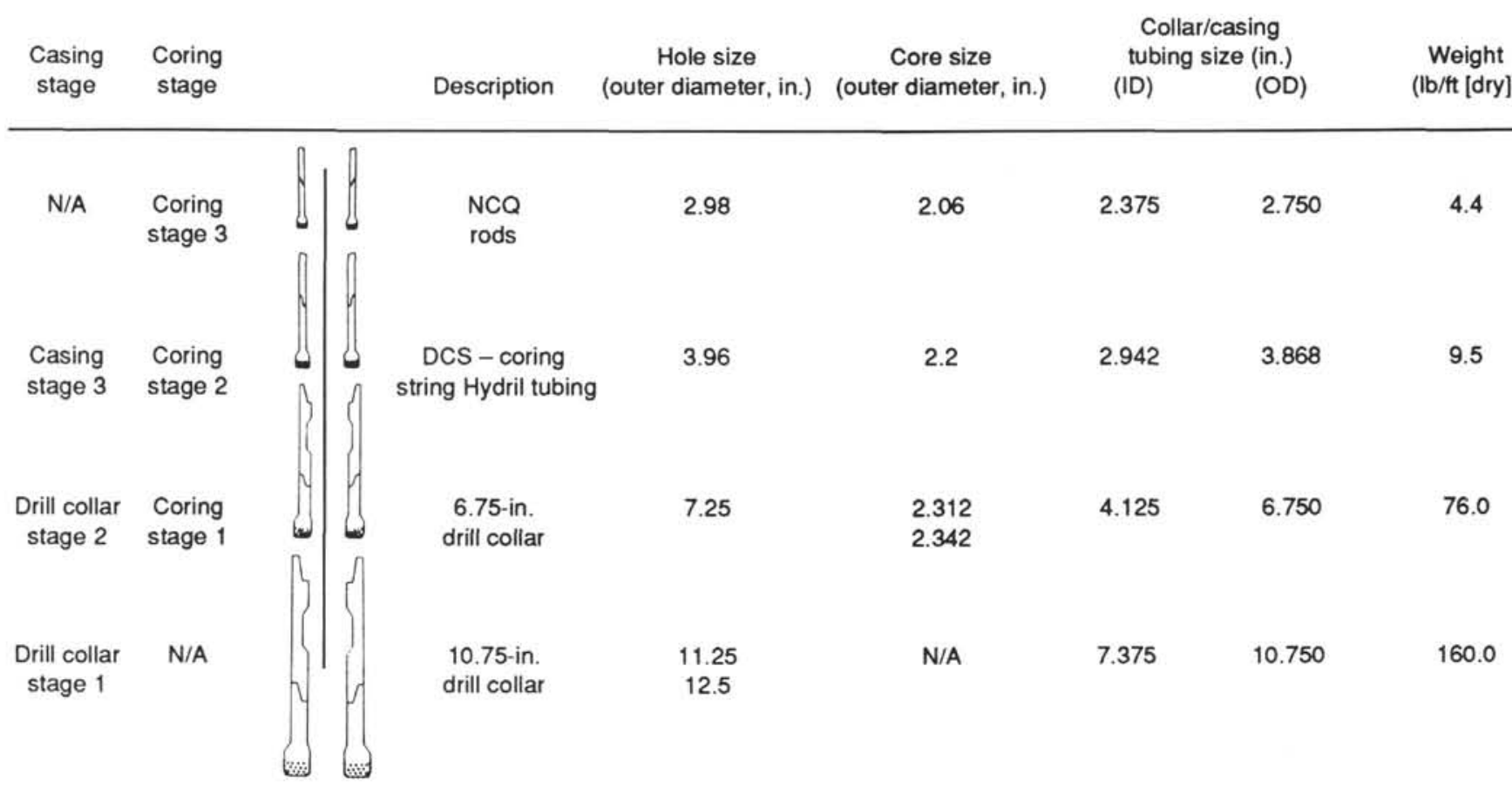

Figure 2. DCS/DCB drill-in casing/coring options. (NCQ cores not available for Leg 142.)

(864B and $864 \mathrm{C}$ ) were primarily used to test different bits and combinations of center bits. Hole $864 \mathrm{~B}$ was also used to test the prototype DCB.

\section{BACKGROUND}

One of the primary objectives of Leg 132 was to provide a cased hole to isolate unstable formations in the upper portion of the borehole so that the DCS could be deployed as soon as possible. This was accomplished by drilling in and backing off a BHA. The drill bits required to perform this operation were similar to ODP's conventional roller-cone coring bits, but with the throat enlarged to a diameter of 4.05 in. $(10.3 \mathrm{~cm})$ to allow the DCS core bit/tubing to pass. In order to ensure that core would not enter the bit and pass into the BHA while drilling in the assembly, the bits were designed to accept a removable center bit.

The deployment location of these bits mandated that they be protected as much as possible to ensure that the highly abrasive formations would not prematurely limit the life of the bits. Short bit-life has a significant impact on how the drill-in BHA systems perform. Two sizes of bits were manufactured for Leg 132: 11-5/8-in. $(29.5 \mathrm{~cm})$ and 9-7/8-in. $(25.1 \mathrm{~cm}) 4$-cone bits. In addition to the two sizes of bits provided, two different types of cutting structures were used on these bits because several formation types were to be attempted during Leg 132.

Upon completion of Leg 132, it was felt that a dual-or nested casing concept should be developed to enhance the depth capabilities of the DCS when encountering unstable formations at depth. The original prototype DI-BHA system developed for Leg 132 would still be retained as a back-up system to be used if the larger hole size of the nested system proved unfeasible or difficult to drill in certain formations.

In order to develop this nested system, new drill bits also had to be designed to allow the two larger strings to be deployed prior to initiating DCS coring. Hole size for the DCS is $3.96 \mathrm{in}$. (100.6 mm). Working backward from the size of hole required for the DCS, the two largest BHA sizes for the DI-BHA consisted of $10-3 / 4 \times 7-3 / 8$-in. $(27.3 \times 18.7 \mathrm{~cm})$ and 6-3/4 $\times 4-1 / 8$-in. $(17.2 \times 10.5 \mathrm{~cm})$ drill collars. Since strength was an important factor, thin-walled casing was unacceptable. Therefore, the thick-walled drill collars were designed as the DI-BHA. Also, because the drill collars selected were a nonstandard size due to the bore requirements, a new thread form was designed for both. Another requirement for the nested system was a way to prevent core from entering the BHA. This required the development of removable center bits along with a latching system to retain them during drilling operations.

A $12-1 / 2 \times 7.92$-in. $(31.75 \times 20.1 \mathrm{~cm})$ large-diameter roller-cone bit was developed as the primary nested system bit. A slightly smaller sized diamond bit $(11-1 / 4 \times 7-5 / 16$ in. $[28.6 \times 18.6 \mathrm{~cm}])$ was also developed as an alternative to the roller cone. Secondary sized bits for the 6-3/4-in. $(17.2 \mathrm{~cm})$ string consisted solely of diamond bits. Size selected for these bits were $7-1 / 4 \times 4-1 / 8 \mathrm{in}$. $(18.4 \times 10.5 \mathrm{~cm})$, with both surface-set and impregnated bits developed. Center bits for the two sizes of DI-BHAs consisted of two types of 7-1/4-in. $(18.4 \mathrm{~cm})$ roller-cone bits (1- and 2-cone), along with two types of 4-in. (10.2 cm) roller-cone bits (1-and 2-cone). Some additional tricone bits for both sizes of DI-BHAs $(12-1 / 2$ in. [31.75 cm] and 7-1/4 in. [18.4 cm] ) were also designed, which allowed flexibility in the hardware should formation conditions be stable enough for their use.

This chapter presents all of the bit options available for Leg 142 (Figs. 4, 5, and 6), along with laboratory test results conducted on the large roller-cone nested assembly. Performance evaluation of the bits run, along with suggested improvements for future applications, is also included.

\section{PRIMARY NESTED BIT OPTIONS}

\section{2-1/2-in. 6-cone Roller Bit}

The bit designed for the primary nested DI-BHA was a 6-cone roller bit. Size requirements for the nested 6-3/4-in. $(17.2 \mathrm{~cm})$ string required the large bit to have a throat of a least 7-5/16 in. $(18.6 \mathrm{~cm})$ for the 7-1/4-in. $(18.4 \mathrm{~cm})$ secondary stage bit to pass. The large roller-cone bit is made up of six 4-3/4-in. (12 cm) journal-bearingstyle cones placed in pairs between three integral hybrid pads. Three junk slots are also positioned between each of the three groups of pads/cones. The cones are actually positioned to cut a 7.92-in.-gage $(20.1 \mathrm{~cm})$ hole because of the potential of the DCS tubing to lay over on one side near an upset and protrude into one of the carbide inserts 


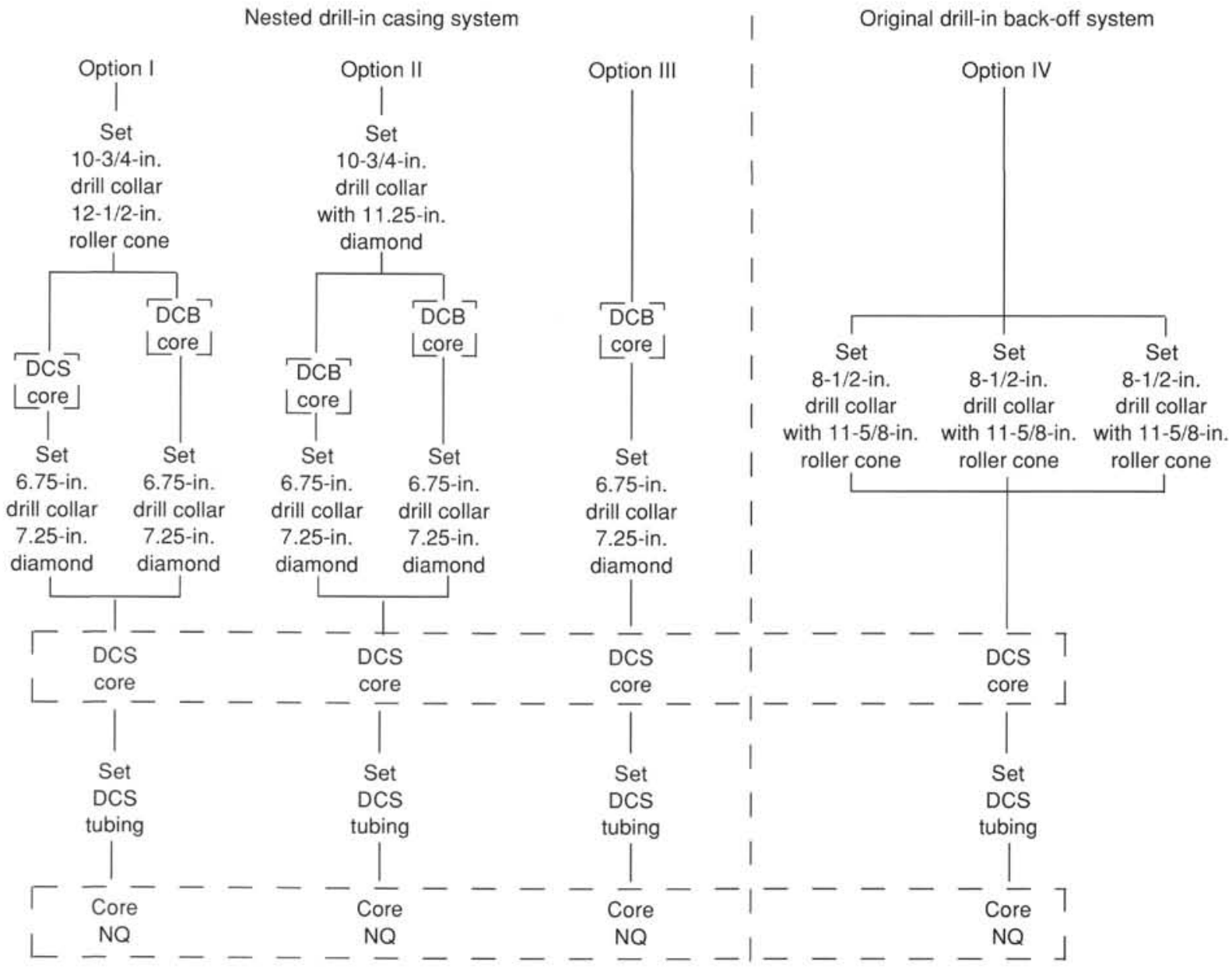

Figure 3. Seafloor spudding options for hard-rock locations.

on the cones themselves. The additional diameter was actually not required since a centralization scheme for the DCS tubing was developed after the drill bit had already been manufactured. The bit is further protected on the shirttails with hard facing on the leading edge and tungsten carbide shirttail compacts. Protective guards were welded behind the grease reservoir to provide extra wear protection. The hybrid pads were a new addition which ODP had never tried before on a bit. In concept, should the small cones be lost, the pads would provide another cutting surface to allow the bit to continue to make hole. The pads are protected with compacts placed on the face and along the outer diameter (OD) of the bit body. The face and cone compacts used are designated as an M89TF by the manufacturer. The "M" describes the compact selected for medium to hard formations. The inserts are shaped with a moderate extension with a closely spaced chisel design. There are no jet or flow ports in the bit. A modified $60^{\circ}$ stub-V box thread was used on these large bits. International Association of Drilling Contractors (IADC) description of the bit is given as a $627 \mathrm{X}$. Table 1 presents a listing of the roller-cone bits available for DI-BHA operations. Figure 7 presents a schematic of the $12-1 / 2$-in. $(31.75 \mathrm{~cm}) 6$-cone roller bit with actual illustrations presented in Figures 8 and 9.

\section{1-1/4-in. Diamond Bit}

Two styles of diamonds bits were manufactured as an alternative to the roller-cone bits. These bits produced a outside hole diameter of $11-1 / 4$ in. $(28.6 \mathrm{~cm})$, which was slightly smaller than the large rollercone bits used for the primary nested system. The smaller diameter was selected to reduce the size of the hole in an attempt to limit the amount of damage done to the formation. Two different design philosophies were adopted in the manufacture of these bits since rotational speeds were expected to be below $140 \mathrm{rpm}$. Hobic recommended the more conventional impregnated approach, whereas Longyear suggested a surface-set bit with carbonado-type diamonds. Descriptions of each bit are presented in the following paragraphs and summarized in Table 2, and a comparison of bit profiles is presented in Figure 10.

\section{Impregnated Bit}

Impregnated bits were manufactured by Hobic based on hard-fractured basalts expected at the EPR location. These bits used a semiround profile with an OD gage of $11-1 / 4$ in. $(28.6 \mathrm{~cm})$ and an ID gage of $7-5 / 16$ in. $(18.6 \mathrm{~cm})$. Hobic designates the semiround profile as an $\mathrm{H} 403$. The bit has 18 waterways that are $0.2 \mathrm{in}$. wide $(5 \mathrm{~mm}) \times 0.35 \mathrm{in}$. deep $(9 \mathrm{~mm})$. The bit matrix was set with a $20-25$-mesh-size synthetic grit industrial diamond which had a total concentration of approximately 1300 carats (ct). The industrial diamonds were graded as a DeBeers SDA 100. Due to the size of the bit throat required, the same modified 10-3/4-in. (27.3 cm) $60^{\circ}$ stub-V (Hycalog type) thread used on the roller-cone bit was again employed. Overall length of the bit was identical to the larger roller cone so that the same center-bit spacers could be interchanged.

\section{Surface-set Bit}

Surface-set bits with carbonado diamonds were recommended by Longyear as the preferred choice for drilling fractured basalt at EPR 


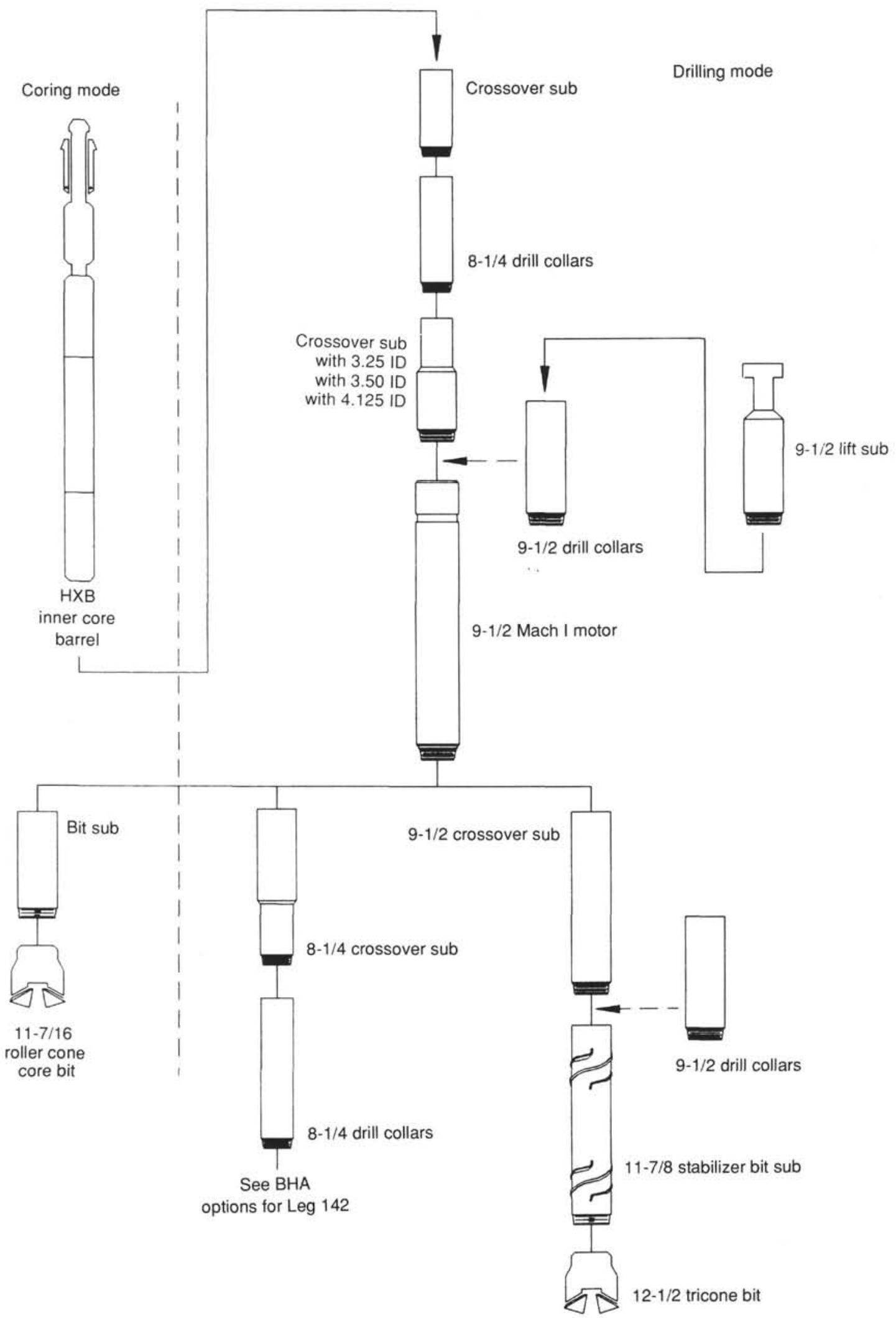

Figure 4. Drilling options with positive displacement coring motor. All dimensions in inches. 


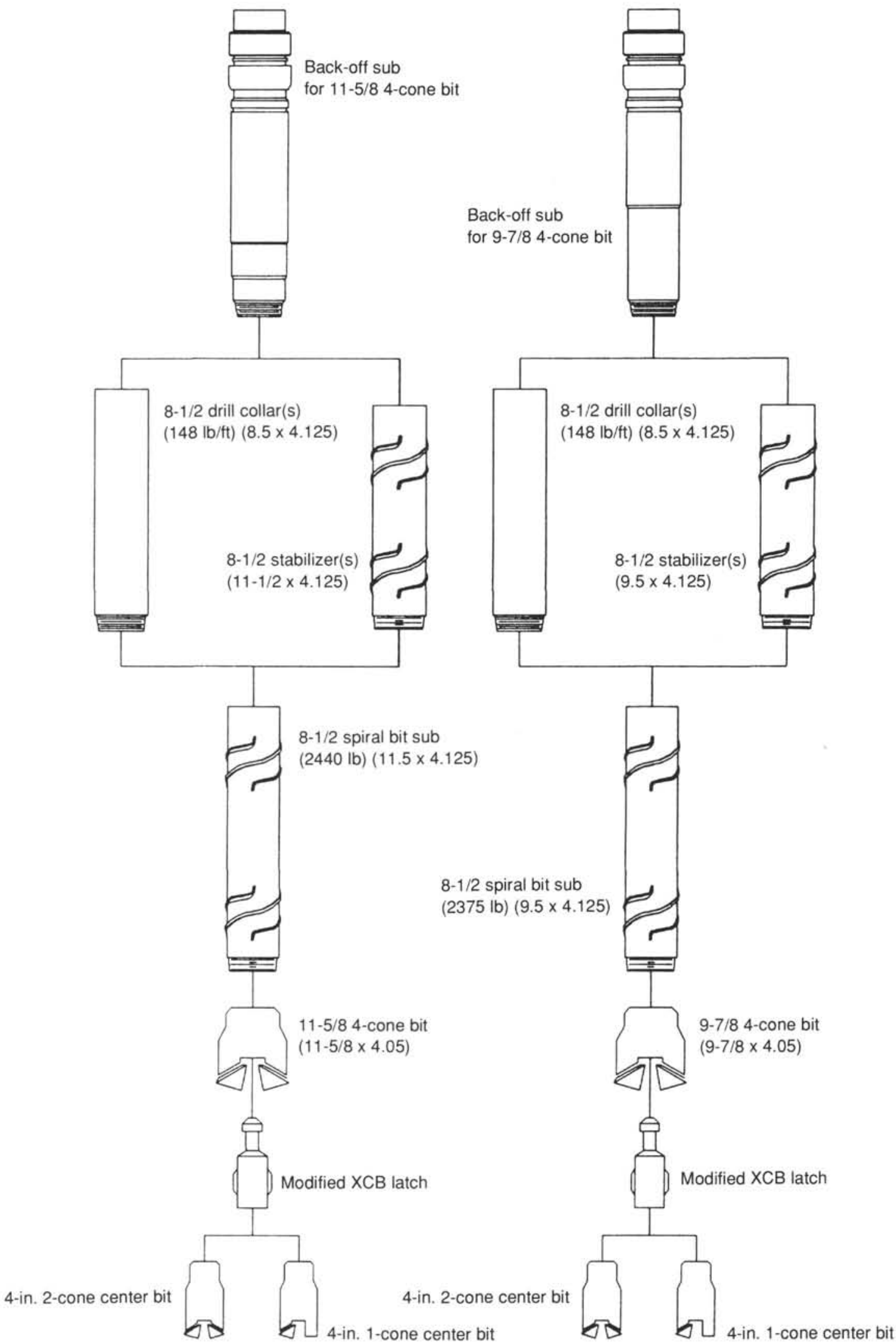

Figure 5. Original drill-in back-off system. (All weights are reported as dry.) All dimensions in inches unless otherwise noted. 
First stage

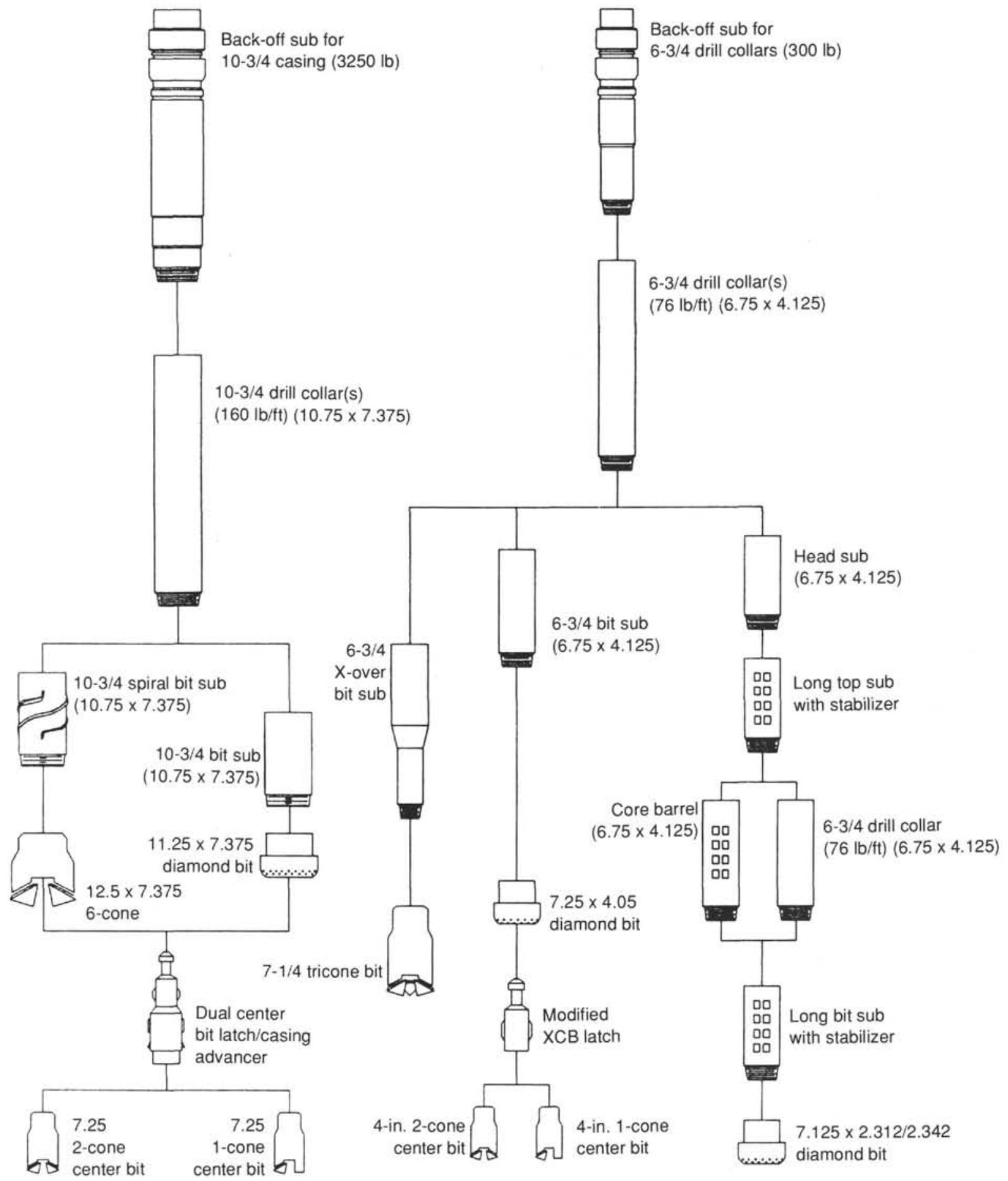

First or second stage

Back-off sub for

-3/4 drill collar(s)

$(76 \mathrm{lb} / \mathrm{ft})(6.75 \times 4.125)$

Figure 6. Nested drill-in back-off system (modified Leg 132 system). Dimensions in inches.

(Fig. 11). Longyear felt that these bits were more forgiving than the impregnated style bit. The carbonado diamond, also called black diamonds, exhibit very few cleavage plains which make the stone typically harder than natural diamonds used in conventional surfaceset bits. The bits manufactured by Longyear had the same dimensions and thread form as the impregnated bits produced by Hobic. However, the Longyear bits had five junk slots placed $72^{\circ}$ apart. The carbonado bits used 4 to 6 stones per carat, with a total count per bit of $490 \mathrm{ct}$. There was a total of 30 water courses per bit with dimensions of $1 / 8$ in. wide $(3 \mathrm{~mm}) \times 3 / 16 \mathrm{in}$. deep $(5 \mathrm{~mm})$. The carbonado bit is shown alongside the impregnated bit in Figure 10.

\section{2-1/2-in. Tricone Bit}

As an alternative to the large 6-cone drill-in bits, a 12-1/2-in. $(31.75 \mathrm{~cm})$ tricone bit was developed. There was some concern as to the life of the small 4-3/4-in. (12 cm) bearings on the 6-cone bit, especially at the higher rpm typically generated by the positive dis- 
Table 1. Roller cone bits for drill-in BHA hardware.

\begin{tabular}{|c|c|c|c|c|c|c|c|c|c|c|}
\hline Item & $\begin{array}{l}\text { Size } \\
\text { (in.) }\end{array}$ & $\begin{array}{l}\text { Inner } \\
\text { diameter } \\
\text { (in.) }\end{array}$ & Length & Description & $\begin{array}{l}\text { Number } \\
\text { of cones }\end{array}$ & Compact & $\begin{array}{l}\text { LADC } \\
\text { grade }\end{array}$ & Flow ports & $\begin{array}{l}\text { Size } \\
\text { (in.) }\end{array}$ & $\begin{array}{l}\text { Bearing } \\
\text { size (in.) }\end{array}$ \\
\hline 1 & 12.5 & 7.92 & 15.819 & Hybrid DI-BHA & 6 & M89TF & $627 \mathrm{X}$ & None & N/A & $4-3 / 4$ \\
\hline 2 & 12.5 & 7.92 & 15.819 & Hybrid DI-BHA & 6 & M89TF & $627 \mathrm{X}$ & None & N/A & $4-3 / 4$ \\
\hline 3 & 12.5 & 7.92 & 15.819 & Hybrid DI-BHA & 6 & M89TF & $627 \mathrm{X}$ & None & N/A & $4-3 / 4$ \\
\hline 4 & 11.625 & 4.05 & 13.5 & DI-BHA & 4 & $\mathrm{H} 87 \mathrm{~F}$ & $737 \mathrm{X}$ & 4 STD NB & N/A & $7-7 / 8$ \\
\hline 5 & 11.625 & 4.05 & 13.5 & DI-BHA & 4 & $\mathrm{H} 87 \mathrm{~F}$ & $737 \mathrm{X}$ & 4 STD NB & N/A & $7-7 / 8$ \\
\hline 6 & 11.625 & 4.05 & 13.5 & DI-BHA & 4 & $\mathrm{H} 87 \mathrm{~F}$ & $737 \mathrm{X}$ & 4 STD NB & N/A & $7-7 / 8$ \\
\hline 7 & 11.625 & 4.05 & 13.5 & DI-BHA & 4 & M84F & $617 X$ & 4 STD NB & N/A & $7-7 / 8$ \\
\hline 8 & 11.625 & 4.05 & 14.25 & Hybrid DI-BHA & 4 & M84F & $617 X$ & 4 & $7 / 16$ & $7-7 / 8$ \\
\hline 9 & 11.625 & 4.05 & 14.25 & Hybrid DI-BHA & 4 & M84F & $617 \mathrm{X}$ & 4 & $7 / 16$ & $7-7 / 8$ \\
\hline 10 & 9.875 & 4.05 & 12.625 & DI-BHA & 4 & $\mathrm{M} 84 \mathrm{~F}$ & $617 \mathrm{X}$ & 4 STD NB & N/A & $6-1 / 2$ \\
\hline 11 & 9.875 & 4.05 & 12.625 & DI-BHA & 4 & H87F & $737 \mathrm{X}$ & 4 STD NB & N/A & $6-1 / 2$ \\
\hline 12 & 9.875 & 4.05 & 14.25 & Hybrid DI-BHA & 4 & M84F & $617 X$ & 4 & $7 / 16$ & $6-1 / 2$ \\
\hline 13 & 9.875 & 4.05 & 14.25 & Hybrid DI-BHA & 4 & M84F & $617 \mathrm{X}$ & 4 & $7 / 16$ & $6-1 / 2$ \\
\hline 14 & 12.5 & N/A & & Tricone & 3 & M89FL & $637 \mathrm{Y}$ & 3 STD NB & N/A & \\
\hline
\end{tabular}

Notes: All bits manufactured by Security. STD NB refers to standard nozzle bore. N/A = not applicable.

placement coring motor (PDCM) used to spud the holes. Since drilling conditions were unknown for the EPR site, it was possible that this bit could be used to predrill a hole for the 6-cone DI-BHA if formation conditions allowed the hole to remain open. The larger cones and more robust design would be an added benefit especially in the hard basalts expected at the site. These tricone bits were a standard design off the shelf $(12-1 / 4 \mathrm{in}$. [31.1 cm] ) that were opened slightly to produce the $12-1 / 2$-in.-diameter $(31.75 \mathrm{~cm})$ required for the nested system. Compacts selected for this bit were an M89FL. Three standard nozzles were available for jet sizes ranging from $8 / 32$ in. $(6.35 \mathrm{~mm})$ to $18 / 32 \mathrm{in}$. (14.3 mm). The IADC designation of the bit is $632 \mathrm{Y}$.

\section{SECONDARY NESTED STAGE BIT OPTIONS}

All the bits designed for the second stage of the nested DI-BHA are diamond bits. This was dictated by the external and internal size requirements of the primary nested BHA and the DCS core bit. The secondary diamond bits were $7-1 / 4$-in. OD $(18.4 \mathrm{~cm}) \times 4.05$-in. ID $(10.3 \mathrm{~cm})$. The same two types of diamond bits (impregnated and carbonado) used for the primary hardware were again duplicated for the second-stage bits for the same reasons presented above. Hobic supplied four impregnated-style bits with three varying degrees of matrix hardness. These matrix hardness varied from medium hard to hard to extra hard. The matrix hardness corresponded to a different total carat weight in each type of bit. Medium hard bits were mixed with 575 total ct, hard bits with 600 total ct, and $650 \mathrm{ct}$ for the extra hard bits. Grit size ranged from 20 to 25 mesh for all three types of bits. All three bits were manufactured with semiround ( $\mathrm{H} 403)$ profiles. Fifteen waterway courses of 0.2 in. $(5 \mathrm{~mm}) \times 0.35$ in. $(9 \mathrm{~mm})$ were symmetrically positioned around the crown. The Longyear surface-set bits were identical in crown profile, stone size, and watercourse area as the larger primary stage Longyear bits. The only difference was the reduced total carat weight per bit. A complete listing of the diamond bits available is presented in Table 2. The secondary stage bits are illustrated in Figure 12.

\section{CENTER BIT OPTIONS}

\section{7-1/4-in. Center Bit}

Two styles of a 7-1/4-in. (18.4 cm) center bits (1-cone and 2-cone) were developed for use with the nested DI-BHA hardware. The two cone bit manufactured by Security was very similar to the smaller 4-in. $(10.2 \mathrm{~cm})$ version designed for the single stage back-off hardware of Leg 132. The larger version bit was designed with two 5/8-in. $(15.9 \mathrm{~mm})$ ports and $8-1 / 4$-in. $(6.35 \mathrm{~mm})$ flutes around the exterior body. This produced a flow area of $1.399 \mathrm{in} .(35.5 \mathrm{~mm})$ with an additional annular area of 1.435 in. $(36.5 \mathrm{~mm})$ between the OD of the center-bit body and the ID of the primary bit. The M89TF compacts selected were the same used in all the other Security bits designed for the EPR location. The overall length of the bit was selected at $15.1 \mathrm{in}$. $(38.4 \mathrm{~cm})$. A schematic of the center bit is presented in Figure 13.

The second type of bit designed employed a more radical approach. This bit manufactured by Rock Bit Industries (RBI) used a massive, single-cone bearing assembly (Fig. 14). The cone was offset to one side with a hybrid arm positioned $180^{\circ}$ from the cone. The arms, bit body, and shank were heavily reinforced with carbide inserts. Two 1/2-in. $(12.7 \mathrm{~mm})$ flow ports were positioned on the trailing side of the cone. The bit body was fluted with 4-7/16-in. (11 mm) flutes on both sides of the cone. Compacts designated by RBI as 411 (C-7) were used throughout the bit. IADC designation of the 1-cone center bit is 637 . This bit is compared to the 2-cone bit in Figure 15.

\section{4-in. Center Bit}

The 2-cone 4-in. (10.2 cm) center bit developed by Security for the single-stage back-off sub was modified slightly based on results from Leg 132. The most significant change made was diverting some of the flow through the bit around it. This was accomplished by increasing the diameter of the flow ports from $7 / 16$ in. $(11 \mathrm{~mm})$ to $1 / 2 \mathrm{in}$. (13 mm) through the body of the bit, along with repositioning the two flow ports. Flutes were also added to the stabilizer pads to help divert the flow around the bit. The same H100F compacts were again used. The overall length of the bit body was shortened to 13 in. $(33 \mathrm{~cm})$ in order to provide additional flexibility with the space out.

A second style of center bit was developed which had only a single cone instead of the two cones found on the Security bit. This bit was developed by RBI as a stronger alternative to the 2-cone option. The bit was designated as a 637 by the IADC grading system. Compacts selected for the abrasive basalt expected at EPR were designated as 231 by the manufacturer. Aside from the eccentric nature of the 1-cone, the bit body was similar in appearance to the 2-cone version. A schematic of both the 1-cone and 2-cone center bits is presented in Figure 16 with an actual illustration presented in Figure 17. A listing of all the center bits available for Leg 142 is presented in Table 3.

\section{SINGLE-STAGE BIT OPTIONS}

The two sizes of DI-BHA bits (11-5/8 in. [29.5 cm] and 9-7/8 in. [25.1 cm]) developed for Leg 132 were modified slightly as a back-up option to the nested system bits. The majority of the original design changes on both sizes of these bits was outlined in detail in the Leg 132 Initial Reports (Storms, Natland, et al., 1991). The most significant modification was the introduction of hybrid pads placed on the 


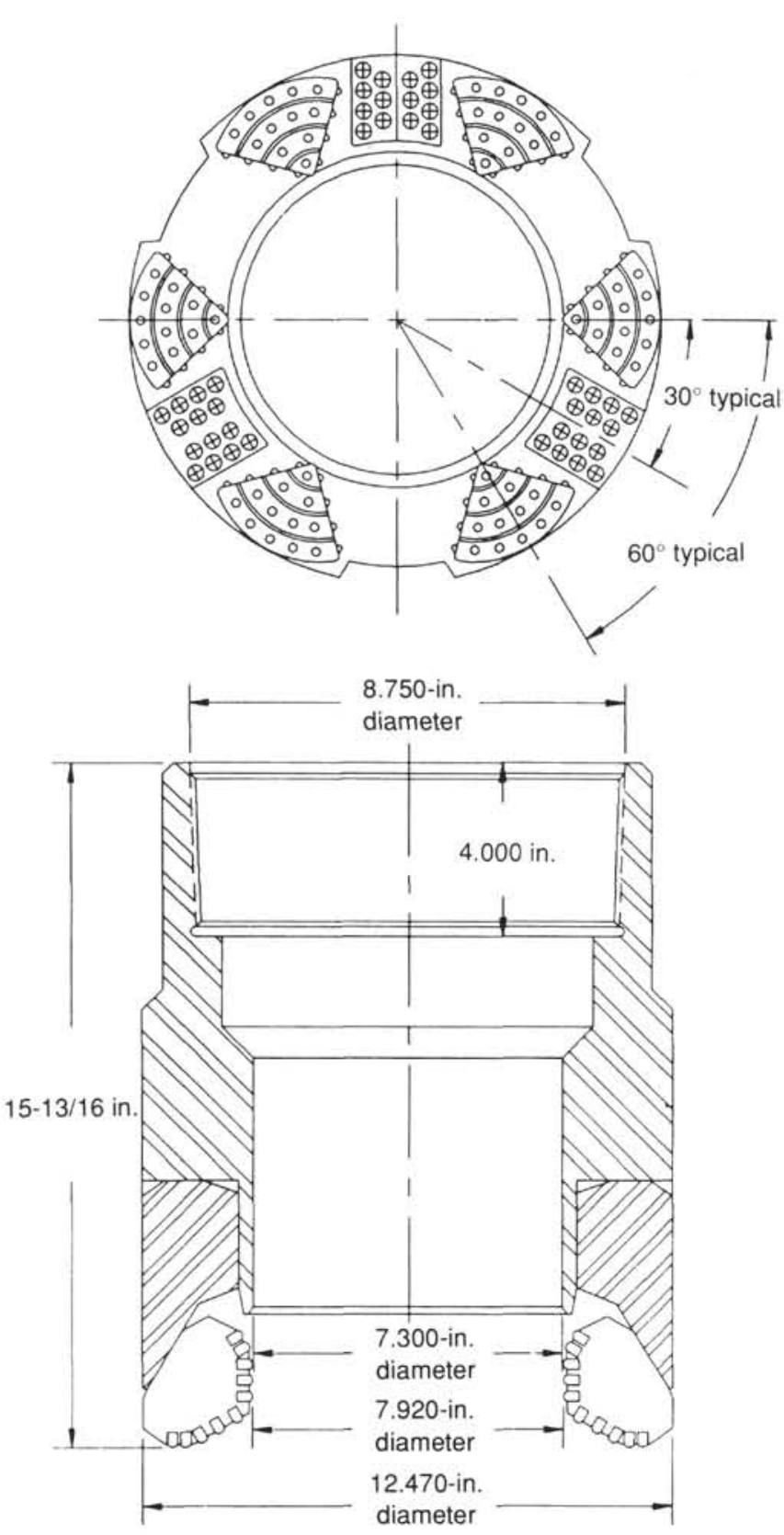

Figure 7. 12-1/2-in. Security 6-cone roller bit.

face of the bits. Experience gained during Legs 106 and 109 indicated that penetration rates were not significantly reduced once the cones either fell off or locked up and that drilling ahead with just a stub of a bit body proved just as successful as drilling with a new bit. The only drawback in allowing the bit to completely be destroyed is the potential problem of junk left in the hole, which the DCS bit would eventually encounter if the junk were not ground up or pushed into a cavity in the formation.

In an attempt to provide additional bit life and penetration, several of the single-stage DI-BHA bits were manufactured with hybrid pads. These pads were integral-body with heavy reinforcing of compacts and hardfacing. Compacts were placed on both the OD and face of the pads. A total of four independent pads were placed between the large roller cones. Pad dimensions are approximately 1 in. wide $(25.4 \mathrm{~mm}) \times 3$ in. long $(76.2 \mathrm{~mm})$ and extend to within $1 \mathrm{in}$. of the farthest compact on the cone. Four fixed 7/16-in. (11 mm)

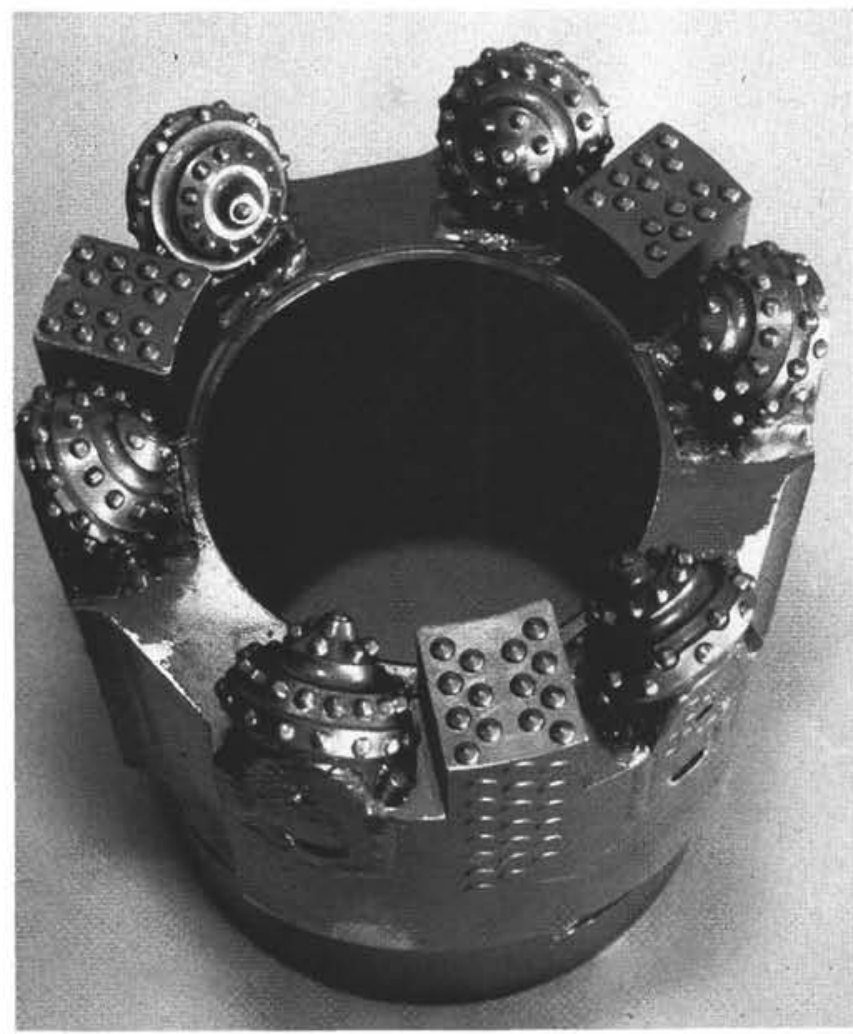

Figure 8. Security 12-1/2-in. 6-cone bit without center.

flow ports were added between each of the hybrid arms and roller cones. The 11-5/8-in. $(29.5 \mathrm{~cm})$ bits retain the 7-7/8-in. $(20 \mathrm{~cm})$ bearing, and the 9-7/8-in. $(25.1 \mathrm{~cm})$ bit has $6-1 / 2$-in. $(16.5 \mathrm{~cm})$ bearings. Both of the hybrid bits used Securities M84F compacts and were designated as $617 \mathrm{X}$ by IADC standards. Table 1 presents a listing of the roller-cone bits available for Leg 142 .

\section{CENTER-BIT LATCHES/SPACE-OUT ASSEMBLIES}

\section{7-1/4-in. Latch Assembly}

A large center-bit latch was designed and built in collaboration with Christensen Mining Products (CMP). The latch assembly was modified from a casing advancer latch that CMP sells commercially. The large latch assembly was designed to drive the 7-1/4-in. $(18.4 \mathrm{~cm})$ center bit for the primary stage DI-BHA hardware. The actual latch assembly consists of three separate pieces: (1) modified XCB latch, (2) 7-1/4-in. (18.4 cm) latch, and (3) bit sub.

The latch body was designed with two sets of dogs positioned $180^{\circ}$ out of phase. The large upper dogs used to drive the bit are rectangular in shape. Overall dimensions are $5.25 \mathrm{in}$. long $(13.3 \mathrm{~cm})$ and $1 \mathrm{in}$. wide $(2.54 \mathrm{~cm})$, with engagement depth approximately $0.5 \mathrm{in} .(12.7 \mathrm{~mm})$ per dog. Three springs provide positive engagement over the whole length of the dogs. Since the latch/bit assembly required only one direction operation, the triangular slots in the dogs were changed to elongated slots so that upward motion of the inner mandrel was required before the dogs would release. A schematic of the 7-1/4-in. $(18.4 \mathrm{~cm})$ latch assembly is shown in Figures 18 and 19. Figure 20 illustrates where the latch assembly is used in the seafloor operations.

The smaller dogs positioned beneath the driver dogs were primarily used as a safety latch to prevent the assembly from falling out the bottom of the bit in some unforeseen situation. The safety dogs were also designed so that they would operate in one direction only. These dogs were held open by a single spring and allowed to rotate about a retaining pin. 


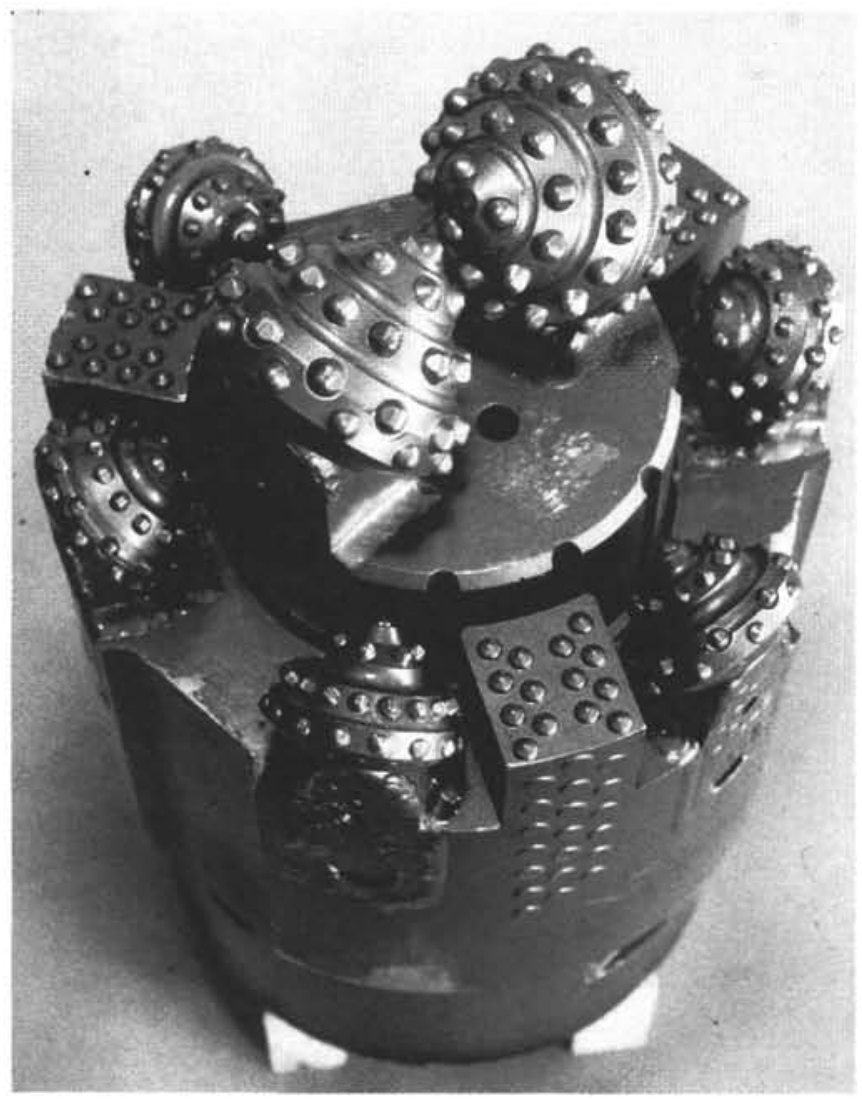

Figure 9 . Security 12-1/2-in. 6-cone bit with 2-cone center bit.

The bit sub was located beneath the latch body. This adapter was ported with four 1-in. $(25.4 \mathrm{~mm})$ holes and fluted along the OD to provide a passageway for fluid flow. There were sixteen 0.25 -in.-diameter $(6.35 \mathrm{~mm})$ flutes positioned at $22.5^{\circ}$ intervals around the adapter body. Three sizes of adapter bodies were manufactured in order to space the center at different elevations within the throat of the large outer bits. Additional elevations could be obtained using three shims placed between the latch body and bit sub.

The upper portion of the latch assembly used a modified version of ODP's XCB latch. This latch operates in ODP's standard 4-1/8in.-bore $(10.5 \mathrm{~cm})$ drill pipe. This smaller latch was necessary to capture the larger latch since it could not be retrieved through the API drill string. A schematic of how the small latch is used to retrieve the latch assembly is illustrated in Figure 21. This same latch is used in several other applications for seafloor deployments involving the DCS. Further description of the modified XCB latch is presented in the following section.

\section{4-in. Latch Assembly}

The 4-in. (10.2 cm) latch assembly is a modified version of ODP's XCB latch. Several modifications to the latch were made for Leg 132 where it was used to drive the center bit for the single-stage DI-BHA. This same latch with some additional modifications is used in several key operational deployments schemes for the DCS seafloor hardware. The modifications include:

1. Retrieval latch for 7-1/4-in. (18.4 cm) center bit for $10-3 / 4$-in. $(27.3 \mathrm{~cm})$ DI-BHA system,

2. Center-bit latch for 6-3/4-in. (17.2 cm) nested DI-BHA system,

3. Primary latch system for the single-stage DI-BHA system,

4. Holder latch for bit guide, and

5. Stinger-bit latch for 7-1/4-in. $(18.4 \mathrm{~cm})$ reaming-bit option.
Modifications made to the latch since it was use during Leg 132 include:

1. Placing a square shoulder on the bottom of the latch dogs,

2. Fluting the pulling neck,

3. Tapering the upper portion of the landing shoulder cap,

4. Slotting the washers to allow flow to pass, and

5. Reducing the slot length of the latch body.

Additional discussion of the modifications made to the latch for Leg 132 is included in that leg's Initial Reports (Storms, Natland, et al., 1991). Figures 22 through 25 illustrate the modified XCB latch in the various deployment schemes in which it was used on Leg 142.

\section{SPECIAL APPLICATION BITS}

\section{7-1/4-in. Diamond Core Barrel}

As the nested-stage drill-in BHA was being developed, it became apparent that the second stage could also be developed for use as a core barrel. Since the 6-3/4-in. $(17.2 \mathrm{~cm})$ drill collars would have the same bore as ODP's conventional hardware, the standard RCB wireline tools could be used to retrieve core. Thus, the DCB was developed as a smaller, diamond version of the standard RCB system. Diamond bits manufactured for this core barrel were made in two styles for Leg 142: the carbonado surface-set diamond bit and the impregnated-type bit. A schematic of the core barrel is illustrated in Figure 26, and a comparison of the two bits is shown in Figure 27. Table 4 presents a list of the DCS bits upon which the DCB bits were modeled.

Longyear again pursued the surface-set-style bit, and Hobic manufactured the impregnated-style bits. The Longyear bit is almost identical to the two other sizes of surface-set bit described in earlier sections of this report. Aside from the size of the throat (2.312 in. [58.7 mm] vs. 4.05 in. [102.9 mm]) and total carat weight $(245 \mathrm{ct})$, the only other noticeable difference is the number of waterways. The DCB bit has only 10 waterways across the face of the bit. The Hobic bit, also designed for the fractured formations at EPR, is again similar to the diamond bits that Hobic manufactured for the nested DI-BHA system, the only difference being the higher diamond concentrations in the newer bit. Two matrix/diamond combinations were manufactured by Hobic. These included bits with total carat weights of 700 and 800 . Additional information pertaining to both bits is presented in Table 2 .

\section{7-1/4-in. Reaming Bit}

A reaming bit was developed by Christensen Mining Products as a means to open the diameter of the DCS hole from $3.96 \mathrm{in}$. (100.6 mm) to $7-1 / 4$ in. (18.4 cm). The bit consists of three pieces of hardware: (1) the reaming bit, (2) a fluted stinger pipe, and (3) a stinger bit.

The stinger bit is run ahead of the reaming bit by $18 \mathrm{in} .(45.7 \mathrm{~cm})$ so that the reamed hole will remain concentric to the DCS hole. The reaming bit was designed as an option to open up the DCS hole so that conventional logging tools could be run. The only slimhole logging tools presently available for the smaller DCS hole is a caliper log and temperature log.

The impregnated bit is set with a matrix of 692 total ct of synthetic diamonds with a mesh size ranging from 25 to 35 . The bit has a V-ring-style face profile with six waterways and six face discharge ports. CMP designates the face profile as a $7 \mathrm{C}$. The six waterways are $1 / 4 \mathrm{in}$. wide $(6.35 \mathrm{~mm}) \times 5 / 8$ in. deep $(15.9 \mathrm{~mm})$. The face discharge ports are funneled through an internal manifold set up on a fluted stinger arrangement.

The stinger bit, which is slightly smaller than the DCS bit, is 3.94 in. in diameter. The small bit uses premium-grade 15-stones-per-carat natural diamonds with a total carat weight of nearly 74 . A concave face profile with 12 waterways of $3 / 16 \mathrm{in}$. wide $(5 \mathrm{~mm}) \times 3 / 16 \mathrm{in}$. deep $(5 \mathrm{~mm})$ are set on the stinger bit. 

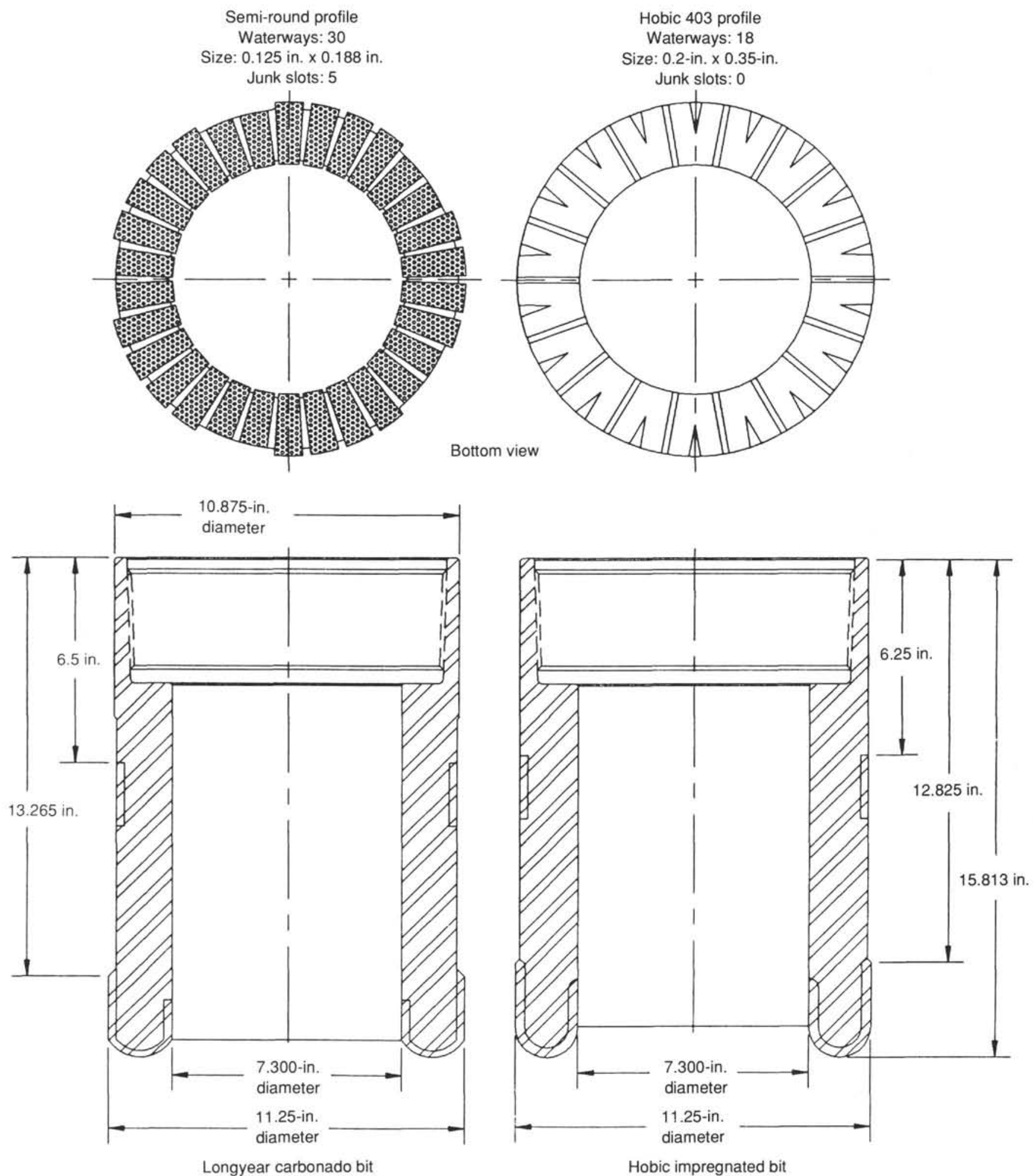

Figure 10. Primary stage drill-in BHA diamond bits.

The bit is attached to the stinger pipe, which is wireline retrieved. The stinger bit/pipe are latched into a bit sub with a modified XCBstyle latch. Flow is restricted at the stinger pipe exiting the throat of the reaming bit. Flow is divided between the manifold for face discharge onto the reamer bit and through the interior of the stinger pipe for discharge onto the concave face of the stinger bit. A schematic of the reaming-bit option is presented in Figure 24.

\section{7-1/4-in. Tricone Bit}

A rugged, full-face 7-1/4-in. $(18.4 \mathrm{~cm})$ tricone bit was manufactured to complement the 6-3/4-in. $(17.2 \mathrm{~cm})$ system as a drill-ahead option for the secondary stage of the nested DI-BHA. This bit can only be used in formations where conditions allow the string to be removed and an open-throat bit drilled in and backed off. The 7-1/4-in. (18.4 cm) 

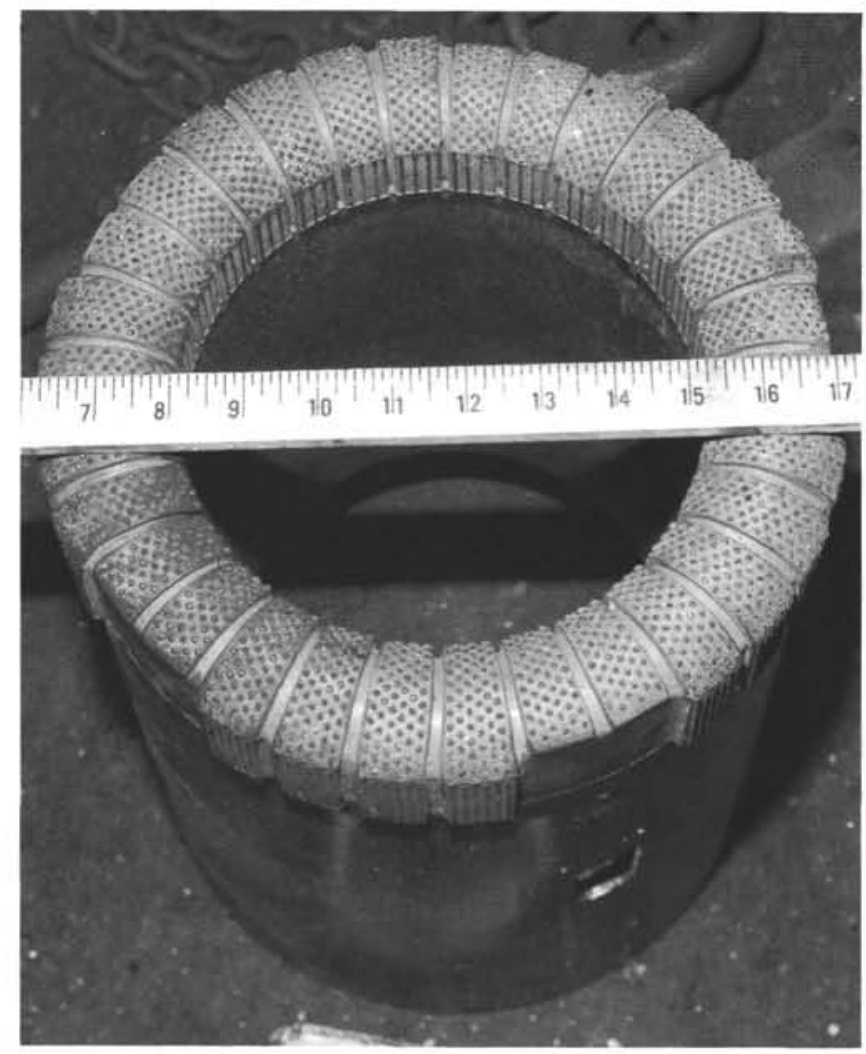

Figure 11. Longyear 11-1/2-in. carbonado bit.

tricone bit manufactured by RBI is strengthened with extra gage protection and hardfacing along the shirttails. The three nozzle ports can accept jet sizes ranging from $8 / 32$ in. $(6.35 \mathrm{~mm})$ to $18 / 32$ in. (14.3 $\mathrm{mm}$ ). The bit is designated as a 637 by IADC guidelines. A carbide insert specified as a 231 by RBI standards is used in the bit.

\section{LABORATORY TESTS}

Two series of bit test were run at Terra Tek's facility in Salt Lake City, Utah. These test were performed to verify the survivability of the small 4-3/4-in. $(12 \mathrm{~cm})$ bearings on the 12-1/2-in. $(31.75 \mathrm{~cm})$ 6 -cone roller bit. The tests were run on the $12-1 / 2$-in. $(31.75 \mathrm{~cm})$ 6 -cone roller bit in combination with a 7-1/4-in. $(18.4 \mathrm{~cm}) 2$-cone center bit. The first test series was performed in October 1991 with a complete bottom-hole assembly consisting of the following items:

1. 12-1/2-in. $(31.75 \mathrm{~cm}) 6$-cone roller bit,

2. 10-3/4-in. $(27.3 \mathrm{~cm})$ bit sub,

3. 7-1/4-in. (18.4 cm) 2-cone center bit,

4. casing advancer latch,

5. modified XCB latch, and

6. crossover sub.

A schematic of the drilling assembly is illustrated in Figure 28.

A second series of tests was performed the week of 16-20 December 1991. As the latch assembly hardware had been verified in the October test program, a small crossover sub was made that allowed the two bits to be tested together without the bit sub and full latch-assembly hardware. This compact test arrangement allowed for easy set-up and observation of the test at the surface instead of $20 \mathrm{ft}(6 \mathrm{~m})$ below in the test pit sump. A schematic of the bit assembly is presented in Figure 29.

\section{Test Series I}

At the recommendation of Security, the 7-1/4-in. $(18.4 \mathrm{~cm})$ center bit was positioned approximately $1 \mathrm{in}$. $(25.4 \mathrm{~mm})$ behind the main cones on the outer bit. Sierra white granite was the material selected for testing the bit because its characteristics (highly abrasive and similar compressive strength) were similar to those expected at the EPR. Table 5 presents the first seven passes made with the bit, along with the different drilling parameters (weights and rpm) used.

In summary, the placement of the center bit proved to be the main component in determining the wear and life on this particular bit. In less than $1-1 / 2 \mathrm{hr}$ on the bit, the nose on the leading six cones had worn away. This was partially due to the limited amount of carbide that could be placed on the nose of the small cones themselves. This limited nose area wore away rather quickly as the core being cut became larger and larger to a point where the center bit could not effectively remove it. An annular kerf was forming which was preventing the large bit from drilling ahead, thus reducing the penetration significantly. At this point the test was stopped because no meaningful data were being generated. This test confirmed that the center should be positioned ahead of the

Table 2. Diamond bits for nested drill-in BHA hardware.

\begin{tabular}{|c|c|c|c|c|c|c|c|c|c|c|}
\hline Item & $\begin{array}{l}\text { Size } \\
\text { (in.) }\end{array}$ & $\begin{array}{l}\text { Inner } \\
\text { diameter } \\
\text { (in.) }\end{array}$ & $\begin{array}{l}\text { Length } \\
\text { (in.) }\end{array}$ & Manufacturer & Description & Grade & $\begin{array}{l}\text { Stones per } \\
\text { carat/set wt }\end{array}$ & Profile & Waterways & $\begin{array}{l}\text { Size } \\
\text { (in.) }\end{array}$ \\
\hline 1 & 11.25 & 7.30 & 15.813 & Hobic & DI-BHA & $100 \mathrm{~S}$ & $20-25 / 1300$ & $\mathrm{H} 403$ & 18 & $0.2 \times 0.35$ \\
\hline 2 & 11.25 & 7.30 & 15.813 & Hobic & DI-BHA & $100 \mathrm{~S}$ & $20-25 / 1300$ & $\mathrm{H} 403$ & 18 & $0.2 \times 0.35$ \\
\hline 3 & 11.25 & 7.30 & 15.813 & Hobic & DI-BHA & $100 \mathrm{~S}$ & $20-25 / 1300$ & $\mathrm{H} 403$ & 18 & $0.2 \times 0.35$ \\
\hline 4 & 11.25 & 7.30 & 15.813 & Longyear & DI-BHA & Carb & $4-6 / 490$ & Semi-round & 30 & $1 / 8 \times 3 / 16$ \\
\hline 5 & 11.25 & 7.30 & 15.813 & Longyear & DI-BHA & Carb & 4-6/490 & Semi-round & 30 & $1 / 8 \times 3 / 16$ \\
\hline 6 & 7.25 & 4.05 & 14.50 & Christensen & Reaming & Synthetic & $25 / 35-692$ & $7 \mathrm{C}$ & $6 / 6$ & $1 / 4 \times .625$ \\
\hline 7 & 7.25 & 4.05 & 14.50 & Christensen & Reaming & Synthetic & $25 / 35-692$ & $7 \mathrm{C}$ & $6 / 6$ & $1 / 4 \times .625$ \\
\hline 8 & 7.25 & 4.05 & 14.25 & Hobic & DI-BHA & $100 \mathrm{~S}$ & $20-25 / 575$ & $\mathrm{H} 403$ & 15 & $0.2 \times 0.35$ \\
\hline 9 & 7.25 & 4.05 & 14.25 & Hobic & DI-BHA & $100 \mathrm{~S}$ & $20-25 / 575$ & $\mathrm{H} 403$ & 15 & $0.2 \times 0.35$ \\
\hline 10 & 7.25 & 4.05 & 14.25 & Hobic & DI-BHA (hard) & $100 \mathrm{~S}$ & $20-25 / 600$ & $\mathrm{H} 403$ & 15 & $0.2 \times 0.35$ \\
\hline 11 & 7.25 & 4.05 & 14.25 & Hobic & DI-BHA (extra hard) & $100 \mathrm{~S}$ & $20-25 / 650$ & $\mathrm{H} 403$ & 15 & $0.2 \times 0.35$ \\
\hline 12 & 7.25 & 4.05 & 14.25 & Longyear & DI-BHA & Carb & $4-6 / 230.4$ & Semi-round & 18 & $1 / 8 \times 3 / 16$ \\
\hline 13 & 7.25 & 4.05 & 14.25 & Longyear & DI-BHA & Carb & $4-6 / 230.4$ & Semi-round & 18 & $1 / 8 \times 3 / 16$ \\
\hline 14 & 7.25 & 2.33 & 12.123 & Longyear & DCB & Carb & $4-6 / 245$ & Semi-round & 10 & $1 / 8 \times 3 / 16$ \\
\hline 15 & 7.25 & 2.33 & 12.123 & Longyear & DCB & Carb & $4-6 / 245$ & Semi-round & 10 & $1 / 8 \times 3 / 16$ \\
\hline 16 & 7.25 & 2.33 & 12.123 & Longyear & DCB & Carb & $4-6 / 245$ & Semi-round & 10 & $1 / 8 \times 3 / 16$ \\
\hline 17 & 7.25 & 2.33 & 12.11 & Hobic & DCB & $100 \mathrm{~S}$ & $20-25 / 700$ & $\mathrm{H} 403$ & 15 & $0.2 \times 0.35$ \\
\hline 18 & 7.25 & 2.33 & 12.11 & Hobic & DCB & $100 \mathrm{~S}$ & $20-25 / 700$ & $\mathrm{H} 403$ & 15 & $0.2 \times 0.35$ \\
\hline 19 & 7.25 & 2.33 & 12.11 & Hobic & DCB (extra hard) & $100 \mathrm{~S}$ & $20-25 / 800$ & $\mathrm{H} 403$ & 15 & $0.2 \times 0.35$ \\
\hline 20 & 3.94 & $\mathrm{~N} / \mathrm{A}$ & 3.74 & Christensen & Stinger bit & Premium & $15-73.58$ & Concave & 12 & $3 / 16 \times 3 / 16$ \\
\hline 21 & 3.94 & N/A & 3.74 & Christensen & Stinger bit & Premium & $15-73.58$ & Concave & 12 & $3 / 16 \times 3 / 16$ \\
\hline
\end{tabular}

Notes: Reaming bit has six 3/8-in. face discharge ports in addition to 6 waterways. N/A $=$ not applicable. 

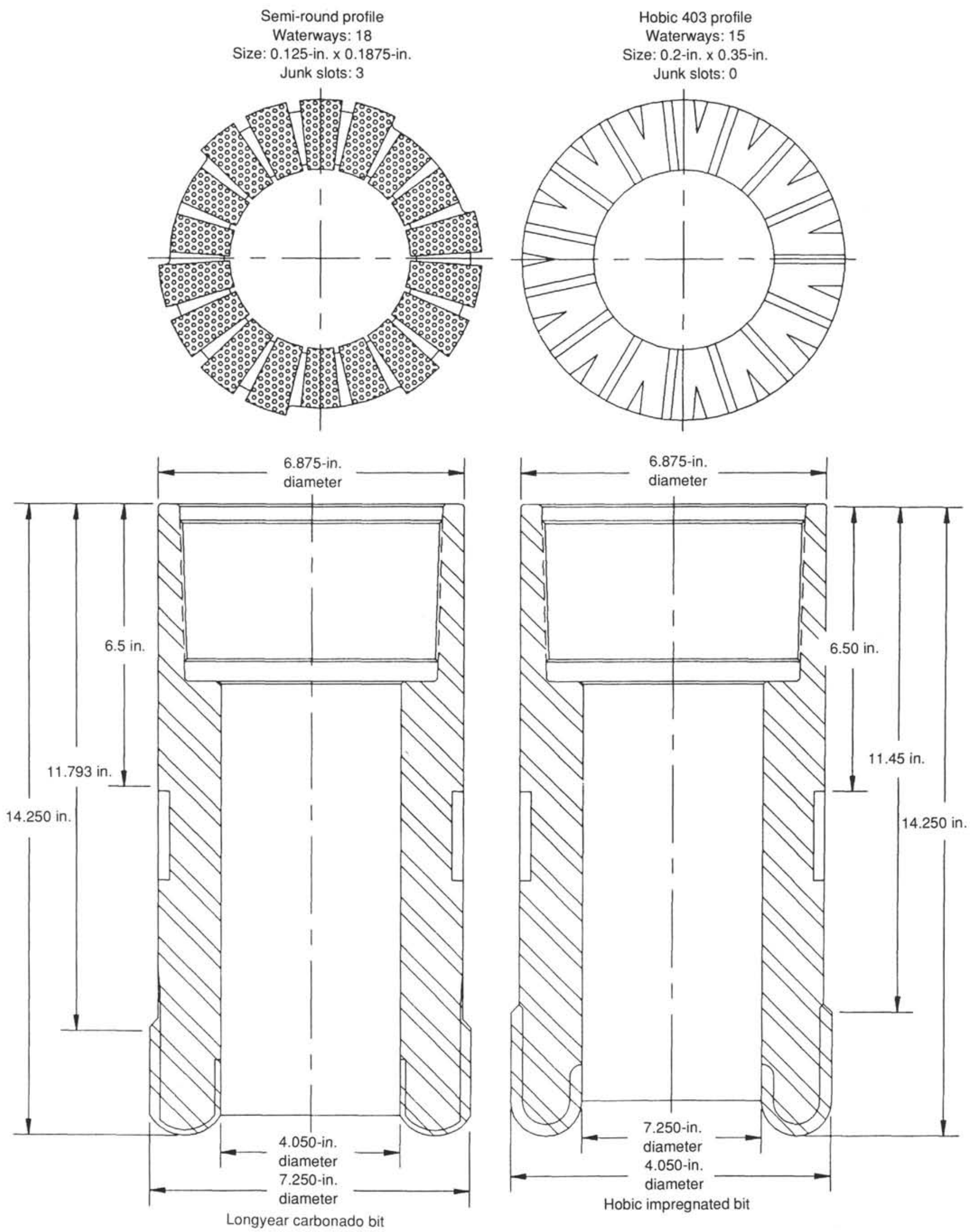

Figure 12. Secondary stage drill-in BHA diamond bits. 


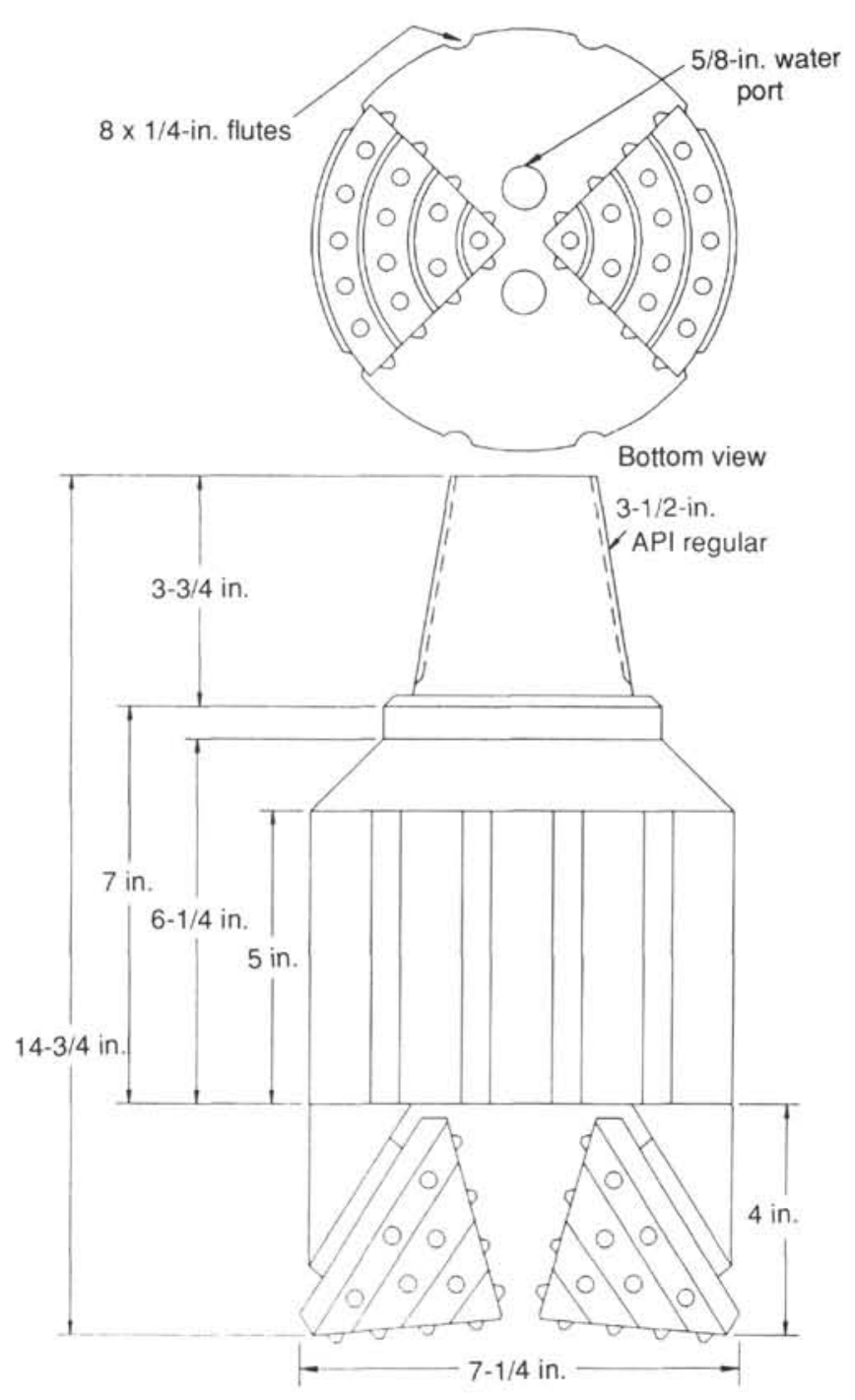

Figure 13. 7-1/4-in. Security 2 -cone roller bit.

outer cones in order to form a pilot core. This leading pilot hole would reduce the amount of material that the outer cones on the 12-1/2-in. $(31.75 \mathrm{~cm})$ bit would have to remove. It was also theorized that if several ( 2 or 3 ) of the outer cones were reversed, the nose cutters would not have worn away as fast. As a second bit and adapter were not available at this time, the test series were suspended.

\section{Test Series II}

The second test series performed at Terra Tek was run in Columbia Basin basalt in an attempt to simulate the conditions at EPR as closely as possible. The same bit tested in October was again tested but with a new set of cones installed. The three hybrid arms had also been removed since it was surmised that these arms may have contributed to reducing the life of the bit. A total of four holes were drilled through the basalt with five additional tests performed in the Sierra white granite. Each hole drilled in the basalt was approximately $17 \mathrm{in.} \mathrm{(43.2}$ $\mathrm{cm})$ deep. Tests were run at three load ranges $(5,10$, and $15 \mathrm{kips}[2.3$, 4.5 , and $6.8 \mathrm{~T}]$ ) of weight on the bit with revolutions varying between 90 and 140 in increments of $10 \mathrm{rpm}$. The bit weight was intentionally held in the low range since the actual conditions for bare-rock spudding would require the neutral point in the drill string to be kept as low as possible to prevent the PDCM from going into compression.
The higher rpm were used to simulate typical rotational output of the mud motor. Each new test hole was generally started with $60 \mathrm{rpm}$ until the bit set into a pattern on the material being drilled. This normally required around 10 to $12.5 \mathrm{~min}$ to establish before the weight was brought up to test conditions. Each series of test is summarized in Tables 5 through 14 . Total test time on the 6-cone roller bit amounted to over $24 \mathrm{hr}$. Figure 30 presents the three distinct levels of penetration rates achieved based on varying the rpm in the Columbia Basin basalt. Penetration rates ranged from an average of $0.33,0.82$, and $1.15 \mathrm{ft} / \mathrm{hr}$ $(0.1,0.25$, and $0.35 \mathrm{~m} / \mathrm{hr})$ for the three distinct levels of weight applied. The latter tests performed in Sierra white granite (Fig. 31) did not illustrate the distinction of weight-on-bit characteristics as well as did the tests in basalt. Erosion on the cones and wear on the inserts at this stage of testing most likely was the reason for this, rather than the type of material being tested. At the completion of the testing program, the 6-cone bit still appeared in good shape with only slight wear beginning to show on the bearings. There were a few compacts that had been chipped but the majority were still intact. The test was deemed successful, as none of the small bearings failed at the high $\mathrm{rpm}$ while the bit drilled more than $24 \mathrm{hr}$. The only question remaining was survivability under actual field conditions.

\section{FIELD PERFORMANCE}

Evaluation of the drill bits and latch-assembly hardware used for spudding and drilling the three holes at the EPR is discussed in the following sections. Five different types of bits were used in Hole $864 \mathrm{~A}$, with a total of seven bits required to establish the $43.6 \mathrm{ft}$ $(13.3 \mathrm{~m})$ hole. These were:

1. 12-1/2-in. (31.75 cm) 6-cone roller bit,

2. $12-1 / 2$-in. $(31.75 \mathrm{~cm})$ tricone bit,

3. 11-1/4-in. $(28.6 \mathrm{~cm})$ diamond bit,

4. 7-1/4-in. (18.4 cm) 2-cone center bit (run with bit 1),

5. 7-1/4-in. (18.4 cm) 1-cone center bit (run with bit 3 ), and

6. 7-1/4-in. $(18.4 \mathrm{~cm})$ tricone bit.

Hole $864 \mathrm{~B}$ was primarily used to test several combinations of bits and center-bit assemblies in the upper portion of the hole. These tests provided additional insight into whether any of the diamond bit designs were worth pursuing for future basalt locations. Three different types of 7-1/4-in. $(18.4 \mathrm{~cm})$ bits, along with one style of center bit, were used during the tests:

1. 7-1/4-in. $(18.4 \mathrm{~cm})$ carbonado diamond bit,

2. 4-in. $(10.2 \mathrm{~cm}) 1$-cone center bit (run with bit 1$)$,

3. 7-1/4-in. (18.4 cm) impregnated (DCB) bit, and

4. 7-1/4-in. (18.4 cm) tricone bit.

Hole $864 \mathrm{C}$ was also drilled as a test hole when Hole $864 \mathrm{~B}$ had to be abandoned after what was surmised to be fatigue failure with the 6-3/4-in. (17.2 cm) DI-BHA. Only one bit and center bit combination were investigated in this hole due to the amount of time remaining in the leg. The bit and center bit combination included:

1. 7-1/4-in. (18.4 cm) carbonado diamond bit, and

2. 4-in. $(10.2 \mathrm{~cm}) 2$-cone center bit (run with bit 1).

Each bit and latch assembly is discussed separately in terms of how, why, and when it was run in the drilling program. The following section describes the bits in sequential order as they were run. The performance of the latch-assembly hardware follows the section on bits. Table 15 presents the order the bits and latch assemblies were run, along with pertinent drilling information. Table 16 provides total footage and hours run on each bit, along with the IADC grades. 


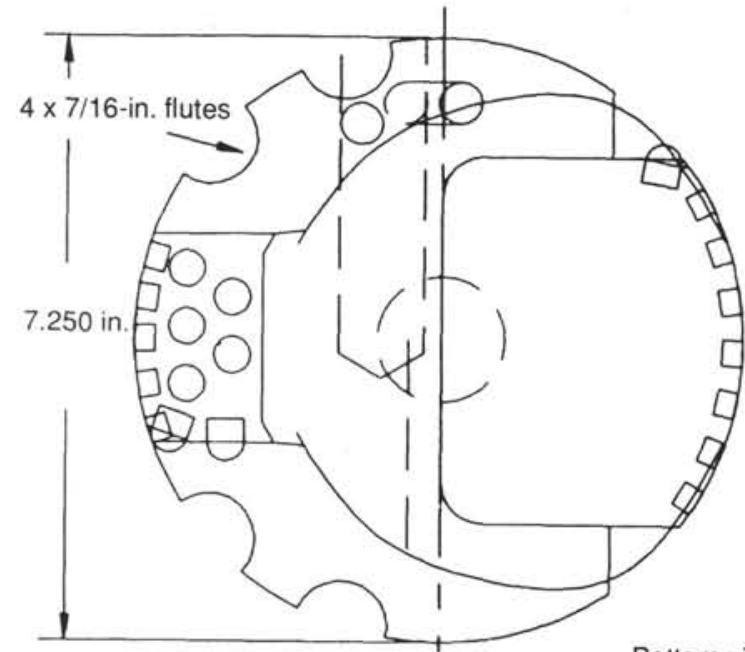

Bottom view

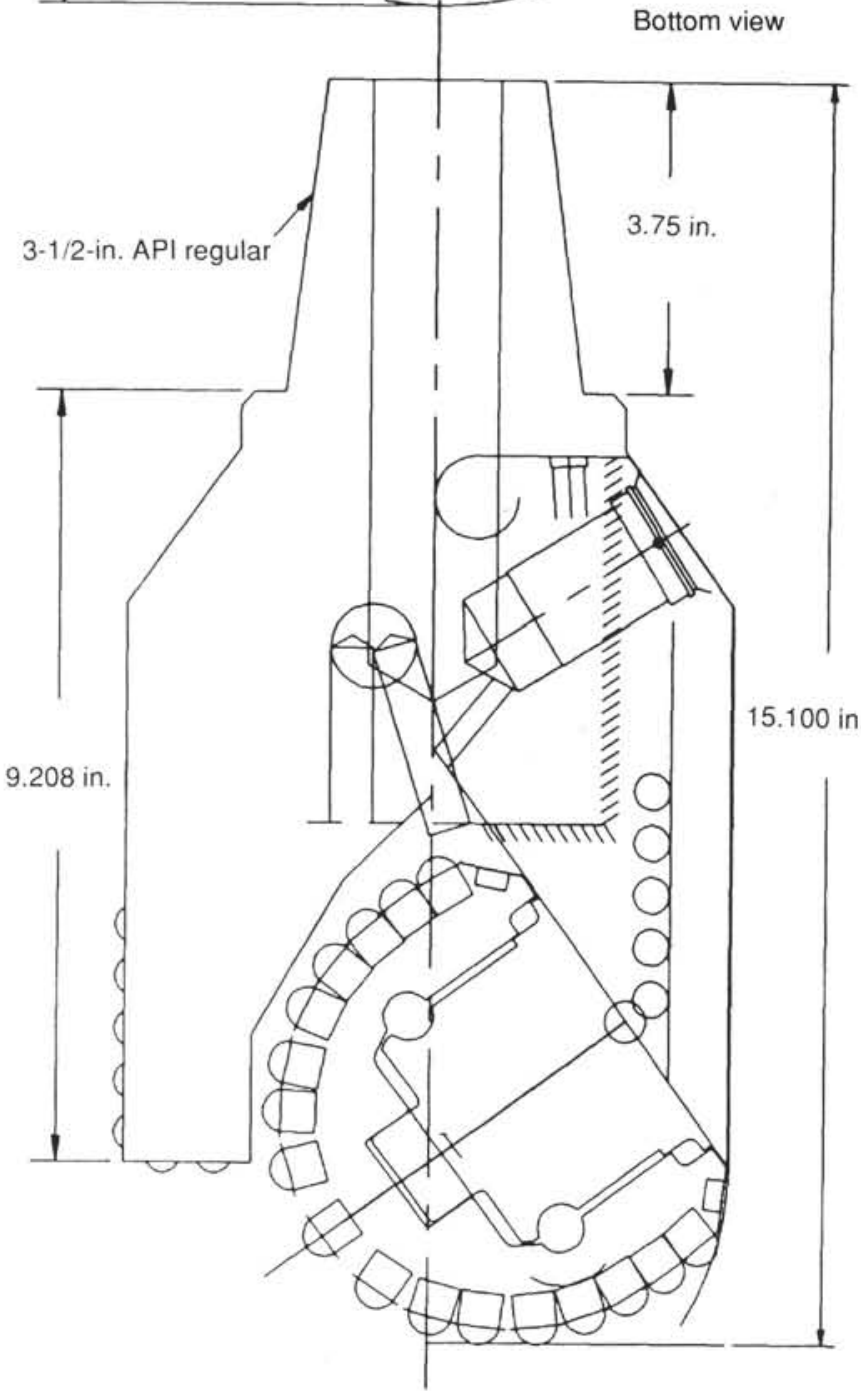

Figure 14. 7-1/4-in. RBI 1-cone roller bit.

\section{Hole 864A Drill Bits}

\section{2-1/2-in. Roller-Cone Bit}

The first $12-1 / 2$-in. $(31.75 \mathrm{~cm})$ roller-cone bit was run approximately $24 \mathrm{hr}$, with bit weights varying from 2 to $10 \mathrm{kips}(0.9$ to $4.54 \mathrm{~T}$ ). Total penetration of the bit into the massive flow unit was estimated at

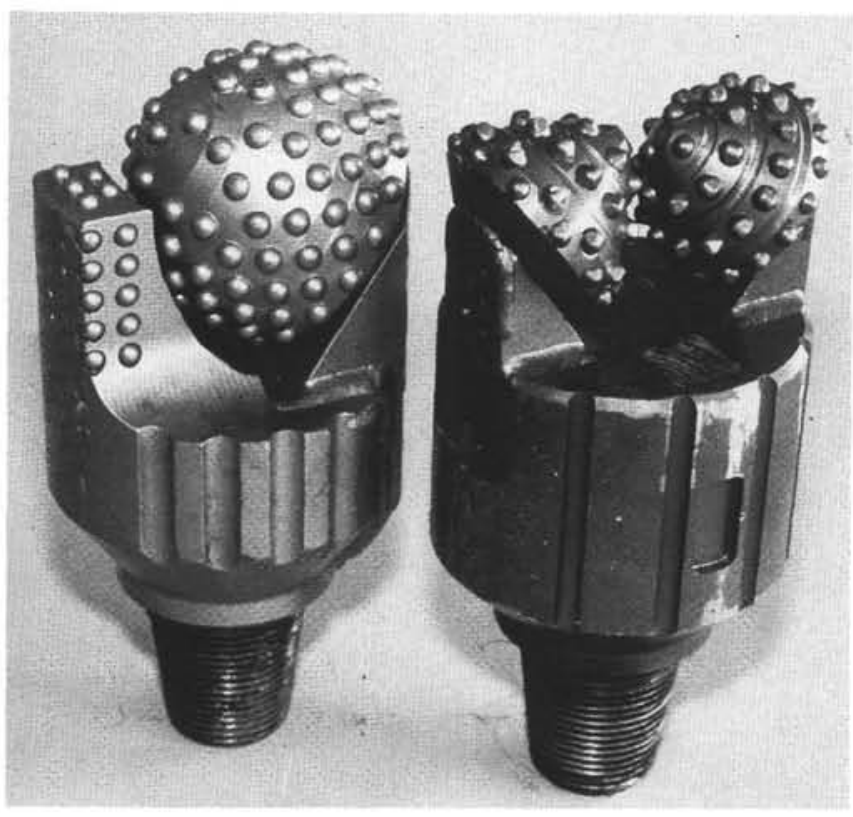

Figure 15. Comparison of 7-1/4-in. center bits.

9.84 to $11.5 \mathrm{ft}$ ( 3 to $3.5 \mathrm{~m}$ ). Actual measurement back-calculated from the marks on the drill collar indicated that the bit penetrated $11 \mathrm{ft}$ $(3.36 \mathrm{~m})$. Sea states throughout this period were producing long swells which resulted in drill-floor heave of $6.56-8.2 \mathrm{ft}$. $(2-2-1 / 2 \mathrm{~m})$. The hole was drilled with a PDCM with occasional slugs of bentonite.

Due to the drilling rate achieved in the formation, it was difficult to discern the difference between tidal fluctuations and actual penetrations of the bit. The penetration of the bit as a function of cumulative time is presented in Figure 32. It should be noted that the actual penetration of the bit may be significantly different since there was no way to adjust the curve for tidal fluctuations. However, from the data presented, it appears that the penetration rate flattened out at around 11-12 hr of rotation. This flattening out could be interpreted as the point at which damage first appears on the bit, or it could coincide with the steepest portion of the tidal curve. However, this length of time corresponds favorably to the point at which vessel heave was the greatest from the time rotation began.

After $24 \mathrm{hr}$ of rotation, the bit returned almost totally demolished (Fig. 33), with five of the six cones missing. Two of the three hybrid arms were heavily damaged from the junk in the hole. A piece of basalt was recovered wedged in between the one cone remaining and a hybrid arm. This phenomenon may help explain why the cones could have locked up and added to loss of the cones. The bearings on the one cone remaining appeared to be in good shape. The hybrid arms thought to help the bit in fractured material probably added to the deterioration in the massive flow material by trapping pieces of basalt and intermittently locking up the cones. Furthermore, once the cones became dislodged and broke off, the carbide buttons on the bottom of the arms probably allowed the bit to skate on these buttons. This may have prevented the bit from sustaining additional damage and from further penetration.

Probably the most significant damage suffered was the result of the dynamic impact of the bit pounding into the hard basalt. This was due to the inefficiency of the heave compensator operating at relatively light bit weights. There is indication that the bit shanks were broken off on several of the arms, adding to the theory that dynamic impact was the major culprit. The shirttails on all of the arms were worn extensively, as was the bit body. The bit was graded as 2, 2, LC, $1-5,3,0$, JD, TD, according to the 1987 Society of Petroleum Engineers (SPE)/IADC roller-cone dull-bit grading system.

The second 12-1/2-in. $(31.75 \mathrm{~cm}$ ) 6-cone bit was run into the hole after predrilling and cleaning up the hole with the tricone bit and junk 


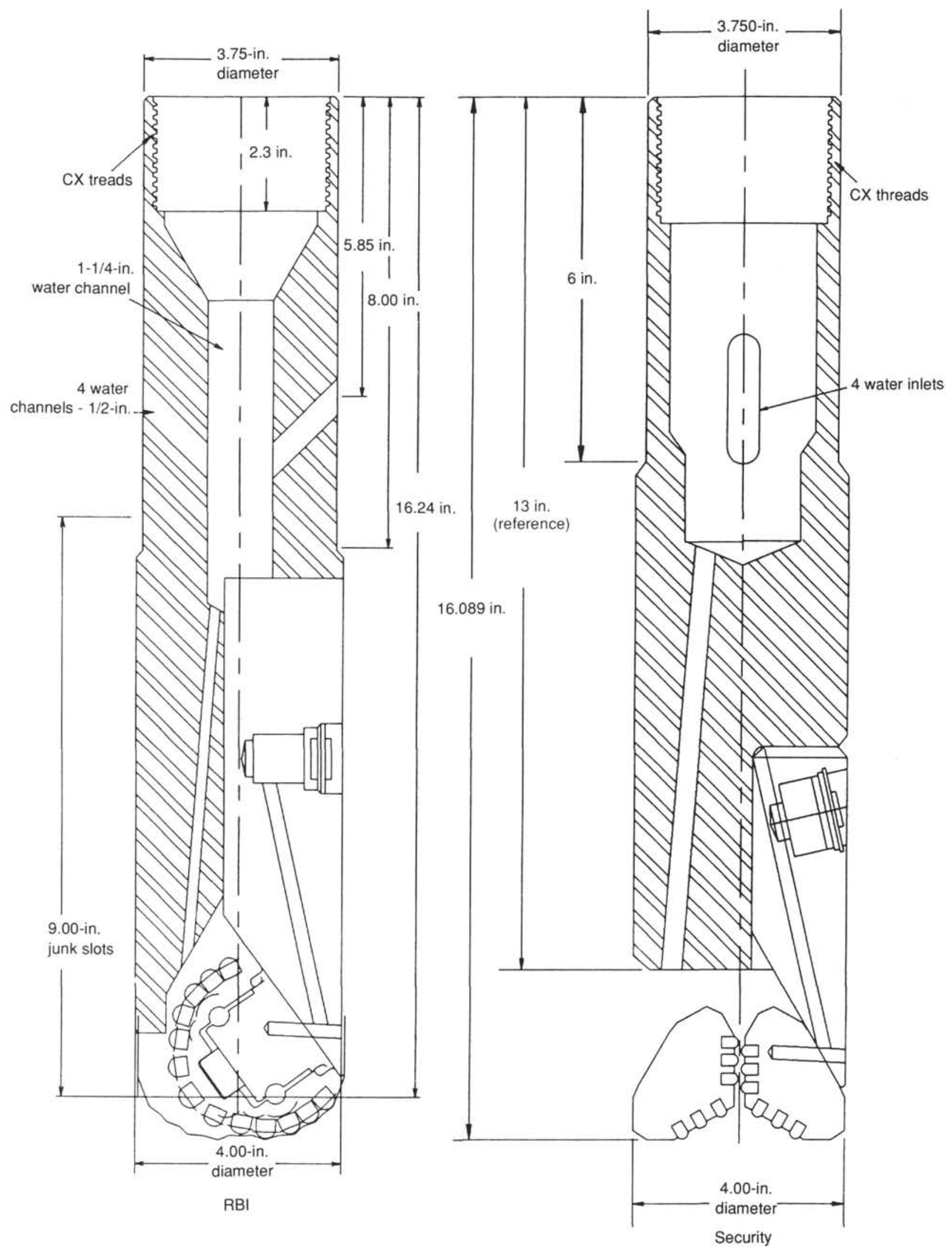

Figure 16. 4-in. center bits for secondary stage drill-in BHA. 


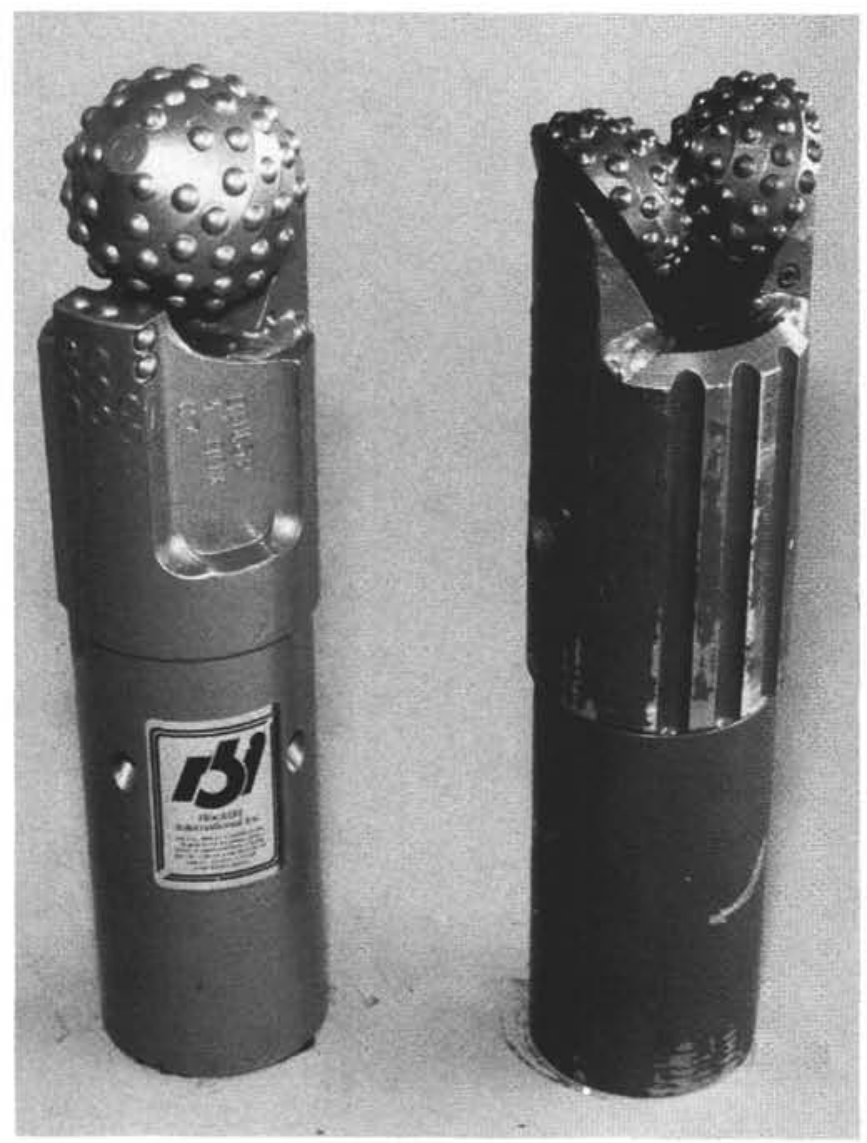

Figure 17. Comparison of 4 -in. center bits.

basket. About $1 \mathrm{~m}$ of fill was noted on the bottom of the hole after tagging down. The fill material took less than $5 \mathrm{~min}$ to move out of the way as the bit was brought to the bottom of the predrilled hole. Once on bottom a considerable amount of difficulty was experienced in attempting to rotate the last several inches in order to seat the back-off sub. Torques of $15,000 \mathrm{ft}-\mathrm{lb}(19,500 \mathrm{Nm})$ were experienced, as were overpulls of $20,000 \mathrm{lbs}(9 \mathrm{~T})$. Total rotation time on the bit was less than $10 \mathrm{~min}$. Prior to running the bit, it was left suspended off the bottom of the hole for about an hour while the vibration-isolated televiewer (VIT) frame was removed. This allowed the bit to heave into what we thought was open hole before rotation could be initiated.

Since the back-off sub could not land out on the seat, we thought that it may have overtorqued itself during the initial $24 \mathrm{hr}$ of rotation. Therefore, the BHA was pulled to sort out why the back-off sub had not engaged. With the BHA on deck, it was obvious that the back-off nut had never entered the landing seat but that the problems were caused by the bit's inability to drill the remaining distance to the landing seat. Small pieces of basalt were found trapped in the bit, along with a spherical piece about $3 \mathrm{in} .(76.2 \mathrm{~mm})$ in diameter. What was most disturbing was that one of the six cones was missing. The bit itself was badly worn, especially on the OD of the bit body. The bit was graded with the IADC guidelines as 0, 0, LC, X, E, IX, TD.

Explanation of what may have actually happened is unclear; however, in one scenario, the bit was heaving in the hole while rubble from above and underneath the massive flow sheet was reintroduced into the bottom of the hole and on top of the bit. This allowed the bit to impact on the rubble, causing the majority of the damage to the bit while the VIT was being removed. Thus, when the bit was rotated, large pieces of rubble locked up the cones as annular material adding to the high torques experienced. This scenario also adds validity to the overpull experienced when attempting to remove the bit.

\section{7-1/4-in. 2-cone Center Bit}

The first 2-cone center bit was run in conjunction with the 12-1/2in. ( $31.75 \mathrm{~cm}) 6$-cone bit (Fig. 34). This bit sustained far less damage than the outer larger diameter 6-cone bit. The center bit was run as a pilot bit that led the outer bit by approximately $1 \mathrm{in}$. $(25.4 \mathrm{~mm})$. There was some vertical play in the center-bit latch cavity, which may have resulted in adding life to the bit. This play allowed the latch to absorb much of the energy created during the $6.56-8.2 \mathrm{ft}(2-2-1 / 2 \mathrm{~m})$ of heave experienced during the drilling operations.

Some damage was seen on the cones themselves, with a few of the carbide buttons broken, but in general the bit was intact. Bearings on both cones were tight without any excess play. No wear was seen on the shirttails or bit body primarily because the center bit was recessed into the outer bit throat. There was no noticeable erosion on or around the cones. The annular flutes were welded shut to provide more flow through the center of the bit. The bit was graded as 2, 2, ND, A, 3E, I, NO, BHA, according to the 1987 SPE/IADC roller-cone dull-bit grading system.

The second 2-cone center bit was run in conjunction with a modified 12-1/2-in. ( $31.75 \mathrm{~cm})$ roller-cone bit. The bit did not drill any new material but was only lowered to the bottom of the hole. It was installed since we were not sure if rotation would have to be initiated to reach the bottom of the hole. The bit was piloted 1 in. $(25.4 \mathrm{~mm})$ ahead of the diamond bit. The center bit and latch assembly were recovered by the wireline procedure outlined in an earlier section. No appreciable wear was recorded on the bit. The bit was graded 0, 1, CT, M, E, I, LC, TD, according to the 1987 IADC bit grading guide.

\section{2-1/2-in. Tricone Bit}

The $12-1 / 2$-in. $(31.75 \mathrm{~cm})$ tricone bit was run as a precautionary measure into the same hole to ensure that any junk remaining from the $12-1 / 2$-in. $(31.75 \mathrm{~cm}) 6$-cone bit would be removed prior to initiating the DCS. The hole was to be deepened to $21.3 \mathrm{ft}(6.5 \mathrm{~m})$ if drilling rates were favorable with the tricone bit. A milling run with a 9-1/2-in. ( $24.1 \mathrm{~cm}$ ) Gotco concave mill with boot basket positioned above was made prior to running the tricone. The mill returned with all tungsten chips missing from its face but without any metal or carbide in the boot basket. The material trapped in the basket was mainly glass fragments with some phyric, plagioclase basalt. The occurrence of the glass material suggests that the ponded flow had been penetrated into very thin sheets of either lobate pillow fragments or intact lobate pillows filled with lava from the ponded flow.

Reentering the hole with the tricone bit after the milling operation confirmed what appeared to be about $3.28 \mathrm{ft}(1 \mathrm{~m})$ of fill. Exact penetration depth was difficult to determine due to the unknown amount of tides and the variable heave. It was thought that the hole had been drilled to between 9.84 and $11.5 \mathrm{ft}(3.0-3.5 \mathrm{~m})$ before milling. Based on observation of removed paint from the drill collars, the hole appeared to have been deepened to about $11.8 \mathrm{ft}(3.6 \mathrm{~m})$ with the mill.

Sea states were relatively calm during the run with the tricone, with drill-floor heave less than $3.28 \mathrm{ft}(1 \mathrm{~m})$. The tricone drilled extremely well through the glass, with penetration rates approaching $3.28 \mathrm{ft} / \mathrm{hr}(1 \mathrm{~m} / \mathrm{hr})$. After reaching $18 \mathrm{ft}(5.5 \mathrm{~m})$ of penetration, the advancement rate dropped significantly. Similar rates of less than $0.66 \mathrm{ft} / \mathrm{hr}(0.2 \mathrm{~m} / \mathrm{hr})$ were seen for the remainder of the hole. The hole was terminated at $21.65 \mathrm{ft}$ (6.6 meters below seafloor, or mbsf). Penetration rate vs. elapsed time for the $12-1 / 2$-in. $(31.75 \mathrm{~cm})$ tricone bit run is presented in Figure 35.

The tricone was in good shape after having been run only $3 \mathrm{hr}$. The bit was slightly undergage by $1 / 32 \mathrm{in}$. $(0.8 \mathrm{~mm})$, with only four chipped compacts. Some wear was noted on the gage cutters and a little evidence of erosion on the cones themselves. High flow rates of over 625 gallons per minute (gpm) (39.4 liters per second, or L/s), with pressures exceeding $2700 \mathrm{psi}(18,617 \mathrm{kPa})$, may partially explain 
Table 3. Roller cone center bits for drill-in BHA hardware.

\begin{tabular}{|c|c|c|c|c|c|c|c|c|c|c|c|}
\hline 2 & 7.25 & N/A & 15.1 & Security & Mod. CB & 2 & M89TF & $627 X$ & 2 & $5 / 8$ & $6-1 / 2$ \\
\hline 3 & 7.25 & N/A & 15.1 & Security & Mod. CB & 2 & M89TF & $627 \mathrm{X}$ & 2 & $5 / 8$ & $6-1 / 2$ \\
\hline 4 & 7.25 & N/A & 15.1 & Security & Mod. CB & 2 & M89TF & $627 X$ & 2 & $5 / 8$ & $6-1 / 2$ \\
\hline 7 & 7.25 & N/A & 7.5 & Rock Bit & Tricone & 3 & 231 & 637 & 3 & $8-18$ jets & $7-7 / 8$ \\
\hline 8 & 7.25 & N/A & 7.5 & Rock Bit & Tricone & 3 & 231 & 637 & 3 & $8-18$ jets & $7-7 / 8$ \\
\hline 9 & 4.00 & N/A & $19-3 / 32$ & Security & Centerbit & 2 & $\mathrm{M} 100 \mathrm{~F}$ & $837 Y$ & 2 & $7 / 16$ & 4 \\
\hline 10 & 4.00 & N/A & $19-3 / 32$ & Security & Centerbit & 2 & MIOOF & $837 \mathrm{Y}$ & 2 & $7 / 16$ & 4 \\
\hline 11 & 4.00 & N/A & $19-3 / 32$ & Security & Centerbit & 2 & $\mathrm{M} 100 \mathrm{~F}$ & $837 Y$ & 2 & $7 / 16$ & 4 \\
\hline 12 & 4.00 & N/A & $19-3 / 32$ & Security & Centerbit & 2 & MIOOF & $837 Y$ & 2 & $7 / 16$ & 4 \\
\hline 17 & 4.00 & N/A & 16.24 & Rock Bit & Mod. CB & 1 & 231 & 637 & 1 & $1 / 2$ & $7-1 / 4$ \\
\hline 18 & 4.00 & N/A & 16.24 & Rock Bit & Mod. CB & 1 & 231 & 637 & 1 & $1 / 2$ & $7-1 / 4$ \\
\hline
\end{tabular}

Notes: Security modified center bit has 8-1/4-in. flutes milled on outer diameter. Tricone bit is measured shoulder to tip of cones. N/A = not applicable.

the erosion seen on the cones. The SPE/IADC dull-bit grade on the tricone for $3 \mathrm{hr}$ of running was $0,1, \mathrm{CT}, \mathrm{H}, \mathrm{E}, \mathrm{IER}$, TD.

The tricone was rerun a second time to deepen the hole the final $0.5 \mathrm{~m}$ when it was discovered that the earlier attempt proved too short. Approximately $6.5 \mathrm{hr}$ of rotation and an additional $2 \mathrm{hr}$ of high circulation rates were placed on the bit. Rotational speeds of $40 \mathrm{rpm}$ and pump pressures of $2250 \mathrm{psi}(15,514 \mathrm{kPa})$ were common during the drilling operation. The bit did an effective job of advancing the hole despite the low weight on bit (WOB) (2-10 kips [0.9-4.54 T]) that was applied. Upon recovery, the bit showed an extensive amount of erosion due the high pump rates being run. Numerous compacts on the heel and drive row were missing on all three of the cones. One of the cone's bearing was beginning to show signs of wear. The majority of the compacts were recovered in the two junk baskets positioned above the bit. The remainder of the junk was thought to have been circulated free of the hole. The bit was graded as 1, 6, LT, H, I, E, R, TD, according to the 1987 IADC code.

\section{1-1/4-in. Diamond Bit}

The large-diameter carbonado diamond bit was run only once on the end of the DI-BHA. The attempt resulted in over $3 \mathrm{hr}$ of rotation. As the bit was lowered into the hole, it tagged fill almost $9.84 \mathrm{ft}$ ( 3 $\mathrm{m})$ above the bottom of the hole. The first $6.56 \mathrm{ft}$. $(2 \mathrm{~m})$ were worked through once flow and rotation were initiated. Additional penetration was not accomplished with the combination of the diamond bit and 1-cone center bit. It appears that the bit never got enough weight to make any headway; the weight was being taken by the $3.28-6.56 \mathrm{ft}$ (1-2 $\mathrm{m}$ ) of rubble still in the hole and the piloted center bit. The bit was with rotated at $120-140 \mathrm{rpm}$ for most of the time with the PDCM.

Because enough advancement to set the DI-BHA was achieved, the bit and assembly were pulled. It was originally thought that the bit may have polished or been totally destroyed, as no headway was made. However, the bit was in excellent shape upon recovery. Only a few of the surface-set diamonds were chipped or lost from the matrix.

The matrix appeared pitted in spots, which indicate that a harder matrix and binder should be used in the future when drilling in similar formations. Both ID and OD were still in gage. Some wear on the leading edges of the of the junk slots could be seen but this was expected. Comparison of the performance of this bit may be somewhat misleading. The bit never actually drilled or was subjected to intact material but only saw rotation in suspended volcanic glass. It is also surmised that the 1-cone center may have prevented the bit from advancing, once larger pieces of fill were encountered in the bottom $3 \mathrm{ft}(1 \mathrm{~m})$ of the hole. The bit was graded as 2, 3, JD, N, X, I, NO, TD.

\section{7-1/4-in. 1-cone Center Bit}

The RBI 1-cone bit was run briefly on one occasion with an 11-1/4-in. $(28.51 \mathrm{~cm})$ Longyear carbonado bit while the DI-BHA was washed by rotating the bit back down to bottom. The bit was exposed to less than $2 \mathrm{~m}$ of fill. Rotational time was approximately $180 \mathrm{~min}$ at $120-140 \mathrm{rpm}$. High flow rates of over 100 strokes per minute (spm) (500-650 gpm [31.5-37.85 L/s]) and pump pressures (900-1500 psi [6205-10,340 kPa]) were experienced. Upon retrieval, the bit had not sustained any noticeable damage. IDAC grading for the bit is $\mathrm{O}, \mathrm{O}$, NO, X, E, I, NO, TD. However, for some reason the bit was unable to achieve any additional advancement. It was hypothesized that the bit might just be spinning on its one cone without any weight actually reaching it. The weight we were attempting to place on the bit was being carried by the rubble around the DI-BHA (i.e., the BHA was load-shedding the weight before any significant amount could reach the bit). It was also observed that the rotational speed of the center bit, which was turning at a slower rpm than the outer bit, was cutting at a slower rate and not allowing the combination of the two bits to make any hole.

\section{7-1/4-in. Tricone Bit}

The 7-1/4-in. $(18.4 \mathrm{~cm})$ tricone bit was run in an attempt to deepen the hole past the $23.3 \mathrm{ft}$ ( $7.1 \mathrm{mbsf}$ ) elevation so that the second-stage DI-BHA could be installed. The first attempt to core with the DCS was hampered by fill in the hole and the inability to maintain a constant flow path for cutting discharge. The fine-grained volcanic fill infiltrated into and plugged off the primary circulation paths, requiring cutting returns to be taken back to the ship. This method worked well; however, the cuttings would periodically break out at the seafloor, causing an instantaneous drop in circulating pressure. This major change in pressure resulted in a pump-off pressure on the face of the DCS bit, causing the secondary compensator to sense an erroneous DCS tubing string weight. The effect was that inaccurate weight was placed on the bit by the compensator. This, coupled with some hardware and additional software problems with the DCS, resulted in immediate and total failure of the DCS core bit.

The original intent on setting the second-stage DI-BHA was only to deepen the hole by $9.84 \mathrm{ft}(3 \mathrm{~m})$. However, the bit drilled so well 


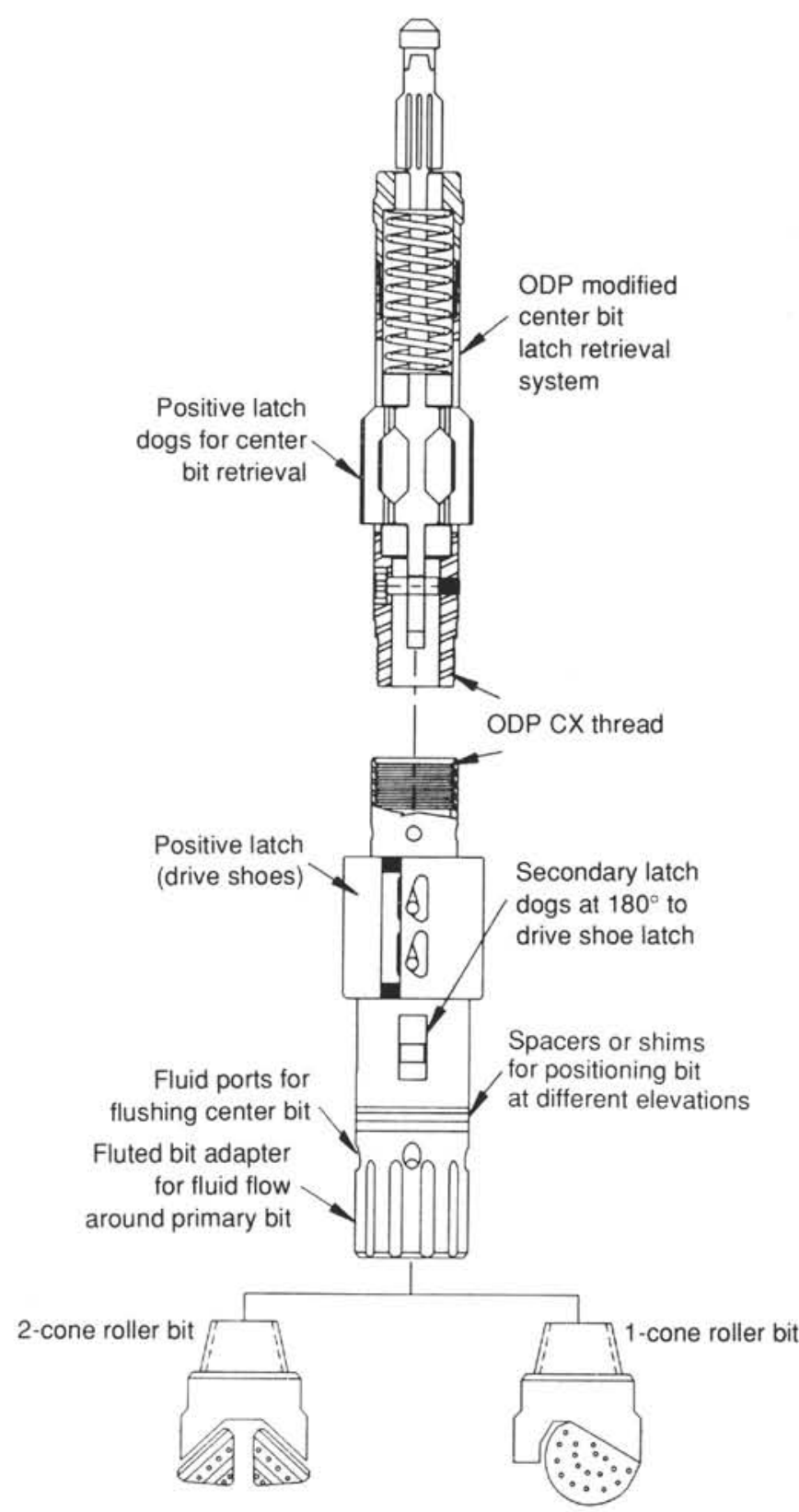

Figure 18. Center-bit latch assembly.

that an additional $3 \mathrm{~m}$ were drilled. The tricone drilled approximately $6.56 \mathrm{ft}(6 \mathrm{~m})$ in $3 \mathrm{hr}$ of rotation. Bit weights ranged from 4-6 kips $(1.8-2.7 \mathrm{~T})$ the first $9.84 \mathrm{ft}(3 \mathrm{~m})$ and were increased to $8-10 \mathrm{kips}$ $(3.6-4.54 \mathrm{~T})$ the remaining distance. A massive layer of basalt was again encountered between the depths of $37 \mathrm{ft}(11.3 \mathrm{mbs})$ and approximately $43 \mathrm{ft}(13.1 \mathrm{mbsf})$. The tricone bit returned with the bearings still in good shape. However, a number of the compacts were broken and significant wear was beginning to appear around the gage cutters. The bit body appeared to have drilled through junk with numerous gouges and cut marks. The bit drilled smooth the entire time in the hole with constant torque. There was no reason to suspect that any junk other than the tricone's own broken inserts could have caused the damage, aside from the formation itself. The IADC grading for the bit is 2, 1, BT, A3, E, 3/32, SD, BHA. Additional information pertaining to the bit is presented in Table 15 .

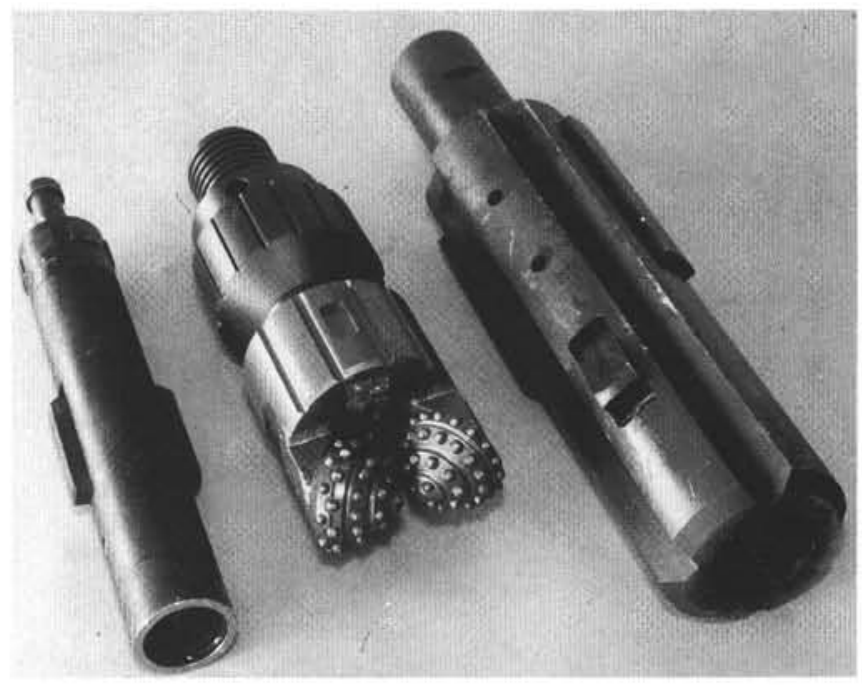

Figure 19. Center-bit latch assembly with 2-cone roller bit.

\section{Hole 864B Drill Bits}

\section{7-1/4-in. Carbonado Diamond Bit}

The Longyear surface-set carbonado bit was run in order to test how the diamond bit would perform in the massive basalt. The $7-1 / 4$-in. $(18.4 \mathrm{~cm})$ diamond bits were designated as the primary bits to be used to set the second stage of the DI-BHA hardware. The carbonado bit was run in conjunction with a 1-cone center bit positioned approximately 2 in. $(50.8 \mathrm{~mm})$ beyond the larger outer bit. The bit was tested at a rotational speed of $60 \mathrm{rpm}$, with flow rates of 40 to $60 \mathrm{gpm}(2.5$ to $3.78 \mathrm{~L} / \mathrm{s})$. Weight on bit fluctuated between 4 and 7 kips $(1.8-3.17 \mathrm{~T})$.

The bit drilled the first $1.64 \mathrm{ft}(0.5 \mathrm{~m})$ in about $10 \mathrm{~min}$, and the next $1.64 \mathrm{ft}(0.5 \mathrm{~m})$ in a similar amount of time. It appeared that almost another $0.5 \mathrm{~m}$ was drilled but the torque began to become erratic and the bit was momentarily picked up off bottom. The final $1.64 \mathrm{ft}$ $(0.5 \mathrm{~m})$ could never be achieved even though the bit was allowed to rotate a total of $2.5 \mathrm{hr}$. The bit was pulled after a 10-bbl mud sweep was circulated without producing any results.

The wear on the bit indicated that the OD gage was totally destroyed, starting with the leading edge. It appears that the two top rows of gage diamonds were crushed due to vibration since the bit was spudded without the aid of a cased or existing hole. The OD also shows signs of excessive heat since some of the outside waterways were closed off. Water erosion was prevalent on the OD of the body, indicating that too high a flow rate was run. The same type of circular gouging markings were again noticed on the bit body, suggesting the hard, abrasive nature of the formation. The bit face showed very little damage. The large carbonado diamonds were well exposed and showed no signs of polishing. The matrix around the diamonds had worn away, leaving a well-exposed stone. The leading edges on each waterway were rounded, indicating impact damage. The inside gage showed no signs of apparent damage, primarily as a result of running a center bit in the throat.

It appears that the OD of the bit was destroyed primarily because it was not being properly centralized or it was rotating in a nonconcentric hole, possibly the result of the cutting pattern developed by the 1-cone center bit. Actual penetration into the seafloor, as measured from paint removed from the bit sub, indicated that only $2.28 \mathrm{ft}(0.6$ $\mathrm{m}$ ) was achieved. Future diamond bits might be manufactured with a harder binder during the furnacing of the bit. The OD should also be set with a heavier concentration of carbonado stones and tungsten carbide inserts on the leading edge of each waterway section. 


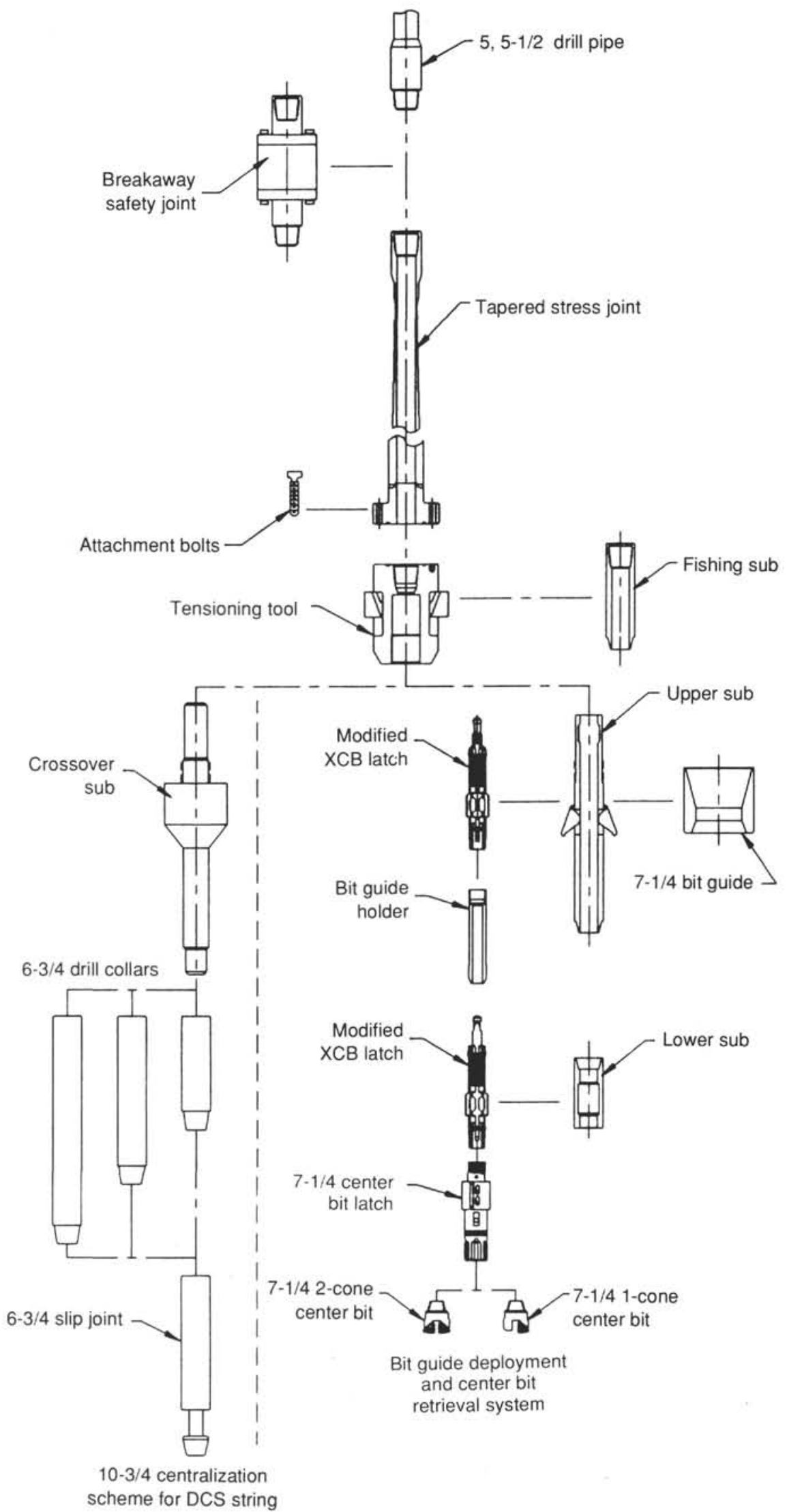

Figure 20. Seafloor hardware options for DCS coring set-up. Dimensions in inches. 


\section{4-in. 1-cone Center Bit}

The RBI 1-cone center bit was used as a pilot bit in conjunction with the Longyear surface-set bit used to spud Hole 864B. The bit was attached to a modified XCB latch with a short spacer which positioned the center bit approximately $2 \mathrm{in} .(50.8 \mathrm{~cm})$ ahead of the diamond bit. Deck tests performed on the bit prior to deployment confirmed that the 1-cone bit turned considerably slower than the rotational speed of the 7-1/4-in. $(18.4 \mathrm{~cm})$ diamond bit. After $2.5 \mathrm{hr}$ of rotation, the BHA was finally pulled when the penetration rate essentially fell to zero. Markings on the bit sub indicted that the bit only penetrated $2.28 \mathrm{ft}(0.6 \mathrm{~cm})$. The center bit did not show any appreciable wear either on the bit body or cone surface itself. There were no broken or chipped compacts, indicating that the bit saw little service. It is hypothesized that because of the bit's slow rotational speed with respect to the outer bit, it could not cut or remove material fast enough to keep up with the larger bit. The eccentric rotational pattern of the 1-cone bit with low rpm added to destabilization of the rotational pattern of the larger outer bit, causing it to ring out. The remaining OD on the carbonado bit face was reduced from 7-1/4 in. $(18.4 \mathrm{~cm})$ to $6-5 / 8$ in. $(16.8 \mathrm{~cm})$. This prevented either bit from additional penetration because the remaining stones on the $\mathrm{OD}$ of the bit body were insufficient to remove the material necessary to allow the bit body and bit sub to follow.

\section{7-1/4-in. Impregnated Diamond Bit}

The DCB with a Hobic impregnated-diamond bit was the second bit run in Hole 864B. The Hobic bit had a medium-hard matrix placed over a semiround-type of crown profile. The bit was run with a rotational speed of $60 \mathrm{rpm}$ and flow rate equal to $40 \mathrm{gpm}$. Typically, 4-8 kips (1.8-3.63 T) of weight were placed onto the BHA. The bit was rotated for approximately $2 \mathrm{hr}$ without any noticeable penetration. Torques of over $(6000 \mathrm{ft}-\mathrm{lb}[7800 \mathrm{Nm}])$ were fairly constant during this period. It was thought that possibly the bit was being held off bottom by the small $(<1 / 8 \mathrm{in}$. [3.2 mm]) stabilizer pads positioned around the bit sub which might be hanging up while passing through the 7-3/8-in.-ID $(18.7 \mathrm{~cm})$ bushing. Another theory presented was that the vessel was offset somewhat and that the 6-3/4-in. $(17.2 \mathrm{~cm})$ drill-collar string was bowed, preventing weight from reaching the bit. In this configuration, the gimbal itself also could have leaned over and prevented the bit from entering the same predrilled hole from the first attempt. Corrections in vessel offset were tried until approximately $1.64 \mathrm{ft}(0.5 \mathrm{~m})$ of penetration were realized. Torque levels continued to be higher than one would expect even after the $1.64 \mathrm{ft}$ $(0.5 \mathrm{~m})$ of penetration was realized. This ruled out the idea that the pads themselves were holding the bit off bottom. After $45 \mathrm{~min}$ of additional rotation the bit was pulled for lack of penetration.

Once on deck, the bit was in still in good condition. The only sign of any wear whatsoever was some slight polishing/glazing of the face profile. Both the OD and ID gages were intact. The bit also did not have any broken or lost geosets or carbides. It appears that the bit saw very little, if any, new hole from the wear markings on the bit sub.

Close inspection of the long bit sub revealed that the first three pads on the stabilizer did not experience any rotational wear. The remaining three pads had the paint worn and some rotational wear marks. The leading bevel on the fifth level of pads was slightly worn, indicating that it had been briefly rotated on. Paint was also worn away $2 \mathrm{in}$. $(50.8 \mathrm{~mm})$ above the stabilizer pads for a distance of $9 \mathrm{in}$. (22.9 $\mathrm{cm})$. This distance from the bottom of the fifth level of pads to the top of the wear marks on the bit sub corresponds to the actual distance drilled. Paint was also worn away on the drill collar at the same elevation of the casing hanger/reentry cone interface. The amount of paint worn away on the drill collar matched the amount worn away near the bit and upper stabilizer pad level. This provides some indication that the weight not reaching the bit was more likely the result of drill-string offset and bowing than the bit hanging up on the pads themselves. The consistent amount of torque seen even after the pads had passed out of the bushing also adds to this theory. Probably the best solution for future use of the DCB is to have sufficient rat hole predrilled so that the core barrel can be well stabilized and the weight can be directed onto the bit.

The bit face was polished and showed some signs of a few missing OD-gage stones. The diamonds did not appear to be stripped off the face. The inside gage did not show any sign of wear since it did not come into contact with the formation. The outside gage did show some missing sections of diamonds and matrix on the leading edge of each waterway section. There were no signs the bit had eroded from excessive flow rates.

The Hobic impregnated DCB bit was rerun in Hole 864B after it had been deepened to $23.3 \mathrm{ft}$ ( $7.1 \mathrm{mbsf}$ ). The bit was sharpened by deformation from repeated hammering with a chisel. This technique is quite common in the mining industry to correct a bit that has polished. The $23.3 \mathrm{ft}(7.1 \mathrm{mbsf})$ of penetration placed the upper stabilizer pads slightly above the casing hanger/cone interface. This would allow the DCB to core approximately $9.84 \mathrm{ft}(3 \mathrm{~m})$ before the upper stabilizer pads on the long top sub would pass into the $7-3 / 8$-in. $(18.7 \mathrm{~cm})$ bushing in the landing seat.

The second coring attempt was aborted after an additional $2.5 \mathrm{hr}$ of rotation produced only $9.84 \mathrm{ft}(3 \mathrm{~m})$ of penetration into the $23.9-\mathrm{ft}$ $(7.3 \mathrm{~m})$ hole. Rubble from beneath the $6.23-\mathrm{ft}(1.9 \mathrm{~m})$ massive layer had refilled the borehole, causing the diamond bit a considerable amount of difficulty in removing the rubble. The impregnated bit selected is ideal for coring but very ineffective in removing rubble. This ineffectiveness is partially due to the particular style of crown (Fig. 36) selected. This bit did not have any junk slots to allow the rubble an escape path. Adding to this difficulty was that the bit was trying to drill on a moving medium. Despite slower than optimum rotation and higher than normal flow rates, the bit did produce a small piece of cored rubble. A 3 -in. $(8 \mathrm{~cm})$ piece of core that was cut was broken into three pieces. Two of the pieces were perfectly cut, and the third piece was rubble captured on top of the other two pieces. The core was not jammed in the barrel but was inside the inner barrel behind the core catcher. This recovery under the worst possible operating conditions illustrates that the DCB is a viable coring system that should be pursued and tested on future sites. A larger selection of matrix types and profiles should be investigated to allow the optimum recovery to be obtained for the particular location in question.

The bit again showed very little signs of additional wear despite rotating in rubble for $2.5 \mathrm{hr}$. Flow rates varied from 40 to $80 \mathrm{spm}(200$ to $400 \mathrm{gpm}$ [ 12.6 to $25.5 \mathrm{~L} / \mathrm{s}$ ]) with the weight on bit fluctuating between 4 and 12 kips (1.8-5.44 T). The face was again polished despite the fact that it was sharpened with a chisel and pipe-wrench heel before being put down the hole. Polishing was especially evident on the outward edge of the face. This is most likely due to some of the fill being trapped in the waterways around the annulus. The bit had still not stripped past the first row of diamonds, indicating that a softer matrix should be chosen for similar material. The ID gage still did not show any appreciable wear despite the fill through which the bit was drilled. The OD gage also showed no additional wear, probably indicating that the bit was better stabilized than the first time it was run.

\section{7-1/4-in. Tricone Bit}

A 7-1/4-in. (18.4 cm) tricone bit was run in Hole 864B to deepen the hole so that the DCB could be again attempted. Two previous attempts with diamond bits for spudding the hole resulted in drilling only $1.64 \mathrm{ft}(0.5 \mathrm{~m})$. The tricone bit achieved a total penetration below seafloor of $23.9 \mathrm{ft}(7.3 \mathrm{~m})$. Rotation was initiated at $40 \mathrm{rpm}$ and gradually brought up to $60 \mathrm{rpm}$. Flow rates were held constant at 40 $\mathrm{spm}$. Weight on bit was begun at 4 to $6 \mathrm{kips}$ ( 1.8 to $2.7 \mathrm{~T}$ ) and increased to 6 to 12 kips ( 2.7 to $5.44 \mathrm{~T}$ ) once several meters of hole were drilled. Several 10-bbl sweeps of mud were used to help clear the cutting from the hole. Torque readings were averaging around $100 \mathrm{amps}$. Penetration rates in the massive basalt were around $30 \mathrm{~min} / \mathrm{m}$. This was fairly 

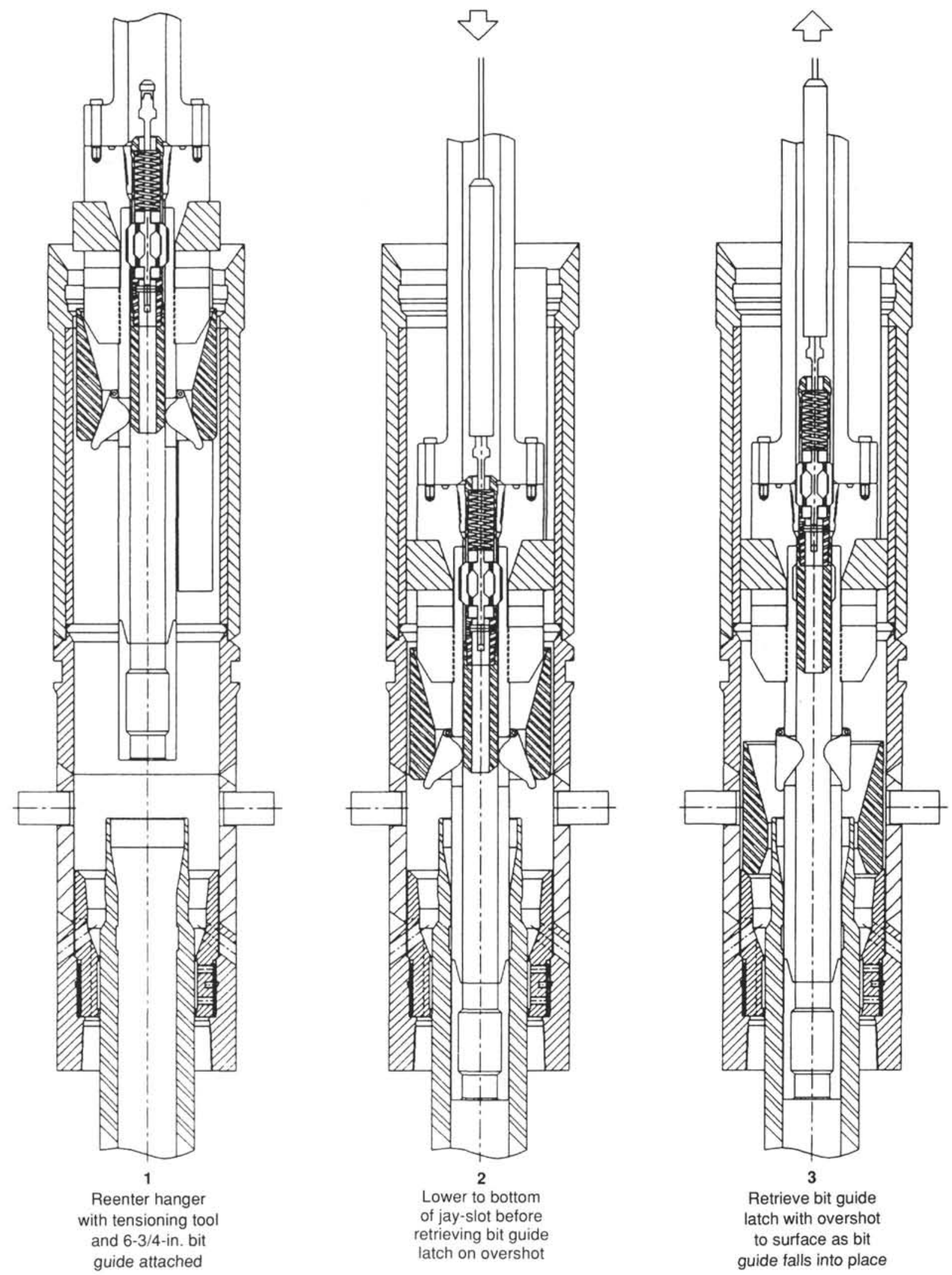

Figure 21. Center-bit latch recovery method. 

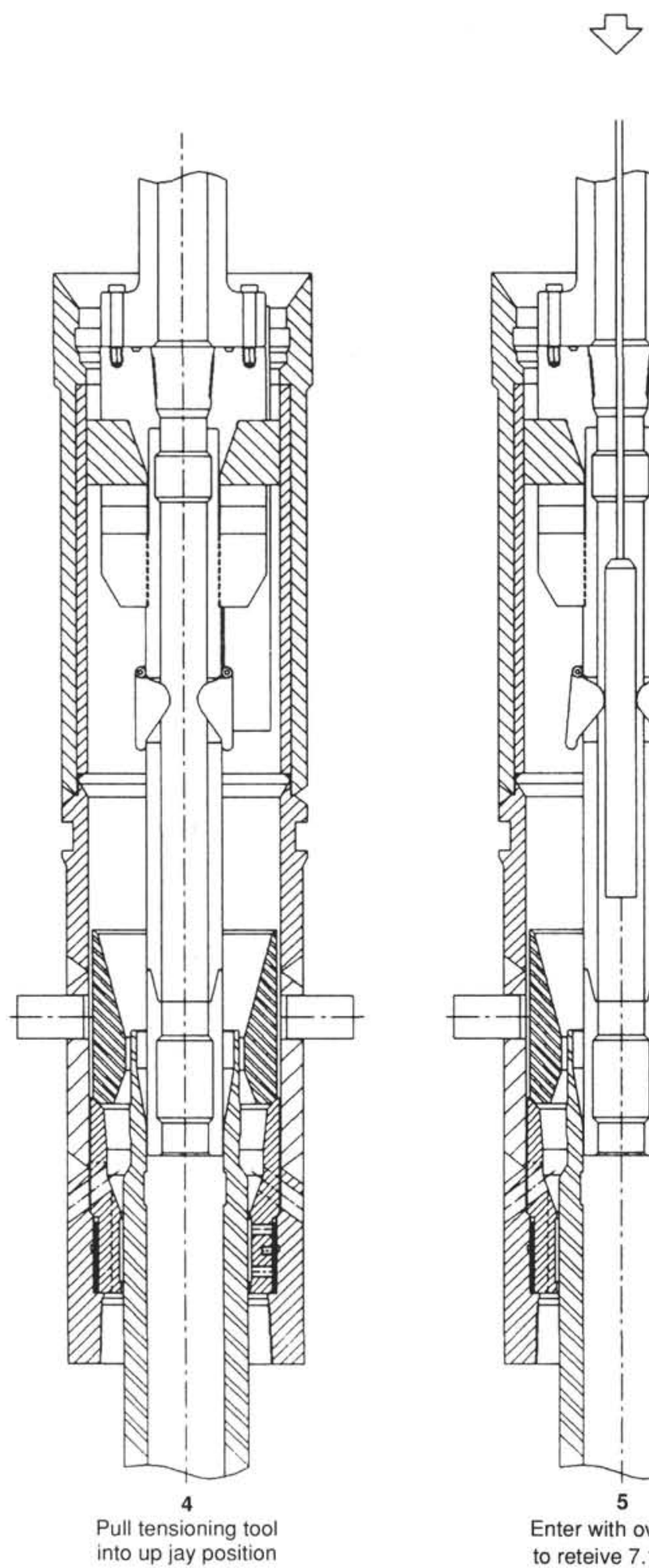
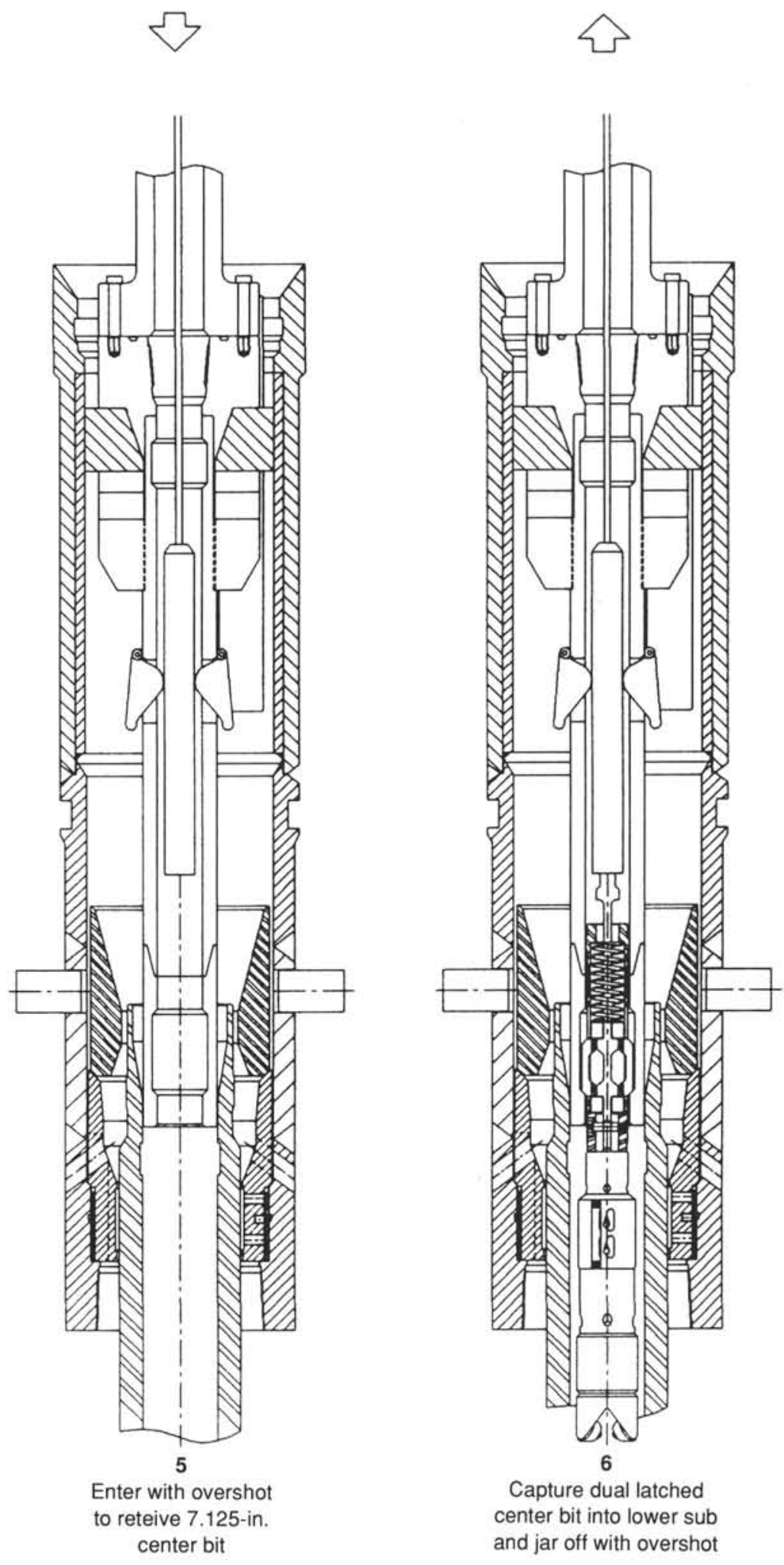

Figure 21 (continued). 


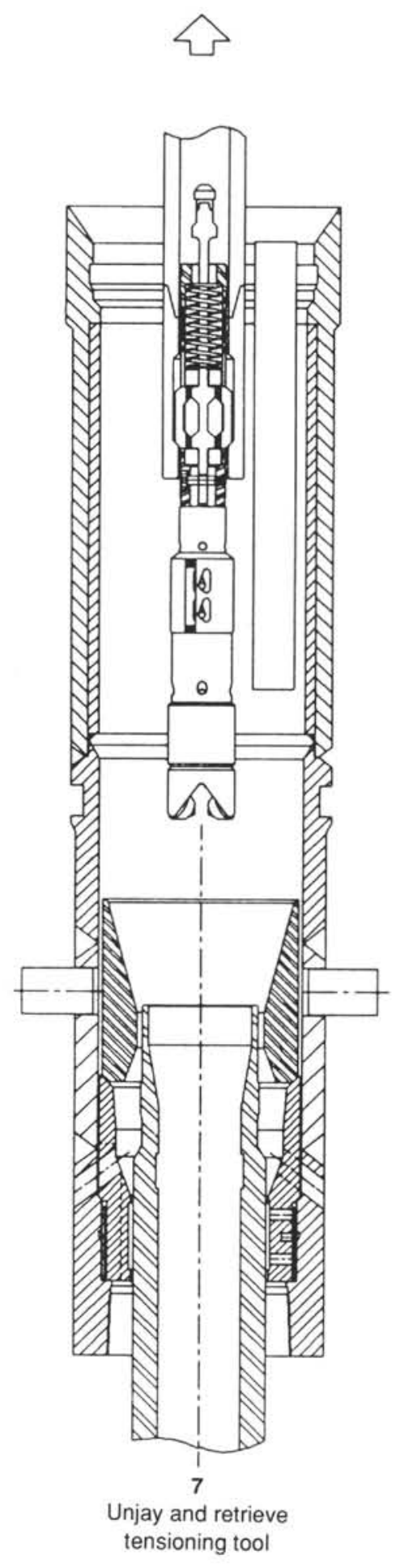

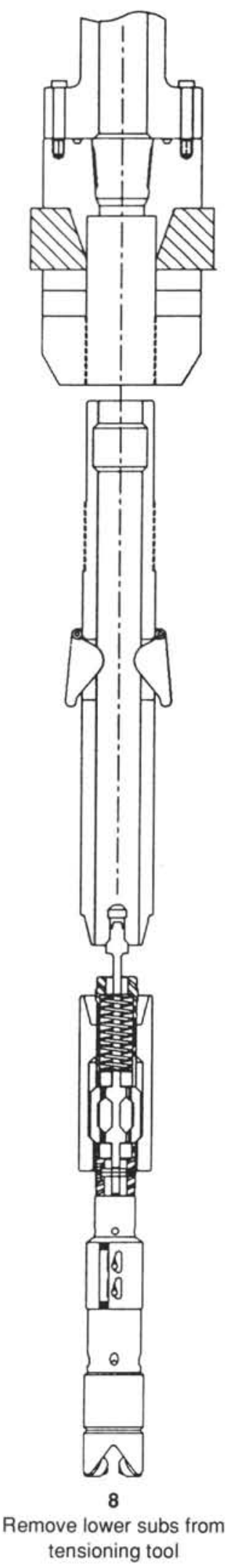

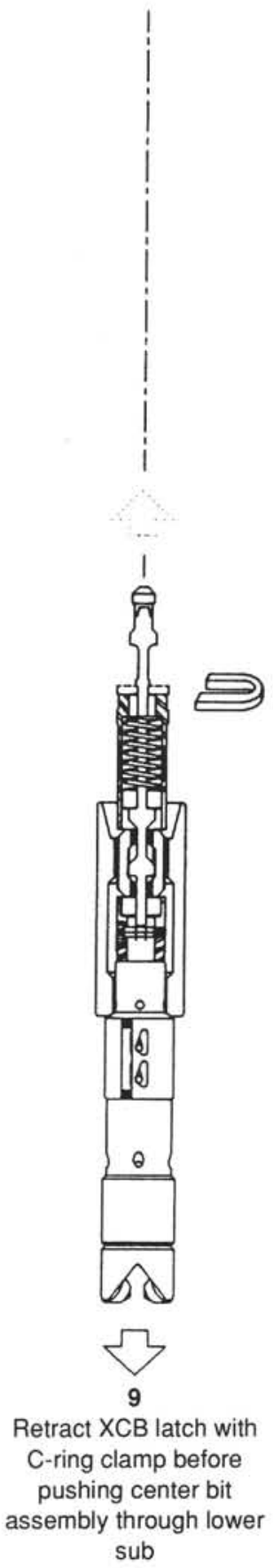




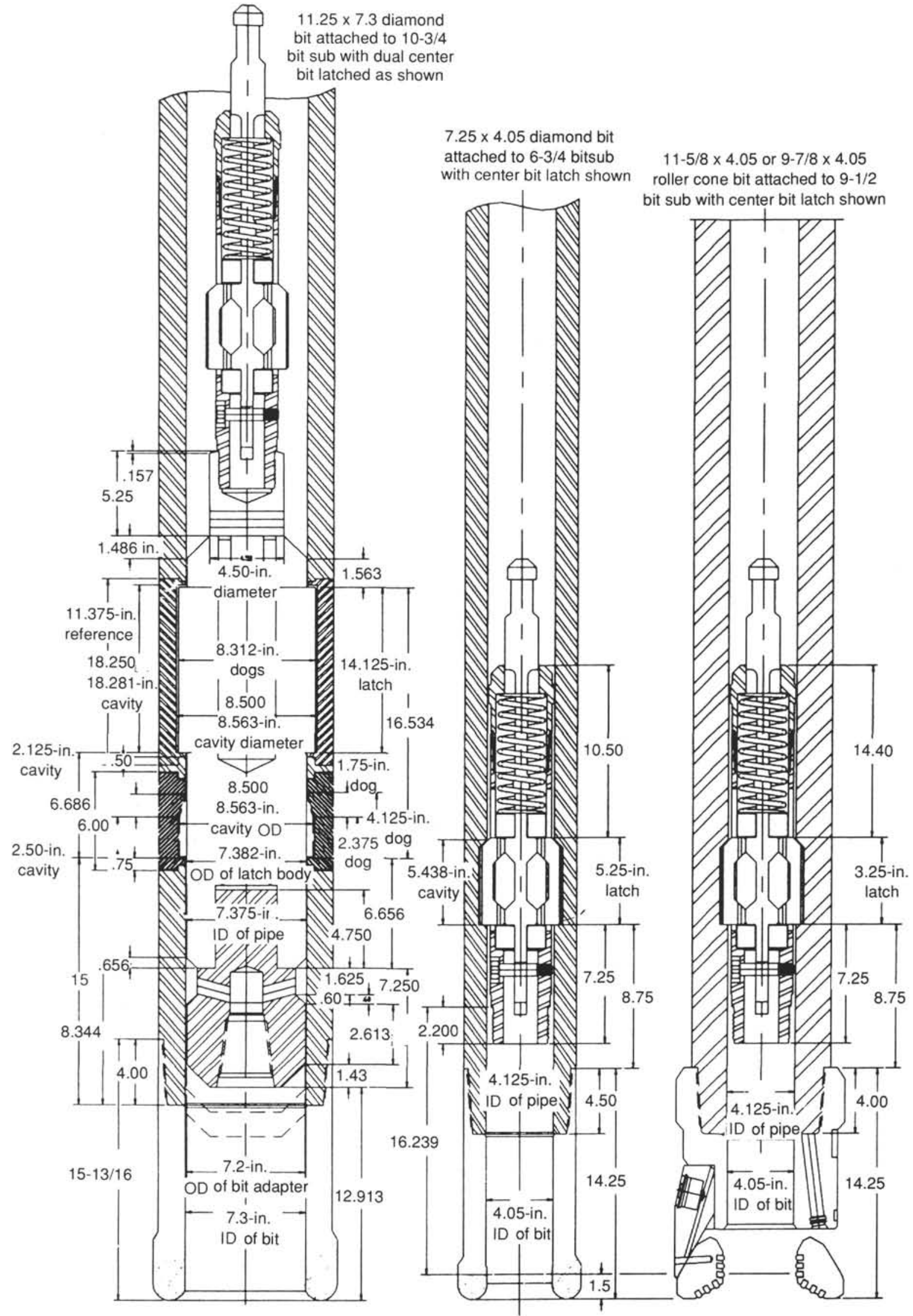

Figure 22. Center-bit latch detail for drill-in BHA options. For clarity, center bits are not shown. All dimensions are in inches. 


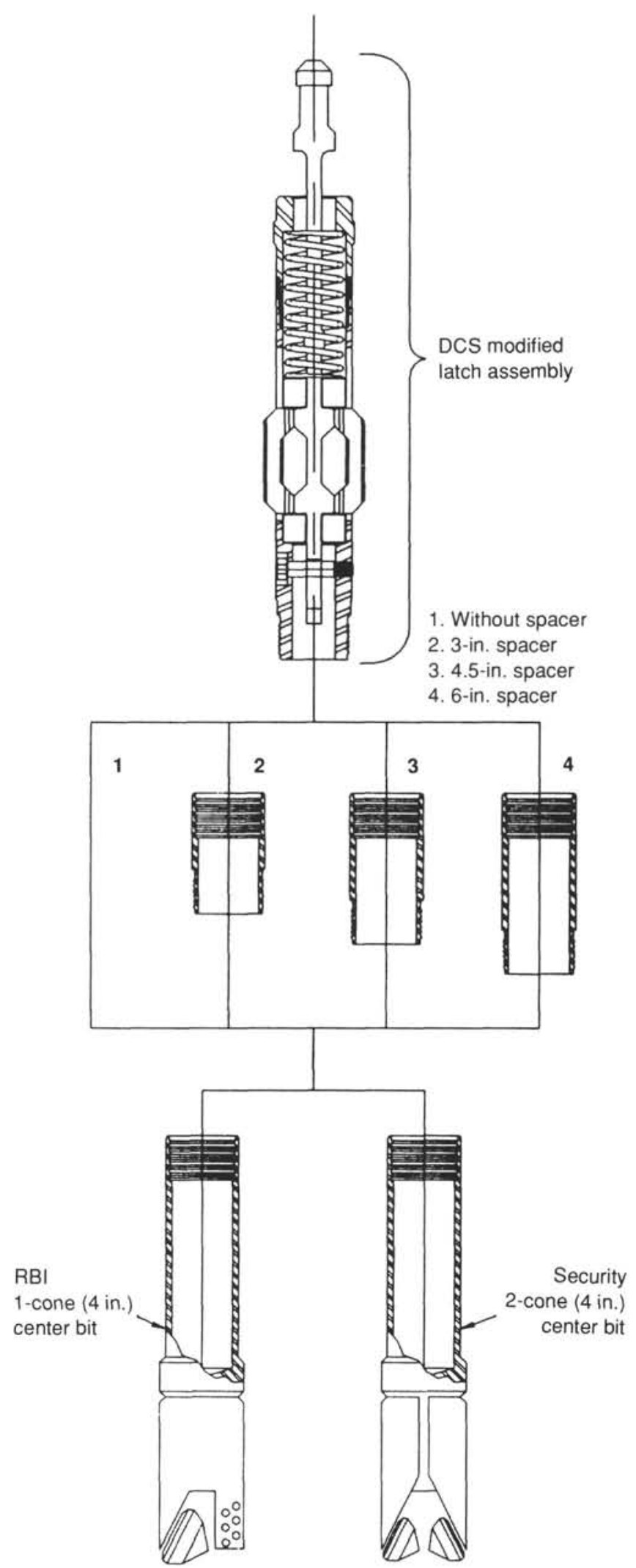

Figure 23. 4-in. center-bit assembly options. consistent with the performance from the tricone bit run in Hole 864A. So as not to leave any carbide in the hole, the bit was pulled after a conservative $3.5 \mathrm{hr}$ of rotation.

The small tricone bit fared much better than the first 7-1/4-in. (18.4 $\mathrm{cm}$ ) tricone run in Hole 864A. All the compacts on the three cones were intact, with none broken or chipped. Bearings were still tight without noticeable play. Compacts placed on the outer cones appeared to have provided better gage protection than during the first tricone bit run, perhaps a result of the bit being exposed to more massive basalt than rubble. The IADC grading for this bit is presented in Table 16.

\section{Hole 864C Drill Bits}

\section{7-1/4-in. Carbonado Diamond Bit}

In order to provide a bit test that could be compared directly with the first carbonado test, a similar test was run with only one variable changed, the type of center bit run in conjunction with the carbonado bit. It was suspected that the 1-cone-style center bits which had been run on several occasions were responsible for the problems with the bits not drilling. The slow rotation of the center-bit cone with the respect to the outer bit, along with the eccentric motion of rotating off center, was preventing the desired advancement. Therefore, a 2-cone center bit was substituted in place of the 1-cone bit, and the run was started with $40 \mathrm{gpm}(2.56 \mathrm{~L} / \mathrm{s})$ and $30-35 \mathrm{rpm}$ with 3 to 6 kips (1.4 to $2.7 \mathrm{~T}$ ) weight placed on the bit. Parameters (rpm and WOB) were gradually increased as the hole was deepened. Typical rotational speed was $70 \mathrm{rpm}$ and the weight on bit was around 6-10 kips (2.7-4.54 T). Penetration of the bit with respect to elapsed time is presented in Figure 37. Total rotational time was in excess of 8.5 $\mathrm{hr}$, with a total penetration of $22.6 \mathrm{ft}(6.9 \mathrm{~m})$ reported. The bit was pulled even though it was still penetrating, due to time limitations at the end of the leg.

The bit face showed very little damage and no signs of polishing. The matrix was eroded behind the diamonds, indicating that the bit was cutting freely and not being held back by the center bit. There were no signs of wear on the inside gage since the center bit prevented any material from entering the throat. The outside gage was worn due to the formation and not from vibration. There was not any indication of damage on the bit from too high a flow rate. The OD wear is especially heavy on the leading edge of each junk slot. It appeared that cuttings were getting trapped in this area and redrilled by the leading edge of the OD waterway (Fig. 38). It is surmised that $3.28-6.56 \mathrm{ft}(2-3 \mathrm{~m})$ of additional penetration could have been drilled with the bit before the OD gage was totally eliminated. Suggestions for improvements to this type of bit are presented later in this chapter.

\section{4-in. Roller-Cone Center Bit}

The 4-in. (10.2 cm) center bit was used exclusively on Leg 132 with the prototype single-stage DI-BHA system. No failures were reported with these bits for rotating in excess of $21 \mathrm{hr}$. All of the spudding operations performed during Leg 132 were done with the aid of a PDCM. This typically produced rotational speeds of 90 to $120 \mathrm{rpm}$ and flow rates as high as $600 \mathrm{gpm}(37.8 \mathrm{~L} / \mathrm{sec})$.

The highlights of the drilling parameters are outlined in the previous "7-1/4-in. Carbanado Diamond Bit" subsection and will not be repeated here. It is important to note that the bit was run 2 in. (50.8 $\mathrm{mm}$ ) ahead of the Carbonado bit. The latch assembly on which it was run allowed approximately $0.5 \mathrm{in} .(12.7 \mathrm{~mm})$ of additional travel. Whether this travel contributed to the life of the bit is questionable. The bit fared quite well without any of the H1OOF compacts being lost or damaged. There was considerable material erosion on both of the arms (Fig. 39). The modifications made since Leg 132 on this bit appeared to eliminate the erosion damage suffered on the prototype bit. There was some bearing play but the bit was far from being totaled. The IADC grade for the bit is presented in Table 16. 


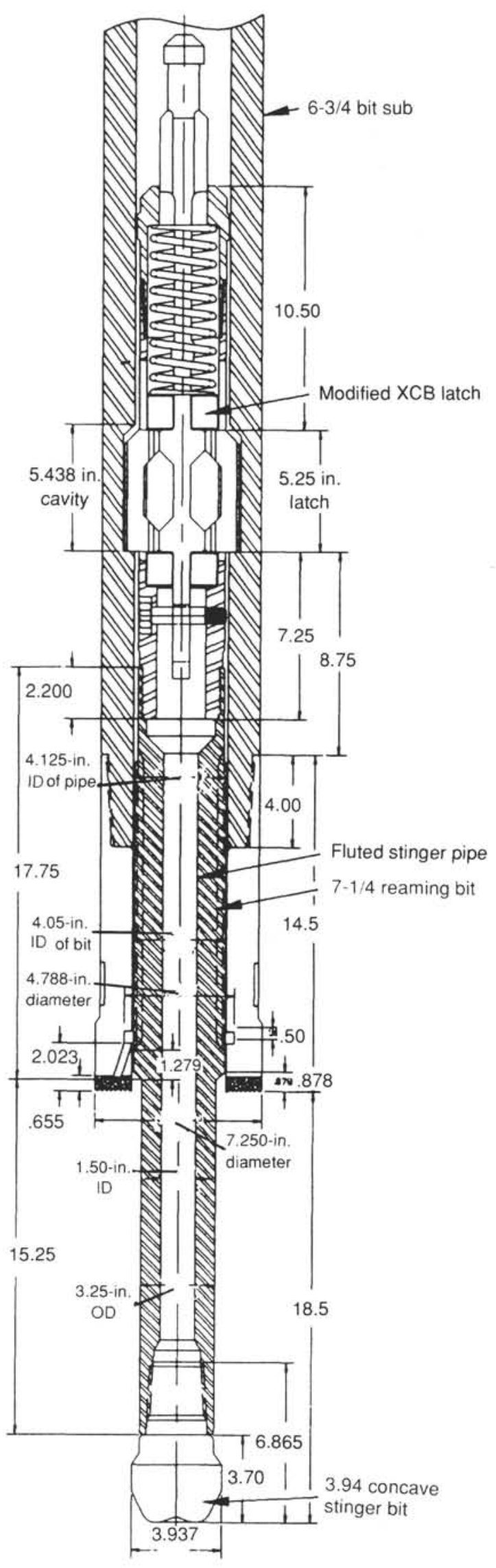

Figure 24. Reaming bit with stinger bit attachment. Dimensions in inches.

\section{Center-Bit Latches}

\section{7-1/4-in. Latch}

The large 7-1/4-in. (18.4 cm) latch was used to drive the center bit every time the primary DI-BHA system was deployed. There were no indications on the driver dogs other than positive engagement. This was partly due to the tight tolerances maintained in the bit sub cavities. Bit ID also provided no telltale signs of misalignment or wobble on either the center bit or latch. The latch assembly proved easy to load into the bit sub with the aid of a large C-ring clamp. Once the driver dogs were inside the throat of the bit sub the latch could be pushed into position. A positive indication of correct alignment could be noted by the sound of the dogs snapping into their respective grooves.

The design of the latch proved easy to disassemble and clean for storage. The four 1-in. $(25.3 \mathrm{~mm})$ ports on the bit sub were tapped as a means to regulate flow through the center bit. In addition, the fluted ports on the bit sub were welded shut as another means to increase annular flow velocity across the face of the outer bit.

Some difficulty was experienced while attempting to retrieve the latch assembly after the DI-BHA was deployed. From all indications the lower portion of the bit sub and bit become lodged, with cuttings/fill entering around the bit after backing off the lower sub. This material may have introduced itself when the back-off sub dropped down 3 in. $(76.2 \mathrm{~mm}$ ) to land out in the $\mathrm{C}$-ring groove because the hole was predrilled slightly deeper than the BHA itself. Another explanation was that cuttings, which had been in suspension from the heavy mud pumped to stabilize the borehole, had time to settle around the latch assembly. Three days had elapsed between the time the back-off sub was deployed and the time the latch was retrieved. Pumping tests performed with the recovery string indicated that the internal area was full of material.

Attempts to pull the center with a wireline overshot were unsuccessful. Overpulls of 6-7 kips (2.7-3.2 T) were attempted before jarring the overshot free. An alternative plan was initiated to pull the center-bit assembly with the secondary $6-3 / 4$-in. $(17.2 \mathrm{~cm})$ drill string. This method proved effective once flow was established around the bit by clearing the cuttings from around the latch assembly. An illustration of the technique used to retrieve the center bit is presented in Figure 40.

Upon recovery, the latch was disassembled to check whether (and where) cuttings may have entered and caused the dogs to remain open. From all visible signs, it appeared that the latch assembly was not at fault but that the annular cavities around the bit and bit sub had filled with cuttings and held the latch in place. Once the latch was taken apart the two large pins used to retain the driver dogs were slightly bent. While this deformation did not prohibit the latch from working once freed, it is obvious that a considerable amount of force was applied to the mandrel before the dogs released.

\section{4-in. Latch}

The modified XCB last was used in three applications during Leg 142. The first application was for retrieval of the large center bit, the second was for deployment of the bit guide, and the third for holding a 4 -in. $(10.2 \mathrm{~cm})$ center bit. The latch performed perfectly in all three applications. However, on one occasion when deploying the bit guide the dogs somehow released, dropping the bit guide prematurely. The only explanations that could be attributed to the dogs releasing were possibly that the hydraulic surge lifted the latch out of position while being run to the seafloor or the dogs themselves were not properly engaged on the rig floor.

The bit-guide holder attached to the end of the latch was designed with a bull-nose section (Fig. 25) upon which the flipper dogs rested, keeping the dogs extended out and thus providing a means to transport the bit guide to the seafloor. The OD of the bull nose ( $4.0 \mathrm{in}$. [10.2 $\mathrm{cm}$ ]) provided a tight annular area for fluid to pass. Therefore, as the drill string was heaving in the water column or being lowered from 


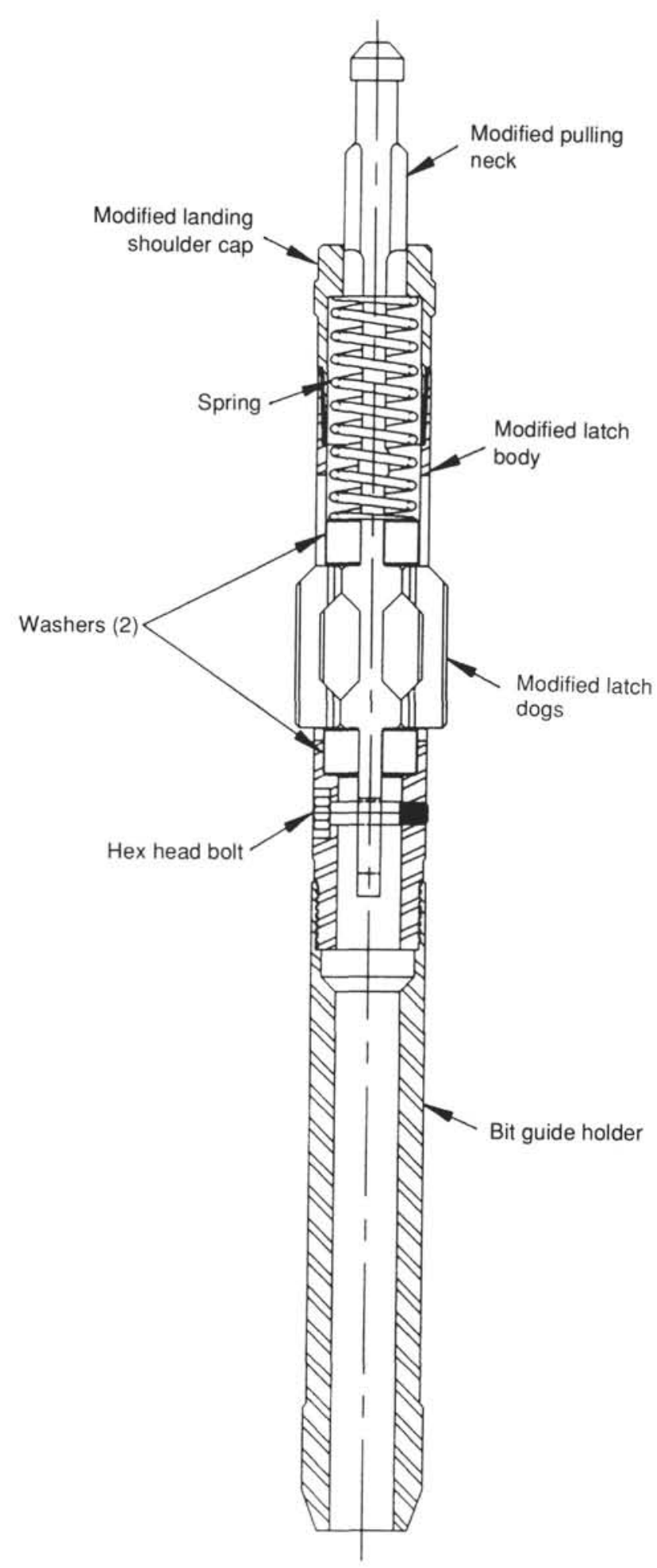

Figure 25. Bit-guide release latch assembly.

the running operation, flow entering around the bit-guide holder was restricted by the tight passageway. This inflow of water might have lifted the latch causing the bit guide to be released if the latch dogs were not totally in place. This flow action, coupled with the dogs being forced inward by the momentum developed by the bit guide itself being pushed down at the bottom of a heave cycle, may have resulted in the latch unseating.
A more probable scenario was that the latch dogs were not totally engaged into the slots but were held in place by the flipper dogs on the upper sub with the bit guide resting on them. Thus, when the bit guide was subjected to surge as it passed through the moonpool, it rode up, releasing the force the flipper dogs exerted on the latch and allowing it to drop. Even though the latch unseated, the latch dogs were captured in the lower sub cavity as the latch slid down the upper sub assembly. While the loss of the bit guide was a minor issue and not really needed for the operations being performed at the time, it did cause some lost time in the program and identified an area where some additional study should be directed.

Another related problem was experienced with the modified XCB latch during retrieval of the large center-bit latch assembly inside the $10-3 / 4$-in. $(27.3 \mathrm{~cm})$ DI-BHA. The small size of the overshot knob on the XCB latch, coupled with the 2-1/4-in. $(5.7 \mathrm{~cm})$ overshot that existed despite some added centralization, made catching the centerbit latch a difficult task. A20-ft $(6.1 \mathrm{~m})$ section of 3-1/2-in. (88.9 mm) sinker bar was added to help centralize the overshot through the tensioning sub so that the smaller jars would remain above the 7-3/8-in. $(18.7 \mathrm{~cm})$ bore of the DI-BHA. This set-up worked effectively while testing on deck but did not aid in recovery of the latch assembly once downhole. Vessel offsets helped to recover the latch, as did the addition of a short, inverted-style funnel to the end of the overshot. In order to pass the top drive and WKM valve assembly, the OD of the funnel had to remain less than $3-1 / 2 \mathrm{in}$. $(88.9 \mathrm{~mm})$. This OD was smaller than desired, as it did not eliminate the possibility of the overshot missing the pulling neck and wedging in between the modified XCB latch and ID wall of the 10-3/4-in. (27.3 cm) DI-BHA. Several hours were lost during this operation which should have been a routine task.

\section{SUGGESTIONS FOR IMPROVEMENTS}

The East Pacific Rise presented a considerable challenge to drilling even a short hole in the abrasive, massive basalts and collapsed features without total destruction of the bit. A total of five bit trips were made into Hole 864A until a penetration of $21.65 \mathrm{ft}(6.6 \mathrm{~m})$ could be established to allow the $10-3 / 4$-in. $(27.3 \mathrm{~cm})$ DI-BHA hardware to be deployed. The upper few meters that were drilled into the massive basalt before breaking out into the collapsed features proved to be a valuable asset, as this made it possible to maintain the hole and make reentries without further deterioration and caving from the seafloor. A primary reason for enhanced bit performance was the successful centralization of the bit by the mini-HRB. The tight diameter of the landing seat inside the casing hanger, coupled with the centralization from the spiral-bladed stabilizers, is thought to have added significantly to bit life and performance. Total annular clearances between the 11-1/2-in. (29.2 cm) spiral blades of the stabilizer and the 12-9/16in. $(31.9 \mathrm{~cm}) \mathrm{ID}$ of the landing seat, if completely centralized, is 18/32-in. (14.3 mm) per side.

A second guide base was deployed near the end of Leg 142 because of the junk left in Hole 864A from the DCS bits. The upper portion of the second borehole was primarily dedicated to testing some of the new prototype bits and to attempting to recover a core with the DCB. This hole was drilled to a total depth of $23.3 \mathrm{ft}$ ( $7.1 \mathrm{mbsf})$ using four different bits. The DI-BHA was deployed and set to a depth of approximately $23 \mathrm{ft}$ ( $7 \mathrm{mbsf}$ ).

The second HRB was moved after a portion of the DI-BHA failed during the back-off procedure due to cyclic fatigue. The failure rendered Hole 864B useless, as fishing the component was unsuccessful. Hole $864 \mathrm{C}$ was used to test the carbonado diamond bit and a modified 2-cone center bit in the limited time remaining in the leg. Total depth of advancement was $22.6 \mathrm{ft}$ ( $6.9 \mathrm{mbsf})$ and $8.5 \mathrm{hr}$ of drilling were accumulated on the bit.

The concept of the DI-BHA allowing the hole to be drilled down only once without retracting the string is considered the most desirable approach. However, until bit life can be improved to the point at 


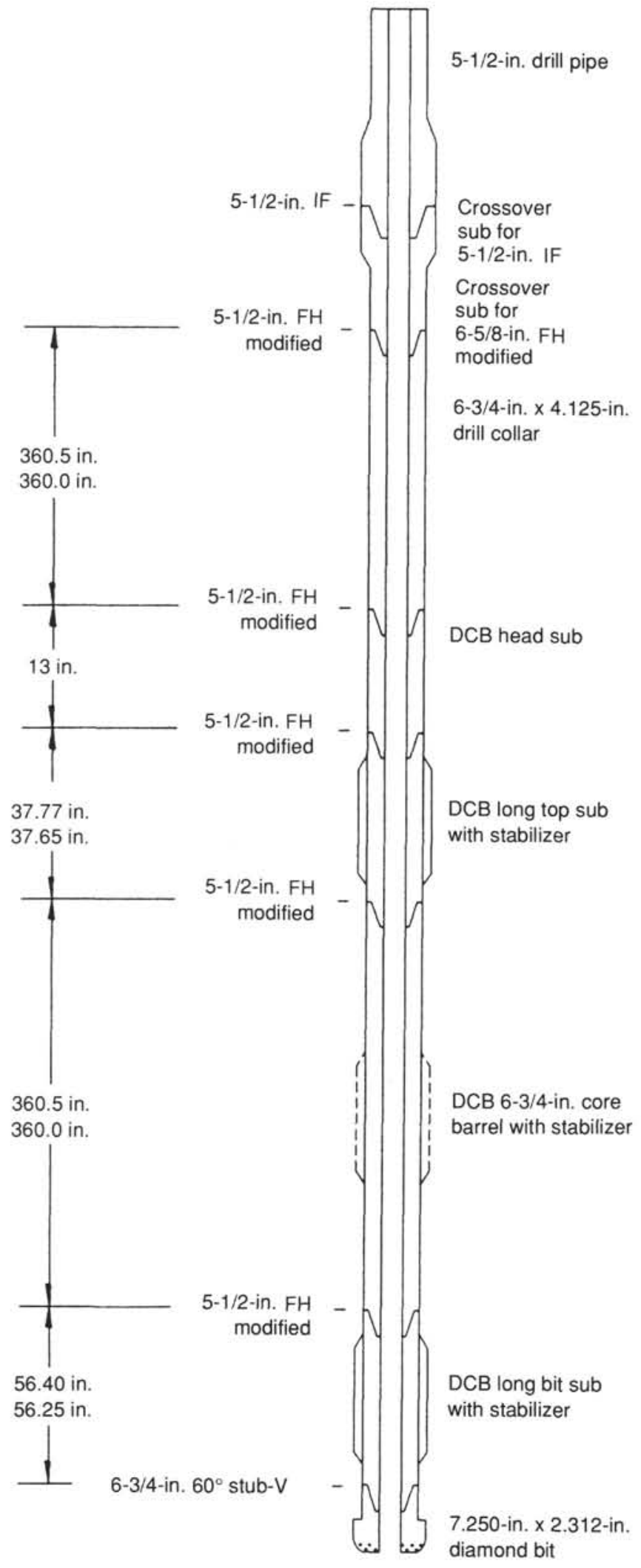

Figure 26, 6-3/4-in. diamond core barrel. $\mathrm{FH}=$ full hole; $\mathrm{IF}=$ internal flush. which this concept can be fully realized, multiple trips into the same hole will still be required. This multiple bit/predrilling a hole may not be an option for some locations where fill the size of small boulders prevents the hole from remaining open after the bit is retracted.

The prototype bits and hardware developed for the nested DI-BHA are a valuable step toward future designs for drilling in harsh marine environments. The large center-bit latches performed mechanically flawlessly every time they were deployed. However, problems with the fine volcanic fill settling out and covering the latch body played havoc with recovery of the center bits. The large tricone bits also held up quite well even though the majority of damage sustained was caused by excessive flow. Several improvements can be readily made to the small tricone bits to enhance their performance and life. There is still a considerable amount of uncertainly regarding the diamond bits. On two occasions when they were run near the surface, centralization and stability problems most likely added to their demise. The 1-cone roller bit run in conjunction with the diamond bits appeared to be the most likely culprit.

The last diamond bit run in conjunction with a 2-cone roller bit produced the most success. It was rotated more than $8.5 \mathrm{hr}$ and was still in reasonable shape after being pulled. Whereas this bit drilled more hole than any other single bit besides the tricone, it fared much better. The diamond bit drills at about half the speed of the tricone. However, the penetration is steady and the bit is not as likely to leave any junk in the hole as the roller cone bits tend to do.

Probably the most disappointing piece of hardware was the 6-cone roller bit. While the bit did a commendable job of making hole, it will require additional strengthening and possibly enlarging to allow it to survive the repeated impact-loading which it will continue to see with the light bit weights required for spudding operations. Any size larger than the existing $12-1 / 2$-in. $(31.75 \mathrm{~cm})$ bit will require some additional redesign of the back-off sub and landing seat arrangement. Compared to the bits used during Leg 106 at the Mid-Atlantic Ridge (MAR), the 6-cone bits lasted over four times as long and with substantially less damage. However, the location on the MAR produced fill the size of cobblestones to boulders, whereas at the EPR fill was generally fine sand to marble-size cuttings.

The actual field performance of all the equipment produced some ideas that can be used to improve the design for future applications. It is recommended that a closer dialogue between the bit manufacturers and ODP be cultivated in order to build bits in the future that will attempt to meet the requirements needed for the harsh, hard-rock environments. In this section, recommendations are cited for each piece of hardware for which improvements are suggested. Some additional concepts and bits that should be investigated for future use are listed in the "Other Bits/Concepts" subsection.

\section{Hole 864A}

\section{2-1/2-in. 6-Cone Roller Bits}

1. Reduce bit ID gage from $7.92 \mathrm{in} .(20.1 \mathrm{~cm})$ to $7.3 \mathrm{in} .(18.8 \mathrm{~cm})$.

2. Eliminate the hybrid arms.

3. Rearrange the orientation of the cones to be run four heels out and two heels in, in order to eliminate excessive nose wear.

4. Investigate whether a larger bearing can be used in place of the small 4-3/4-in. $(12 \mathrm{~cm})$ cones.

5. Increase the arm width in order to strengthen arm attachment to bit body.

6 . Investigate whether harder cone base metal or coatings could be used or applied to inhibit erosion at high flow rates.

7. Investigate alternative bit designs such as hole openers or reamers that could be adapted for the primary BI-BHA bit.

8. Fabricate stronger bit breaker for adapting to ODP rotary table.

9. Add junk mills to inventory in order to accommodate the 6-cone bits. 

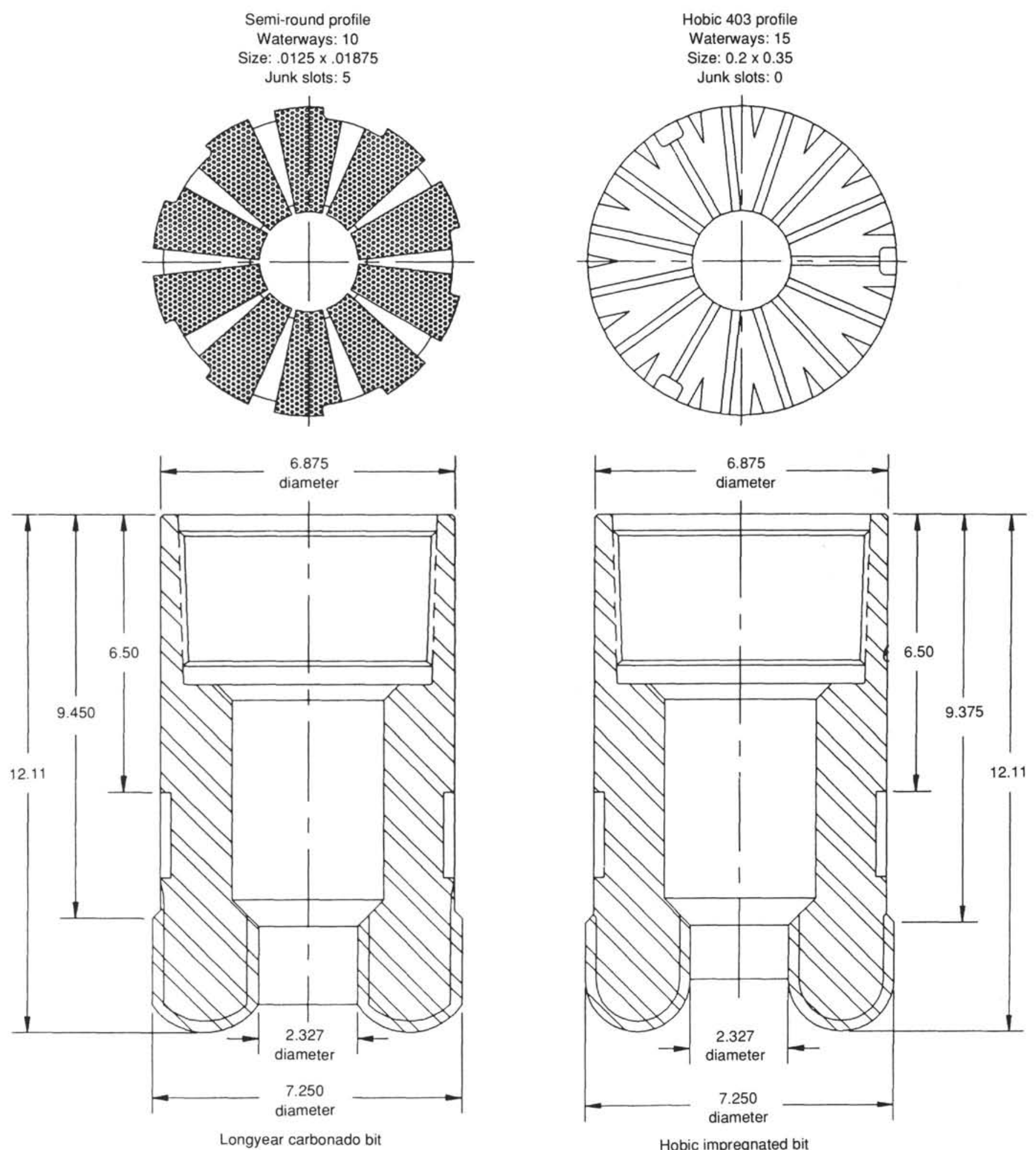

Hobic impregnated bit

Figure 27. Comparison of 7-1/4-in. diamond core barrel bits. Dimensions in inches.

\section{1-1/4-in. Surface-set Diamond Bits}

1. Use harder matrix and binder material for similar formations. 2. Add rectangular tungsten carbon inserts on both the leading and trailing edges of the waterways on the bit OD.

3. Minimize the exposure of the carbonado diamonds to further protect them under adverse drilling conditions. Eliminate the broach and use a flush setting of stones on the OD to possibly enhance bit life.
4. Add four bit breaker slots in place of two.

5. Fabricate stronger bit breaker for adapting to ODP rotary table.

\section{2-1/2-in. Tricone Bit}

1. Investigate whether harder cone base metal or coatings could be used to inhibit erosion at high flow rates.

2. Protect grease reservoirs with caps. 
Table 4. Diamond bits for DCS core barrel.

\begin{tabular}{|c|c|c|c|c|c|c|c|c|c|c|}
\hline Item & $\begin{array}{l}\text { Size } \\
\text { (in.) }\end{array}$ & $\begin{array}{l}\text { Inner } \\
\text { diameter } \\
\text { (in.) }\end{array}$ & $\begin{array}{l}\text { Length } \\
\text { (in.) }\end{array}$ & Manufacturer & Matrix type & Grade & $\begin{array}{l}\text { Stones per } \\
\text { carat/set wt }\end{array}$ & Profile & Waterways & $\begin{array}{l}\text { Size } \\
\text { (in.) }\end{array}$ \\
\hline 1 & 3.96 & 2.20 & 6.31 & Longyear & Series 2 & $100 \mathrm{~A}$ & $25 / 35-145$ & Flat & 10 & $1 / 8 \times .438$ \\
\hline 2 & 3.96 & 2.20 & 6.31 & Longyear & Series ID & $100 \mathrm{~A}$ & $25 / 35-191.25$ & Flat & 10 & $1 / 8 \times .438$ \\
\hline 3 & 3.96 & 2.20 & 6.94 & Dimatec & MX6 (med/hard) & $100 \mathrm{~A}$ & $30 / 50-121$ & Flat & 8 & $.31 \times .65$ \\
\hline 4 & 3.96 & 2.20 & 6.94 & Dimatec & MX6 (med/hard) & $100 \mathrm{~A}$ & $30 / 50-121$ & Flat & 8 & $.31 \times .65$ \\
\hline 5 & 3.96 & 2.20 & 6.50 & Hobic & Series 1 & $100 \mathrm{~S}$ & $20 / 25-100$ & Flat & 8 & $.125 \times .46$ \\
\hline 6 & 3.96 & 2.20 & 6.50 & Hobic & Series 2 & $100 \mathrm{~S}$ & $20 / 25-100$ & Flat & 8 & $.125 \times .46$ \\
\hline 7 & 3.96 & 2.20 & 6.31 & Huddy & Silver/blue & N/A & N/A & Flat & 5 & $.197 \times .29$ \\
\hline 8 & 3.96 & 2.20 & 6.31 & Huddy & Yellow & N/A & N/A & Flat & 5 & $.197 \times .29$ \\
\hline 9 & 3.96 & 2.20 & 6.31 & Huddy & Yellow & N/A & N/A & Flat & 5 & $.197 \times .29$ \\
\hline 10 & 3.96 & 2.20 & 6.31 & Huddy & Gold & N/A & N/A & Flat & 5 & $.197 \times .29$ \\
\hline 11 & 3.96 & 2.20 & 6.31 & Huddy & Surface set & $\mathrm{AA}$ & $18-20 / 43$ & $\operatorname{Mod} X$ & N/A & N/A \\
\hline 12 & 3.96 & 2.20 & 6.31 & Huddy & Surface set & $\mathrm{AA}$ & $25-40 / 37$ & $\operatorname{Mod} X$ & N/A & N/A \\
\hline 13 & 3.96 & 2.20 & 6.31 & Huddy & Surface set & AA & $25-40 / 37$ & Mod X & N/A & N/A \\
\hline 14 & 3.96 & 2.20 & 6.31 & Longyear & Series 2 & $100 \mathrm{~A}$ & $25 / 35-80.75$ & Flat & 10 & $1 / 8 \times 1 / 4$ \\
\hline 15 & 3.96 & 2.20 & 6.31 & Longyear & Series 2 & $100 \mathrm{~A}$ & $25 / 35-80.75$ & Flat & 10 & $1 / 8 \times 1 / 4$ \\
\hline 16 & 3.96 & 2.20 & 6.31 & Longyear & Series 2 & $100 \mathrm{~A}$ & $25 / 35-80.75$ & Flat & 10 & $1 / 8 \times 1 / 4$ \\
\hline 17 & 3.96 & 2.20 & 6.31 & Longyear & Series 6 & $100 \mathrm{~A}$ & $30 / 40-72$ & Flat & 12 & $1 / 8 \times .313$ \\
\hline 18 & 3.96 & 2.20 & 6.31 & Longyear & Series 6 & $100 \mathrm{~A}$ & $30 / 40-72$ & Flat & 12 & $1 / 8 \times .313$ \\
\hline 19 & 3.96 & 2.20 & 6.31 & Longyear & Series 6 & $100 \mathrm{~A}$ & $30 / 40-72$ & Flat & 12 & $1 / 8 \times .313$ \\
\hline 20 & 3.96 & 2.20 & 6.31 & Longyear & Series 6 & $100 \mathrm{~A}$ & $30 / 40-72$ & Flat & 12 & $1 / 8 \times .313$ \\
\hline 21 & 3.96 & 2.20 & 6.31 & Dimatec & M7HP & $100 \mathrm{~A}$ & $30 / 50-79.8$ & V-ring & $10 / 10$ & $3 / 16 \times .44$ \\
\hline 22 & 3.96 & 2.20 & 6.31 & Dimatec & M6HP & $100 \mathrm{~A}$ & $30 / 50-79.8$ & V-ring & $10 / 10$ & $3 / 16 \times .44$ \\
\hline 23 & 3.96 & 2.20 & 6.31 & Hoble & Geoset & Geoset & 130 Geosets & W & N/A & N/A \\
\hline 24 & 3.96 & 2.20 & 6.31 & Huddy & Surface set & AA & $18 / 20-43$ & Mod X & N/A & N/A \\
\hline 25 & 3.96 & 2.20 & 6.43 & Longyear & Surface set & Premium & $35 / 45-37.25$ & $\mathrm{X}$ & 8 & $3 / 16 \times 3 / 32$ \\
\hline 26 & 3.96 & 2.20 & 6.43 & Longyear & Surface set & Premium - & $35 / 45-37.25$ & $\mathrm{X}$ & 8 & $3 / 16 \times 3 / 32$ \\
\hline 27 & 3.96 & 2.20 & 6.43 & Longyear & Surface set & Premium & $15 / 25-38.25$ & $\mathrm{X}$ & 8 & $3 / 16 \times 3 / 32$ \\
\hline 28 & 3.96 & 2.20 & 6.31 & Longyear & Series 6 & $100 \mathrm{~A}$ & $30 / 40-72$ & Flat & 12 & $1 / 8 \times .313$ \\
\hline 29 & 3.96 & 2.20 & 6.31 & Longyear & Series 6 & $100 \mathrm{~A}$ & $30 / 40-72$ & Flat & 12 & $1 / 8 \times .313$ \\
\hline 30 & 3.96 & 2.20 & 6.31 & Longyear & Series 6 & $100 \mathrm{~A}$ & $30 / 40-72$ & Flat & 12 & $1 / 8 \times .313$ \\
\hline
\end{tabular}

Note: Huddy bits have 5 face discharge ports of $5 \mathrm{~mm}$. N/A = not applicable.

3. Increase exposed surface area with additional hardfacing.

4. Use harder compacts for abrasive formations.

\section{7-1/4-in. 2-cone Center Bit}

1. Add 7-1/4-in. junk mills and junk baskets to inventory.

2. Increase the width of the legs.

3. Protect grease reservoirs with caps.

4. Add additional hardfacing on leading edges of arms.

5. Review concept of hybrid arms for center bits to eliminate potential of rubble becoming trapped between cones.

\section{7-1/4-in. 1-cone Center Bit}

The 1-cone center bit used for the primary DI-BHA saw very limited use during Leg 142. It was run only $3 \mathrm{hr}$ without any penetration being recorded when coupled with a larger 11-1/4-in. $(28.6 \mathrm{~cm})$ carbonado-style surface-set bit. The outer bit never appeared to advance into virgin material but was held back by the one cone either not cutting or pivoting about its axis. Additional testing is recommended on this style of bit in order to learn more about optimum performance before is run again in the field. Eccentric wear patterns and rate of penetration should be studied in order to determine whether this style of bit lends itself to use as a center bit for the primary DI-BHA system.

\section{7-1/4-in. Tricone Bit}

1. Add better heel row protection compacts.

2. Protect shirttails with additional hardfacing.

3. Protect grease reservoirs with caps.

4. Develop protective cap/cover for bit during reentry.

5. Investigate potential for using a tougher grade of compacts.

\section{Hole 864B}

\section{7-1/4-in. Carbonado Diamond Bit}

1. Add a harder binder to matrix during furnacing.

2. Substitute heavier setting of carbonado diamonds on outside gage.

3. Add tungsten carbide inserts on leading edge of OD gage.

4. Enlarge junk slots.

\section{4-in. 1-cone Center Bit}

The 1-cone design requires a thorough laboratory testing program to determine whether it is even a viable option for future use. The relatively slow rotation of the center bit as compared to the outer bit does not appear not to lend itself very well to removing the center core in the present orientation. The width of the single arm will also need to be studied to see if the interior space between it and the cone can be reduced. The large, robust design of the center bit is attractive; however, the concentric rotation pattern should be reviewed by RBI to see if it can be improved.

\section{7-1/4-in. Impregnated Bit}

A few improvements as far as bit design and/or matrix is suggested for the Hobic impregnated DCB bit. Some additional types of bits should be designed for different applications and/or material. These might include bits with:

1. A shorter throat length in order to get core into barrel faster.

2. Four bit breaker slots in place of two.

3. Bit body OD reduced to 6-3/4-in. diameter.

4. A softer matrix.

5. Larger junk slots to allow cuttings more annular area to escape. 


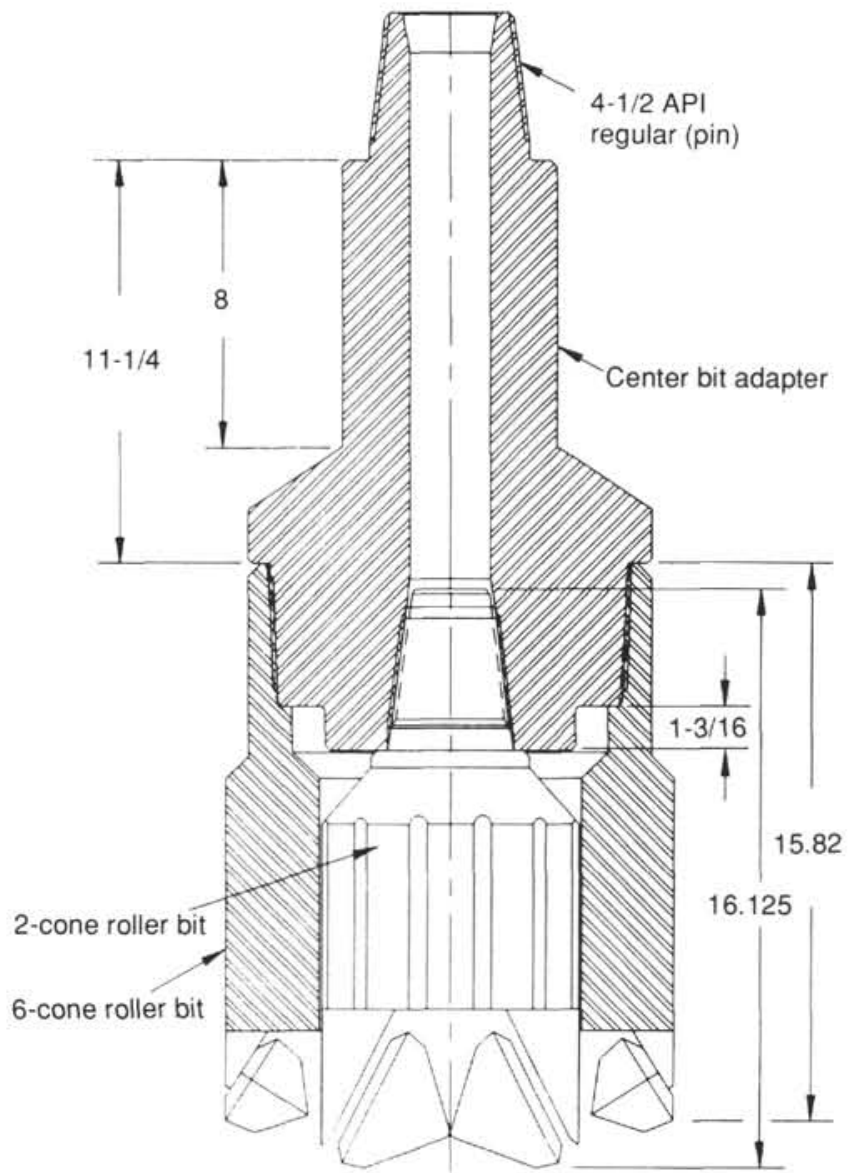

Figure 28. Drilling assembly test set-up. Dimensions in inches.

6. A mixture of mesh sizes such as $20 / 25$ and $30 / 40$ to help control polishing.

7. A more friable diamond (lesser quality) to slow down (control) the polishing. Suggested diamonds might be SDA 85 or MBS 750 .

8. Lower diamond concentrations (by about $15 \%$ ) for similar material, as present load appears excessive.

9. Secondary abrasive added to the matrix to better help it erode and strip the diamonds.

\section{7-1/4-in. Tricone Bit}

Despite the fact that the second 7-1/4-in. $(18.4 \mathrm{~cm})$ tricone was subjected to longer hours of rotation, drilled more massive basalt, and was rerun to clean out the predrilled hole, the same improvements recommended above for the 7-1/4-in. tricone bit in the "Hole 864A" subsection still apply.

\section{Hole 864C}

\section{7-1/4-in. Carbonado Diamond Bit}

The 7-1/4-in. (18.4 cm) carbonado diamond bit was run in Hole $864 \mathrm{~B}$ with little success. The lack of penetration and destruction of the OD was attributed to the 4 -in. $(10.2 \mathrm{~cm}) 1$-cone center bit. Suggestions for improvement of the 7-1/4-in. carbanado diamond bit were made above in the "Hole 864B" subsection. We learned additional information on the second carbonado bit when it was drilled with the same parameters and only the center bit was changed to a 2 -cone bit in place of a single-cone bit. The improvements listed below expand the observations made after the first test. The suggestion for improvements include:

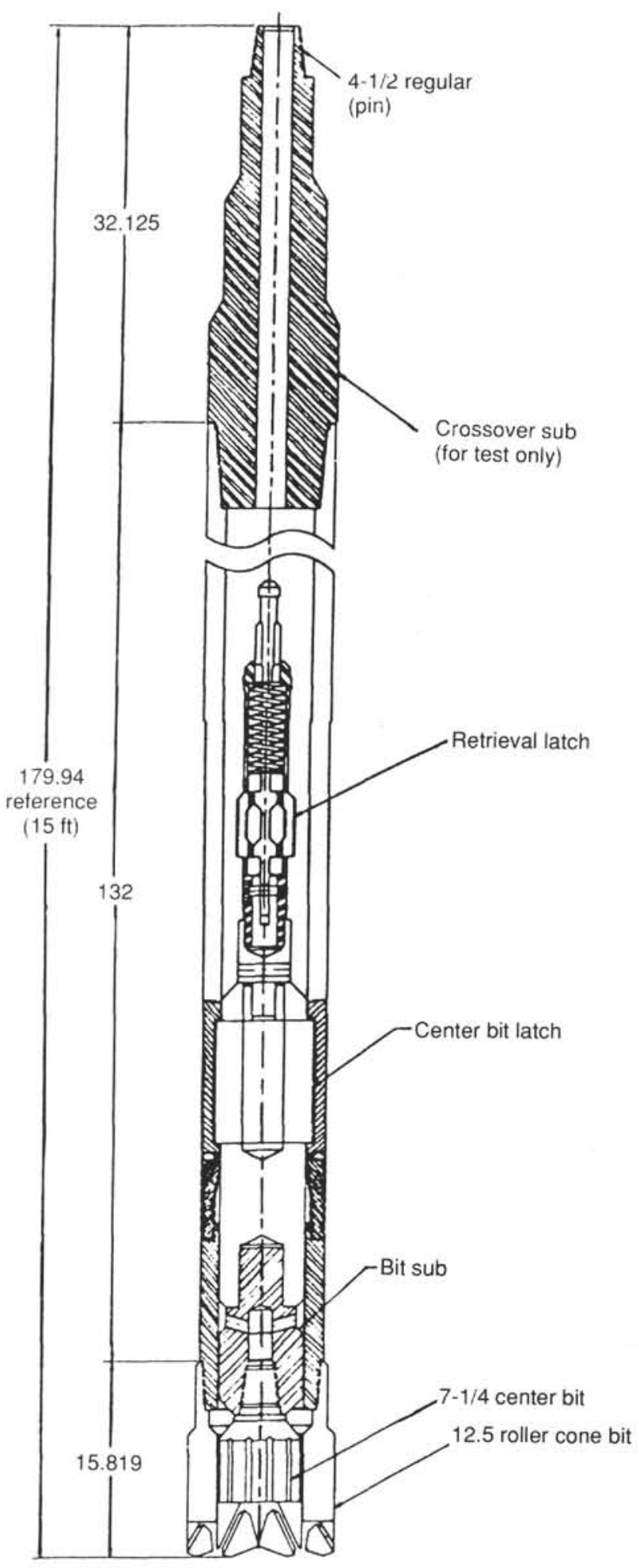

Figure 29. Drilling assembly test set-up. Dimensions in inches.

1. Use harder matrix material.

2. Substitute heavier diamond concentration on the OD gage.

3. Add double row of carbide inserts on leading junk slots.

4. Reinforce leading edges of all waterways with carbide inserts.

5. Investigate whether used geosets can be used as OD gage protection.

6. Add spiral type waterways to help reduce OD gage wear. 
Table 5. Results of 12 1/2-in. six-cone roller bit test series I, test \#1 (Sierra white granite).

\begin{tabular}{|c|c|c|c|c|c|c|c|}
\hline \multirow[b]{2}{*}{ Pass } & \multirow{2}{*}{$\begin{array}{l}\text { Time/pass } \\
\text { (min) }\end{array}$} & \multirow{2}{*}{$\begin{array}{l}\text { Total time } \\
\text { (min) }\end{array}$} & \multirow{2}{*}{$\begin{array}{l}\text { Bit weight } \\
\text { (kips) }\end{array}$} & \multirow[b]{2}{*}{ RPM } & \multirow{2}{*}{$\begin{array}{l}\text { Penetration/pass } \\
\text { (in.) }\end{array}$} & \multicolumn{2}{|c|}{ Penetration rate } \\
\hline & & & & & & $(\mathrm{ft} / \mathrm{hr})$ & $(\mathrm{m} / \mathrm{hr})$ \\
\hline 1 & 12.5 & 12.5 & 5 & 90 & 0.2 & 0.080 & 0.024 \\
\hline 2 & 12.5 & 25 & 5 & $90 / 140$ & 0.6 & 0.240 & 0.073 \\
\hline 3 & $2.91 / 9.58$ & $27.91 / 37.5$ & $5 / 10$ & 90 & 1.6 & 0.640 & 0.195 \\
\hline 4 & 12.5 & 50 & 10 & 110 & 2 & 0.800 & 0.244 \\
\hline 5 & 12.5 & 67.5 & 10 & 110 & 3.6 & 1.440 & 0.439 \\
\hline 6 & $83 / 11,67$ & $68.3 / 75$ & 10 & $110 / 140$ & 3.2 & 1.400 & 0.427 \\
\hline 7 & 12.5 & 87.5 & 10 & 140 & 5.2 & 2.080 & 0.634 \\
\hline 8 & 5 & 92.5 & 15 & 140 & 0.6 & 0.600 & 0.183 \\
\hline Totals & $1.54 \mathrm{hr}$ & & & & $17 \mathrm{in.}$ & & \\
\hline
\end{tabular}

Note: Nose compacts on bearings worn off.

\section{4-in. 2-cone Center Bit}

1. Add hardfacing to shirttails.

2. Investigate whether flat compacts or another type of material can be added to the arms as additional erosion protection.

\section{Center-Bit Latch Assembly}

1. Change XCB mandrel to include threaded shaft so that a larger RS-style pulling neck can be used to aid in the centralization within the 10 -3/4-in. $(27.3 \mathrm{~cm})$ DI-BHA.

2. Modify mandrel on 7-1/4-in. $(18.4 \mathrm{~cm})$ latch to include external flow ports.

3. Investigate whether external body cavities (bit sub and 7-1/4-in. [18.4 cm bit]) can be reduced in size to eliminate potential zone for filling with cuttings.

4. Add alternative GS-style pulling neck adapter to inventory for modified XCB latch.

5. Investigate the possibility of wireline-replaceable center bit.

6. Source stronger primary pins for holding the driver dogs into the latch body.

\section{Other Bits/Concepts}

1. Develop 7-1/4-in. (18.4 cm) and 4-in. (10.2 cm) fixed-cutter polycrystalline diamond compact (PDC) center bits.

2 . Investigate possibility of larger diameter roller-cone bit with same 7-3/8-in. ID to enhance bit life.

3. Develop fixed-cutter center bits for spudding with the DCB.

4. Investigate larger diameter bits with weld on diamond segments.

5. Use the double-jay tool with a tricone bit to land the base and predrill a hole in formations such those at the EPR where only small cuttings and fill are present.

6. Determine if retractable tricone bit concept can be utilized as primary drill-in bit.

7. Discuss the option with manufacturers of hole-opening-type devices for use as a primary means to advance the borehole or in conjunction with tricone type bits.

\section{ADDITIONAL TESTING REQUIREMENTS}

Many of bits designed for use on Leg 142 were not tested in either the field or in laboratory conditions prior to arriving aboard the JOIDES Resolution. The only combination of bits actually tested in a controlled environment were the $12-1 / 2$-in. $(31.75 \mathrm{~cm}$ ) 6-cone roller bit with a 7-1/4-in. $(18.4 \mathrm{~cm}) 2$-cone center bit. Near the completion of Leg 142, we were able to run and evaluate some additional bits and center combinations:

1. 11-1/4-in. $(28.6 \mathrm{~cm})$ carbonado bit with $7-1 / 4-$ in. $(18.4 \mathrm{~cm})$ 1-cone center bit,
Table 6. Results of 12 1/2-in. six-cone roller bit test series II, test \#1 (basalt).

\begin{tabular}{|c|c|c|c|c|c|c|c|}
\hline \multirow[b]{2}{*}{ Pass } & \multirow[b]{2}{*}{$\underset{(\min )}{\text { Time/pass }}$} & \multirow[b]{2}{*}{$\begin{array}{l}\text { Total time } \\
(\mathrm{min})\end{array}$} & \multirow[b]{2}{*}{$\begin{array}{l}\text { Bit weight } \\
\text { (kips) }\end{array}$} & \multirow[b]{2}{*}{ RPM } & \multirow[b]{2}{*}{$\begin{array}{l}\text { Penetration/pass } \\
\text { (in.) }\end{array}$} & \multicolumn{2}{|c|}{ Penetration rate } \\
\hline & & & & & & $(\mathrm{f} / \mathrm{hr}$ ) & $(\mathrm{m} / \mathrm{hr})$ \\
\hline Set bit & 2.5 & 2.5 & $0-5$ & 60 & & & \\
\hline \multirow[t]{2}{*}{1} & 10 & 12.5 & 5 & 60 & 1 & 0.500 & 0.152 \\
\hline & 9.16 & 21.66 & 5 & 60 & & 0.000 & 0.000 \\
\hline 2 & 3.34 & 25 & 5 & 90 & 0.16 & 0.240 & 0.073 \\
\hline 3 & 12.5 & 37.5 & 5 & 90 & 0.6 & 0.240 & 0.073 \\
\hline 4 & 12.5 & 50 & 5 & 90 & 0.6 & 0.240 & 0.073 \\
\hline 5 & 12.5 & 62.5 & 10 & 90 & 1.8 & 0.720 & 0.220 \\
\hline 6 & 12.5 & 75 & 10 & 90 & 1.6 & 0.640 & 0.195 \\
\hline 7 & 12.5 & 87.5 & 10 & 90 & 1.5 & 0.600 & 0.183 \\
\hline 8 & 12.5 & 100 & 10 & 90 & 1.6 & 0.640 & 0.195 \\
\hline 9 & 12.5 & 112.5 & 10 & 110 & 1.6 & 0.640 & 0.195 \\
\hline 10 & 12.5 & 125 & 10 & 120 & 0.9 & 0.360 & 0.110 \\
\hline 11 & 12.5 & 137.5 & 10 & 90 & 1.6 & 0.640 & 0.195 \\
\hline 12 & 12.5 & 150 & 10 & 90 & 1.6 & 0.640 & 0.195 \\
\hline 13 & 12.5 & 162.5 & 10 & 100 & 1.6 & 0.640 & 0.195 \\
\hline 13.4 & 5 & 167.5 & 10 & 100 & 0.7 & 0.700 & 0.213 \\
\hline Totals & $2.79 \mathrm{hrs}$ & & & & $16.86 \mathrm{in.}$ & & \\
\hline
\end{tabular}

2. 7-1/4-in. (18.4 cm) impregnated DCB bit,

3. 7-1/4-in. (18.4 cm) carbonado bit with 4-in. $(10.2 \mathrm{~cm}) 1$-cone center bit,

4. 7-1/4-in. (18.4 cm) carbonado bit with 4-in. $(10.2 \mathrm{~cm})$ 2-cone center bit,

5. $12-1 / 2$-in. $(31.75 \mathrm{~cm})$ tricone bit,

6. 7-1/4-in. $(18.4 \mathrm{~cm})$ tricone bit.

Results from two tests series performed on the 6-cone roller bits at Terra Tek's facility in Salt Lake City, Utah, were described in the "Laboratory Tests" section of this chapter and will not be repeated here. A primary concern, the situation of which could not be readily reproduced in the laboratory for drilling in the difficult formations present at EPR, is whether (1) the small cones on the 12-1/2-in. (31.75 $\mathrm{cm}$ ) bit could withstand the abrasive basalt and (2) the impact-loading from light bit weights produced by the inefficiencies of the primary compensator would destroy the bits. The other primary concern was whether the diamond bits would hold up for any appreciable amount of time and whether this option is even a viable solution to be used in place of the large roller-cone bits. Once these questions are answered, then bit design efforts can continue on both fronts (diamond and roller cone) or can be directed toward hole openers/reamers and roller-cone style bits only.

It appears from both field and laboratory results that the small cones used on the 6-cone bits did not fail from bearings that are too weak when subjected to the high speeds and long hours, but rather from the impact-loading experienced by poor compensation with the drill string under light operating-load conditions. Several improvements in bit design have already been noted in the previous section. Once a new bit is designed and manufactured, these enhanced 6-cone bits should be retested to determine which combination of center bit provides the most efficient drilling and cuttings removal option. A fixed-cutter center-bit option should also be evaluated.

However, prior to any testing with either of the large-style bits $(121 / 2 \mathrm{in}$. [31.75 cm] or $11-1 / 4$ in. [28.6 cm] $)$, the 1 - and 2 -cone center bits should be tested independently. There is some concern that the 1-cone bit, while appearing more robust, in actuality will not cut at all but pirouettes on a single point of the cone or rotates at such a slow rpm compared to the outer bit that it holds back the drilling process. This was somewhat verified during a test case in which the 1-cone bit and a 11-1/4-in. $(28.6 \mathrm{~cm})$ diamond outer bit could not be advanced into fill but continued to rotate at the same elevation for several hours.

The tests performed in both the laboratory and field on the 2-cone center bit have confirmed that is a durable design and able to withstand the rigors of hard-rock drilling. The 7-1/4-in. $(18.4 \mathrm{~cm})$ bit used during Leg 142 sustained very little damage or bearing wear after use during the first bit run, which lasted over $24 \mathrm{hr}$. It is proposed to 
Table 7. Results of 12 1/2-in. six-cone roller bit test series II, test \#2 (basalt).

\begin{tabular}{|c|c|c|c|c|c|c|c|}
\hline \multirow[b]{2}{*}{ Pass } & \multirow[b]{2}{*}{$\begin{array}{c}\text { Time/pass } \\
\text { (min) }\end{array}$} & \multirow[b]{2}{*}{$\begin{array}{l}\text { Total time } \\
\text { (min) }\end{array}$} & \multirow[b]{2}{*}{$\begin{array}{l}\text { Bit weight } \\
\text { (kips) }\end{array}$} & \multirow[b]{2}{*}{ RPM } & \multirow[b]{2}{*}{$\begin{array}{l}\text { Penetration/pass } \\
\text { (in.) }\end{array}$} & \multicolumn{2}{|c|}{ Penetration rate } \\
\hline & & & & & & $(\mathrm{f} / \mathrm{hr})$ & $(\mathrm{m} / \mathrm{hr})$ \\
\hline 1 & 12.5 & 12.5 & $0-7.5$ & 60 & 1 & 0.400 & 0.122 \\
\hline & 5.8 & 18.3 & $7.5-10$ & 60 & 0.5 & 0.431 & 0.131 \\
\hline 2 & 6.67 & 25.0 & 10 & 60 & 0.7 & 0.525 & 0.160 \\
\hline 3 & 12.5 & 37.5 & 10 & 120 & 2.3 & 0.920 & 0.280 \\
\hline 4 & 12.5 & 50.0 & 10 & 120 & 2.3 & 0.920 & 0.280 \\
\hline 5 & 12.5 & 62.5 & 10 & 120 & 2.4 & 0.960 & 0.293 \\
\hline 6 & 12.5 & 75.0 & 10 & 140 & 2.8 & 1.120 & 0.341 \\
\hline 7 & 12.5 & 87.5 & 10 & 140 & 3 & 1.200 & 0.366 \\
\hline 7.7 & 8.75 & 96.2 & 10 & 140 & 2 & 1.143 & 0.348 \\
\hline Totals & $1.60 \mathrm{hr}$ & & & & $17 \mathrm{in.}$ & & \\
\hline
\end{tabular}

conduct all the drilling tests in basalt gathered from the Columbia Basin in Washington State in order to provide as close a comparison basis as possible with the previous work performed. The center-bit test should be conducted at several weights ranging from 2 to 10 kips $(1.8$ to $4.54 \mathrm{~T})$ and at various rotational speeds from 60 to $150 \mathrm{rpm}$.

With some knowledge of center-bit performance, the larger style bits can then be tested with the most advantageous combination of center bit. It is again recommended that several ranges of weight be investigated along with rotational speeds. Once some baseline performance characteristics are established, the next series of testing should be done with a variable load added in order to simulate heave and dynamic conditions in the harsh marine environment. It is expected that several bits of each type will be required unless there is a clear indication that one style or design is just not adequate to withstand the environment in which it is needed to drill.

A similar testing program for the smaller 7-1/4-in. $(18.4 \mathrm{~cm})$ size nested bits is also proposed. The 4-in. $(10.2 \mathrm{~cm})$ center-bit option should again be settled first, with the remainder of testing concentrating on the combination of the roller-cone center bit and diamond or fixed-cutter outer bit. A fixed-cutter center bit should also be tested, along with the 1- and 2-cone center bit options. APDC outer bit should also be investigated, along with the impregnated and surface-set bits. Because these 7-1/4-in. $(18.4 \mathrm{~cm})$ bits will more than likely be drilled with the top drive using rotational speeds in the upper range, they could be eliminated from the testing program. However, since the 4-in. $(10.2 \mathrm{~cm})$ center bit can be used with either the 7-1/4-in. $(18.4 \mathrm{~cm})$
Table 8. Results of 12 1/2-in. six-cone roller bit test series II, test \#3 (basalt).

\begin{tabular}{|c|c|c|c|c|c|c|c|}
\hline \multirow[b]{2}{*}{ Pass } & \multirow[b]{2}{*}{$\begin{array}{c}\text { Time/pass } \\
(\text { min })\end{array}$} & \multirow[b]{2}{*}{$\begin{array}{l}\text { Total time } \\
\text { (min) }\end{array}$} & \multirow[b]{2}{*}{$\begin{array}{l}\text { Bit weight } \\
\text { (kips) }\end{array}$} & \multirow[b]{2}{*}{ RPM } & \multirow[b]{2}{*}{$\begin{array}{l}\text { Penetration/pass } \\
\text { (in.) }\end{array}$} & \multicolumn{2}{|c|}{ Penetration rate } \\
\hline & & & & & & (ft/hr) & $(\mathrm{m} / \mathrm{hr})$ \\
\hline 1 & 12.5 & 12.5 & $0-5$ & 60 & 0.8 & 0.320 & 0.098 \\
\hline 2 & 12.5 & 25 & 5 & 140 & 1.2 & 0.480 & 0.146 \\
\hline 3 & 12.5 & 37.5 & 5 & 140 & 1.7 & 0.680 & 0.207 \\
\hline 4 & 12.5 & 50 & $5-10$ & 60 & 1.7 & 0.680 & 0.207 \\
\hline 5 & 12.5 & 62.5 & 10 & 100 & 1 & 0.400 & 0.122 \\
\hline 6 & 12.5 & 75 & 10 & 100 & 1.26 & 0.504 & 0.154 \\
\hline 7 & 12.5 & 87.5 & 5 & 120 & 1 & 0.400 & 0.122 \\
\hline 8 & 12.5 & 100 & 5 & 120 & 1.1 & 0.440 & 0.134 \\
\hline 9 & 12.5 & 112.5 & 5 & 100 & 0.6 & 0.240 & 0.073 \\
\hline 10 & 12.5 & 125 & 5 & 100 & 0.7 & 0.280 & 0.085 \\
\hline II & 12.5 & 137.5 & 5 & 130 & 0.9 & 0.360 & 0.110 \\
\hline 12 & 12.5 & 150 & 5 & 130 & 0.85 & 0.340 & 0.104 \\
\hline 13 & 12.5 & 162.5 & 5 & 100 & 0.5 & 0.200 & 0.061 \\
\hline 14 & 12.5 & 175 & 5 & 140 & 0.9 & 0.360 & 0.110 \\
\hline 15 & 12.5 & 187.5 & 5 & 130 & 1.4 & 0.560 & 0.171 \\
\hline 16 & 12.5 & 200 & 5 & 120 & 1.1 & 0.440 & 0.134 \\
\hline 17 & 12.5 & 212.5 & 5 & 100 & 0.55 & 0.220 & 0.067 \\
\hline Totals & $3.54 \mathrm{hr}$ & & & & $17.26 \mathrm{in}$. & & \\
\hline
\end{tabular}

secondary stage nested BHA and 9-7/8-in. $(25.1 \mathrm{~cm})$ or $11-5 / 8$-in. $(29.5 \mathrm{~cm})$ primary stage BHA, rotational speeds must be tested over the whole range that may be experienced in the field $(60-150 \mathrm{rpm})$.

Bit longevity is also a major concern in ensuring that adequate penetration can be achieved prior to drilling in the back-off sub. Many formations will not provide a second chance to change a bit before the hole is lost or where the rubble may fill the total depth drilled per run once the bit is withdrawn from the hole. A strong, durable bit that can penetrate at low bit weights and withstand dynamic impacts of fluctuating weights is required. This requirement must be fulfilled before the single-bit-run DI-BHA concept can be totally realized in difficult drilling areas such as the East Pacific Rise and mid-ocean ridges.

\section{REFERENCE}

Storms, M.A., Natland, J.H., et al., 1991. Proc. ODP, Init. Repts., 132: College Station, TX (Ocean Drilling Program).

Ms 142IR-109 
Table 9. Results of 12 1/2-in. six-cone roller bit test series II, test \#4 (basalt).

\begin{tabular}{|c|c|c|c|c|c|c|c|}
\hline \multirow[b]{2}{*}{ Pass } & \multirow{2}{*}{$\begin{array}{c}\text { Time/pass } \\
\text { (min) }\end{array}$} & \multirow{2}{*}{$\begin{array}{l}\text { Total time } \\
(\min )\end{array}$} & \multirow{2}{*}{$\begin{array}{l}\text { Bit weight } \\
\text { (kips) }\end{array}$} & \multirow[b]{2}{*}{ RPM } & \multirow{2}{*}{$\begin{array}{l}\text { Penetration/pass } \\
\text { (in.) }\end{array}$} & \multicolumn{2}{|c|}{ Penetration rate } \\
\hline & & & & & & $(\mathrm{f} / \mathrm{hr})$ & $(\mathrm{m} / \mathrm{hr})$ \\
\hline 1 & 12.5 & 12.5 & 5 & 100 & 0.8 & 0.320 & 0.098 \\
\hline 2 & 12.5 & 25 & 10 & 140 & 2 & 0.800 & 0.244 \\
\hline 3 & 12.5 & 37.5 & 10 & 140 & 1.9 & 0.760 & 0.232 \\
\hline 4 & 12.5 & 50 & 10 & 140 & 1.8 & 0.720 & 0.220 \\
\hline 5 & 12.5 & 62.5 & 10 & 140 & 1.7 & 0.680 & 0.207 \\
\hline 6 & 12.5 & 75 & 10 & 140 & 1.7 & 0.680 & 0.207 \\
\hline 7 & 12.5 & 87.5 & 10 & 140 & 1.9 & 0.760 & 0.232 \\
\hline 8 & 12.5 & 100 & 15 & 140 & 4.25 & 1.700 & 0.518 \\
\hline 8.2 & 2.5 & 102.5 & 15 & 140 & 0.84 & 1.680 & 0.512 \\
\hline Totals & $1.71 \mathrm{hr}$ & & & & 16.89 in. & & \\
\hline
\end{tabular}

Table 10. Results of 12 1/2-in six-cone roller bit test series II, test \#1 (Sierra white granite).

\begin{tabular}{|c|c|c|c|c|c|c|c|}
\hline \multirow[b]{2}{*}{ Pass } & \multirow{2}{*}{$\begin{array}{c}\text { Time/pass } \\
\text { (min) }\end{array}$} & \multirow{2}{*}{$\begin{array}{c}\text { Total time } \\
(\mathrm{min})\end{array}$} & \multirow{2}{*}{$\begin{array}{l}\text { Bit weight } \\
\text { (kips) }\end{array}$} & \multirow[b]{2}{*}{ RPM } & \multirow{2}{*}{$\begin{array}{l}\text { Penetration/pass } \\
\text { (in.) }\end{array}$} & \multicolumn{2}{|c|}{ Penetration rate } \\
\hline & & & & & & (ff/hr) & $(\mathrm{m} / \mathrm{hr})$ \\
\hline 1 & 12.5 & 12.5 & 5 & 100 & 1.3 & 0.520 & 0.159 \\
\hline 2 & 12.5 & 25 & 10 & 140 & 3.3 & 1.320 & 0.402 \\
\hline 3 & 12.5 & 37.5 & 10 & 140 & 3.2 & 1.280 & 0.390 \\
\hline 4 & 12.5 & 50 & 10 & 140 & 3.4 & 1.360 & 0.415 \\
\hline 5 & 12.5 & 62.5 & 10 & 140 & 4 & 1.600 & 0.488 \\
\hline 6 & 12.5 & 75 & 10 & 140 & 4.2 & 1.680 & 0.512 \\
\hline 7 & 12.5 & 87.5 & 10 & 100 & 2.4 & 0.960 & 0.293 \\
\hline 8 & 12.5 & 100 & 10 & 100 & 2.3 & 0.920 & 0.280 \\
\hline 9 & 12.5 & 112.5 & 10 & 100 & 2.2 & 0.880 & 0.268 \\
\hline 10 & 12.5 & 125 & 10 & 100 & 2.2 & 0.880 & 0.268 \\
\hline 11 & 12.5 & 137.5 & 10 & 140 & 4.2 & 1.680 & 0.512 \\
\hline 11.267 & 3.33 & 140.83 & 10 & 140 & 1.1 & 1.652 & 0.504 \\
\hline Totals & $2.35 \mathrm{hr}$ & & & & $33.8 \mathrm{in}$. & & \\
\hline
\end{tabular}

Table 11. Results of 12 1/2-in. six-cone roller bit test series II, test \#2 (Sierra white granite).

\begin{tabular}{|c|c|c|c|c|c|c|c|}
\hline \multirow{2}{*}{ Pass } & \multirow[b]{2}{*}{$\begin{array}{c}\text { Time/pass } \\
\text { (min) }\end{array}$} & \multirow[b]{2}{*}{$\begin{array}{l}\text { Total time } \\
\text { (min) }\end{array}$} & \multirow[b]{2}{*}{$\begin{array}{l}\text { Bit weight } \\
\text { (kips) }\end{array}$} & \multirow{2}{*}{ RPM } & \multirow[b]{2}{*}{$\begin{array}{l}\text { Penetration/pass } \\
\text { (in.) }\end{array}$} & \multicolumn{2}{|c|}{ Penetration rate } \\
\hline & & & & & & (ft/hr) & $(\mathrm{m} / \mathrm{hr})$ \\
\hline 1 & 12.5 & 12.5 & 5 & 100 & 1.4 & 0.560 & 0.171 \\
\hline 2 & 12.5 & 25 & 10 & 140 & 3.6 & 1.440 & 0.439 \\
\hline 3 & 12.5 & 37.5 & 10 & 100 & 2 & 0.800 & 0.244 \\
\hline 4 & 12.5 & 50 & 10 & 100 & 2 & 0.800 & 0.244 \\
\hline 5 & 12.5 & 62.5 & 10 & 100 & 2 & 0.800 & 0.244 \\
\hline 6 & 12.5 & 75 & 10 & 100 & 1.9 & 0.760 & 0.232 \\
\hline 7 & 12.5 & 87.5 & 10 & 140 & 3.8 & 1.520 & 0.463 \\
\hline 8 & 12.5 & 100 & 10 & 100 & 2.1 & 0.840 & 0.256 \\
\hline 9 & 12.5 & 112.5 & 10 & 100 & 2 & 0.800 & 0.244 \\
\hline 10 & 12.5 & 125 & 10 & 100 & 1.9 & 0.760 & 0.232 \\
\hline 11 & 12.5 & 137.5 & 10 & 100 & 1.8 & 0,720 & 0.220 \\
\hline 12 & 12.5 & 150 & 10 & 100 & 1.75 & 0,700 & 0.213 \\
\hline 13 & 12.5 & 162.5 & 10 & 100 & 2 & 0.800 & 0.244 \\
\hline 14 & 12.5 & 175 & 10 & 100 & 2.1 & 0.840 & 0.256 \\
\hline 15 & 12.5 & 187.5 & 10 & 100 & 2.1 & 0.840 & 0.256 \\
\hline 15.2 & 2.5 & 190 & 10 & 100 & 0.4 & 0.800 & 0.244 \\
\hline Totals & $3.17 \mathrm{hr}$ & & & & 32.85 in. & & \\
\hline
\end{tabular}

Table 12. Results of 12 1/2-in. six-cone roller bit test series II, test \#3 (Sierra white granite).

\begin{tabular}{|c|c|c|c|c|c|c|c|}
\hline \multirow[b]{2}{*}{ Pass } & \multirow[b]{2}{*}{$\begin{array}{c}\text { Time/paw } \\
\text { (min) }\end{array}$} & \multirow[b]{2}{*}{$\begin{array}{l}\text { Total time } \\
\text { (min) }\end{array}$} & \multirow[b]{2}{*}{$\begin{array}{l}\text { Bit weight } \\
\text { (kips) }\end{array}$} & \multirow[b]{2}{*}{ RPM } & \multirow[b]{2}{*}{$\begin{array}{l}\text { Penetration/pass } \\
\text { (in.) }\end{array}$} & \multicolumn{2}{|c|}{ Penetration rate } \\
\hline & & & & & & $(\mathrm{f} / \mathrm{hr})$ & $(\mathrm{m} / \mathrm{hr})$ \\
\hline 1 & 12.5 & 12.5 & 5 & 100 & 1.2 & 0.480 & 0.146 \\
\hline 2 & 12.5 & 25 & 10 & 100 & 2.2 & 0.880 & 0.268 \\
\hline 3 & 12.5 & 37.5 & 10 & 100 & 2.1 & 0.840 & 0.256 \\
\hline 4 & 12.5 & 50 & 10 & 100 & 2 & 0.800 & 0.244 \\
\hline 5 & 12.5 & 62.5 & 10 & 100 & 2 & 0.800 & 0.244 \\
\hline 6 & 12.5 & 75 & 10 & 140 & 3 & 1.200 & 0.366 \\
\hline 7 & 12.5 & 87.5 & 10 & 140 & 3.2 & 1.280 & 0.390 \\
\hline 8 & 12.5 & 100 & 10 & 140 & 3.3 & 1.320 & 0.402 \\
\hline 9 & 12.5 & 112.5 & 10 & 100 & 1.9 & 0.760 & 0.232 \\
\hline 10 & 12.5 & 125 & 10 & 100 & 1.8 & 0.720 & 0.220 \\
\hline 11 & 12.5 & 137.5 & 10 & 100 & 1.6 & 0.640 & 0.195 \\
\hline 12 & 12.5 & 150 & 10 & 100 & 1.6 & 0.640 & 0.195 \\
\hline 13 & 12.5 & 162.5 & 10 & 100 & 1.6 & 0.640 & 0.195 \\
\hline 14 & 12.5 & 175 & 10 & 100 & 1.6 & 0.640 & 0.195 \\
\hline 15 & 12.5 & 187.5 & 10 & 100 & 1.6 & 0.640 & 0.195 \\
\hline 16 & 12.5 & 200 & 10 & 100 & 1.6 & 0.640 & 0.195 \\
\hline Totals & $3.33 \mathrm{hr}$ & & & & 32.3 in & & \\
\hline
\end{tabular}

Table 13. Results of 12 1/2-in. six-cone roller bit test series II, test \#4 (Sierra white granite).

\begin{tabular}{ccccccccc}
\hline Pass & $\begin{array}{c}\text { Time/pass } \\
\text { (min) }\end{array}$ & $\begin{array}{c}\text { Total lime } \\
\text { (min) }\end{array}$ & $\begin{array}{c}\text { Bit weight } \\
\text { (kips) }\end{array}$ & RPM & $\begin{array}{c}\text { Penetration/pass } \\
\text { (in.) }\end{array}$ & \multicolumn{2}{c}{$\begin{array}{c}\text { Penetration rate } \\
\text { (f/hr) }\end{array}$} & (m/hr) \\
\hline 1 & 12.5 & 12.5 & 5 & 100 & 1.1 & 0.440 & 0.134 \\
2 & 12.5 & 25 & 10 & 100 & 2.4 & 0.960 & 0.293 \\
3 & 12.5 & 37.5 & 10 & 100 & 1.8 & 0.720 & 0.220 \\
4 & 12.5 & 50 & 10 & 100 & 1.7 & 0.680 & 0.207 \\
5 & 12.5 & 62.5 & 10 & 100 & 1.6 & 0.640 & 0.195 \\
6 & 12.5 & 75 & 10 & 100 & 1.6 & 0.640 & 0.195 \\
7 & 12.5 & 87.5 & 10 & 100 & 1.6 & 0.640 & 0.195 \\
8 & 12.5 & 100 & 10 & 100 & 1.6 & 0.640 & 0.195 \\
9 & 12.5 & 112.5 & 10 & 100 & 1.6 & 0.640 & 0.195 \\
10 & 12.5 & 125 & 10 & 100 & 1.7 & 0.680 & 0.207 \\
11 & 12.5 & 137.5 & 10 & 100 & 1.6 & 0.640 & 0.195 \\
12 & 12.5 & 150 & 10 & 100 & 1.6 & 0.640 & 0.195 \\
13 & 12.5 & 162.5 & 10 & 100 & 1.5 & 0.600 & 0.183 \\
14 & 12.5 & 175 & 10 & 100 & 1.5 & 0.600 & 0.183 \\
15 & 12.5 & 187.5 & 10 & 100 & 1.5 & 0.600 & 0.183 \\
16 & 12.5 & 200 & 10 & 100 & 1.6 & 0.640 & 0.195 \\
17 & 12.5 & 212.5 & 10 & 100 & 1.6 & 0.640 & 0.195 \\
18 & 12.5 & 225 & 10 & 100 & 1.6 & 0.640 & 0.195 \\
19 & 12.5 & 237.5 & 10 & 100 & 1.6 & 0.640 & 0.195 \\
20 & 2.5 & 240 & 10 & 100 & 0.34 & 0.680 & 0.207 \\
& & & & & & 31.14 in. & & \\
\hline
\end{tabular}

Table 14. Results of 12 1/2-in. six-cone roller bit test series II, test \#5 (Sierra white granite).

\begin{tabular}{|c|c|c|c|c|c|c|c|}
\hline \multirow{2}{*}{ Pass } & \multirow[b]{2}{*}{$\begin{array}{c}\text { Time/pass } \\
(\text { min })\end{array}$} & \multirow[b]{2}{*}{$\begin{array}{l}\text { Total time } \\
\text { (min) }\end{array}$} & \multirow[b]{2}{*}{$\begin{array}{c}\text { Bit weight } \\
\text { (kips) }\end{array}$} & \multirow{2}{*}{ RPM } & \multirow{2}{*}{$\begin{array}{l}\text { Penetration/pass } \\
\text { (in.) }\end{array}$} & \multicolumn{2}{|c|}{ Penetration rate } \\
\hline & & & & & & $(\mathrm{f} / \mathrm{hr})$ & $(\mathrm{m} / \mathrm{hr})$ \\
\hline 1 & 12.5 & 12.5 & 5 & 100 & 1 & 0.400 & 0.122 \\
\hline 2 & 12.5 & 25 & 10 & 100 & 1.1 & 0.440 & 0.134 \\
\hline 3 & 12.5 & 37.5 & 10 & 100 & 1.3 & 0.520 & 0.159 \\
\hline 4 & 12.5 & 50 & 10 & 100 & 1.2 & 0.480 & 0.146 \\
\hline 3 & 12.5 & 62.5 & 10 & 100 & 1.2 & 0.480 & 0.146 \\
\hline 6 & 12.5 & 75 & 10 & 100 & 1 & 0.400 & 0.122 \\
\hline 7 & 12.5 & 87.5 & 10 & 100 & $i$ & 0.400 & 0.122 \\
\hline 8 & 12.5 & 100 & 10 & 100 & 1.1 & 0.440 & 0.134 \\
\hline & 12.5 & 112.5 & 10 & 100 & 1.1 & 0.440 & 0.134 \\
\hline 10 & 12.5 & 125 & 10 & 100 & 0.8 & 0.320 & 0.098 \\
\hline II & 12.5 & 137.5 & 10 & 100 & 0.4 & 0.160 & 0.049 \\
\hline 12 & 12.5 & 150 & 10 & 100 & 0.4 & 0.160 & 0.049 \\
\hline Totals & $2.50 \mathrm{hr}$ & & & & $11.6 \mathrm{in}$. & & \\
\hline
\end{tabular}




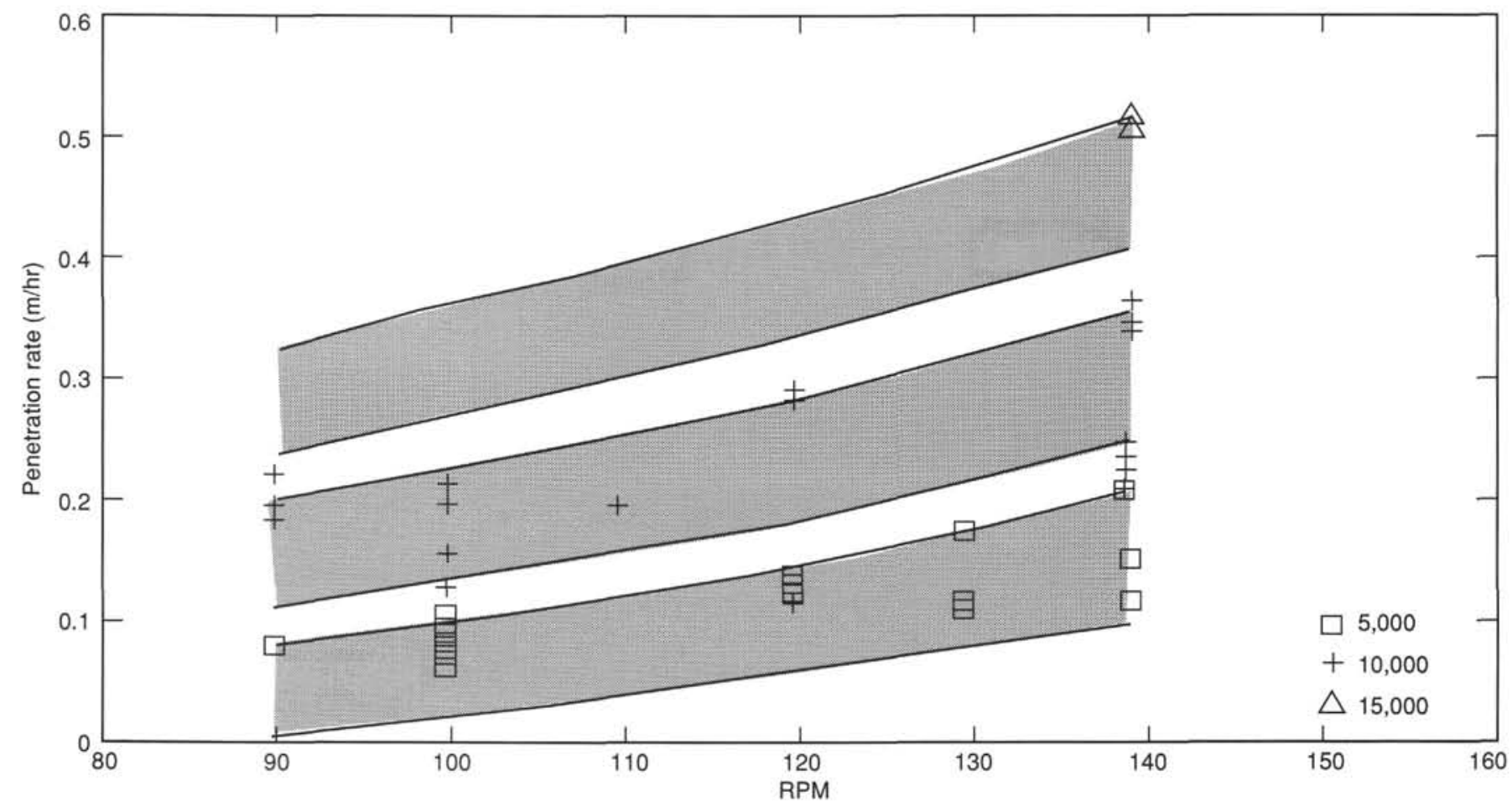

Figure 30. Penetration rate vs. rpm (summary of basalt tests 1-4).

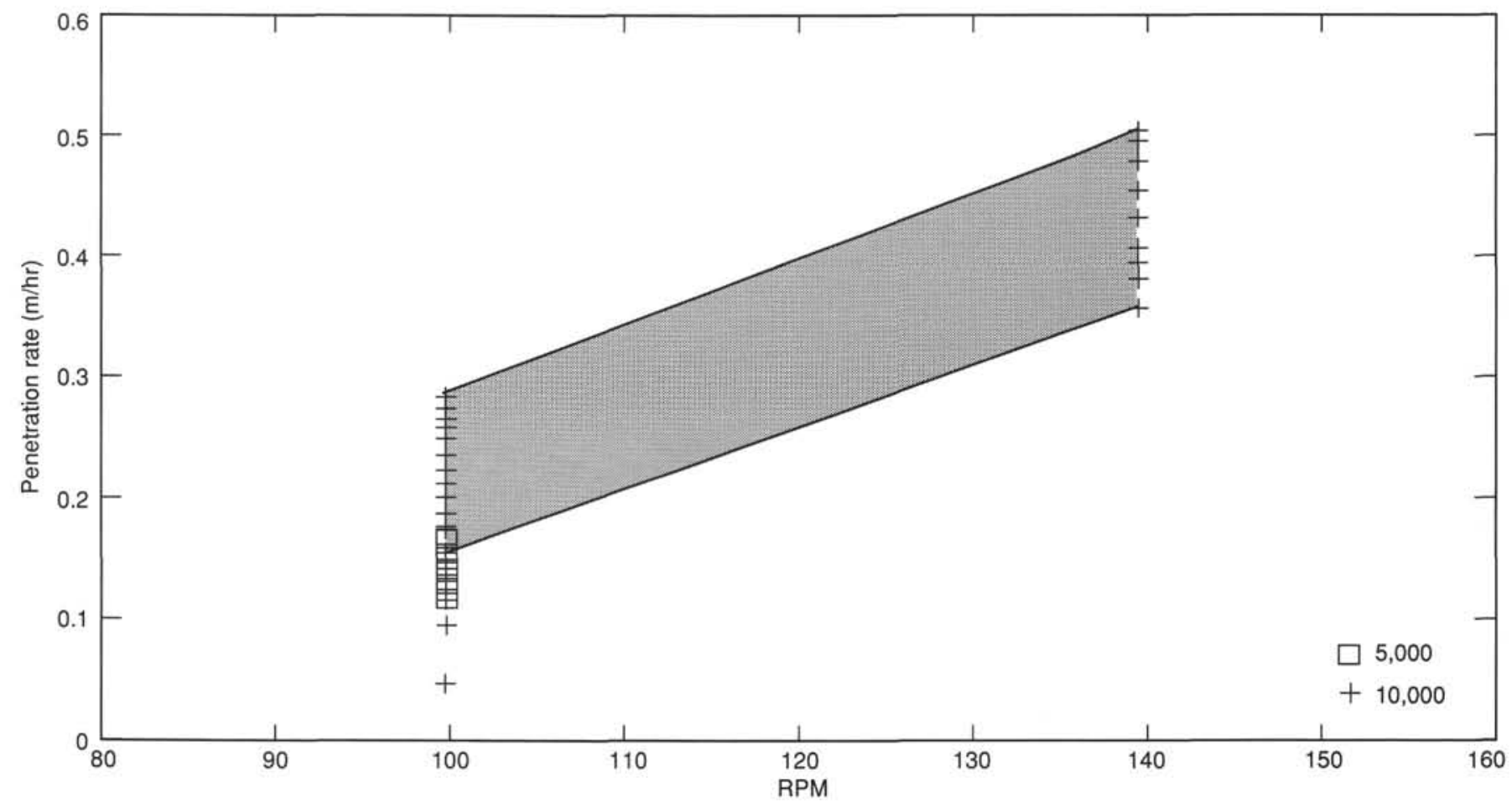

Figure 31. Penetration rate vs. rpm (summary of granite tests 1-5). 
Table 15. Drill bits/latch assemblies in order of occurrence, Leg 142.

\begin{tabular}{|c|c|c|c|c|c|c|c|c|}
\hline Item & Hole & $\begin{array}{c}\text { Bit } \\
\text { description }\end{array}$ & $\begin{array}{l}\text { Size } \\
\text { (in.) }\end{array}$ & $\begin{array}{c}\text { Depth } \\
\text { drilled (m) }\end{array}$ & $\begin{array}{c}\text { Total } \\
\text { penetration }(m)\end{array}$ & $\begin{array}{l}\text { Hours } \\
\text { drilled }\end{array}$ & $\begin{array}{c}\text { Center } \\
\text { bit }\end{array}$ & $\begin{array}{l}\text { Latch } \\
\text { system }\end{array}$ \\
\hline 1 & $864 \mathrm{~A}$ & 6-cone roller bit & $12-1 / 2 \times 7-3 / 8$ & 3.4 & 3.4 & 24 & $7-1 / 4,2$-cone & Dual latch \\
\hline 2 & $864 \mathrm{~A}$ & Tricone bit & $12-1 / 2$ & 3 & 6.6 & 3 & N/A & N/A \\
\hline 3 & $864 \mathrm{~A}$ & 6-cone roller bit & $12-1 / 2 \times 7-3 / 8$ & 0 & 6.6 & 3 & 7-1/4, 2-cone & Dual latch \\
\hline 4 & $864 \mathrm{~A}$ & Surface set diamond & $11-1 / 4 \times 7-3 / 8$ & 0 & 6.6 & 3 & $7-1 / 4,1$-cone & Dual latch \\
\hline 5 & $864 \mathrm{~A}$ & Tricone bit & $12-1 / 2$ & 0.5 & 7.1 & 6.5 & N/A & N/A \\
\hline 6 & $864 \mathrm{~A}$ & Modified roller cone & $12-1 / 2 \times 7-3 / 8$ & 0 & 7.1 & 1 & 7-1/4, 2-cone & Dual latch \\
\hline 7 & $864 \mathrm{~A}$ & Tricone bit & $7-1 / 4$ & 6.2 & 13.3 & 3.25 & N/A & N/A \\
\hline 8 & $864 \mathrm{~A}$ & Impregnated diamond bit & $7-1 / 4 \times 4.05$ & 0 & 13.3 & 0.5 & None & None \\
\hline 1 & $864 B$ & Surface set diamond & $7-1 / 4 \times 4.05$ & 0.6 & 0.6 & 2.5 & 4 l-cone & Mod. XCB \\
\hline 2 & $864 \mathrm{~B}$ & Impregnated DCB bit & $7-1 / 4 \times 2.312$ & 0 & 0.6 & 2.75 & N/A & N/A \\
\hline 3 & $864 \mathrm{~B}$ & Tricone & $7-1 / 4$ & 6.7 & 7.1 & 3.5 & N/A & N/A \\
\hline 4 & $864 \mathrm{~B}$ & Impregnated DCB bit & $7-1 / 4 \times 2.312$ & 0 & 0 & 2.5 & N/A & N/A \\
\hline 5 & $864 B$ & Modified drag & $6-3 / 4 \times 4.05$ & 0.2 & 7.3 & 1.25 & None & None \\
\hline 1 & $864 \mathrm{C}$ & Surface set diamond & $7-1 / 4 \times 4.05$ & 6.9 & 6.9 & 8.5 & 4-2 cone & Mod. XCB \\
\hline
\end{tabular}

Note: A 9-1/2-in. junk mill was run prior to the initiation of the tricone, which produced an additional $0.2 \mathrm{~m}$ of penetration.

Table 16. Bit summary, Leg 142.

\begin{tabular}{|c|c|c|c|c|c|c|c|c|c|c|}
\hline Item & Hole & $\begin{array}{c}\text { Bit } \\
\text { description }\end{array}$ & Manufacturer & Size (in.) & Jets & Serial number & Drilled (m) & $\begin{array}{c}\text { Total } \\
\text { penetration } \\
\text { (mbsf) }\end{array}$ & $\begin{array}{l}\text { Hours } \\
\text { drilled }\end{array}$ & IADC grade $^{a}$ \\
\hline 1 & $864 \mathrm{~A}$ & M89TF 6-cone & Security & $12-1 / 2 \times 7-3 / 8$ & N/A & 498999 & 3.4 & 3.4 & 24 & $2,2, \mathrm{LC}, 1-5,3, \mathrm{O}, \mathrm{JD}, \mathrm{TD}$ \\
\hline 2 & $864 \mathrm{~A}$ & Concave mill & Gotco & $9-1 / 2$ & $4-\# 32$ & N/A & 0.2 & 3.6 & 6 & N/A \\
\hline 3 & $864 \mathrm{~A}$ & M89FL 3-cone & Security & $12-1 / 2$ & $3-\# 14$ & 564550 & 3 & 6.6 & 3 & 1,6,LT,H,E,I,E,R,TD \\
\hline 4 & $864 \mathrm{~A}$ & M89TF 6-cone & Security & $12-1 / 2 \times 7-3 / 8$ & N/A & 498998 & 0 & 6.6 & 3 & $0,0, \mathrm{LC}, \mathrm{X}, \mathrm{E}, \mathrm{I}, \mathrm{X}, \mathrm{TD}$ \\
\hline 5 & $864 \mathrm{~A}$ & Concave mill & Gotco & $9-1 / 2$ & $4-\# 32$ & N/A & 0 & 6.6 & 3 & N/A \\
\hline 6 & $864 A$ & SS diamond & Longyear & $11-1 / 4 \times 7-3 / 8$ & N/A & L84062 & 0 & 6.6 & 3 & $2,3, \mathrm{JD}, \mathrm{N}, \mathrm{X}, \mathrm{I}, \mathrm{NO}, \mathrm{TD}$ \\
\hline 7 & $864 \mathrm{~A}$ & M89FL 3-cone & Security & $12-1 / 2$ & $3-\# 14$ & 564550 & 0.5 & 7.1 & 6.5 & \\
\hline 8 & $864 A$ & Modified roller cone & Security & $12-1 / 2 \times 7-3 / 8$ & N/A & 498999 & 0 & 7.1 & 1 & N/A \\
\hline 9 & $864 \mathrm{~A}$ & C-7 3-cone & RBI & $7-1 / 4$ & 3-\#14 & BD202 & 6.2 & 13.3 & 3.25 & $2,1, \mathrm{BT}, \mathrm{A} 3, \mathrm{E}, 3 / 32, \mathrm{SD}, \mathrm{BHA}$ \\
\hline 10 & $864 \mathrm{~A}$ & Impregnated diamond & Hobic & $7-1 / 4 \times 4.05$ & N/A & & 0 & 13.3 & 0.5 & N/A \\
\hline 1 & $864 \mathrm{~A}$ & M89TF 2-cone & Security & $7-1 / 4$ & $2-\# 20$ & 498838 & 3.4 & 3.4 & 24 & 2,2,ND,A3,E,I,NO,BHA \\
\hline 2 & $864 A$ & M89TF 2-cone & Security & $7-1 / 4$ & $2-\# 20$ & 498837 & 3 & 6.6 & 3 & 0,1,CT,M,E,I,LC,TD \\
\hline 3 & $864 \mathrm{~A}$ & C-71-cone & RBI & $7-1 / 4$ & $2 \# 16$ & BD143 & 0 & 6.6 & 3 & $0,0, \mathrm{NO}, \mathrm{X}, \mathrm{E}, \mathrm{I}, \mathrm{NO}, \mathrm{TD}$ \\
\hline 4 & $864 \mathrm{~A}$ & M89TF 2-cone & Security & $7-1 / 4$ & $2-\# 20$ & 498837 & 0 & 7.1 & 1 & $0,1, C T, M, E, I, L C, T D$ \\
\hline 1 & $864 \mathrm{~B}$ & SS diamond & Longyear & $7-1 / 4 \times 4.05$ & N/A & L84064 & 0.6 & 0.6 & 2.5 & 3,3,RO,S,X,2/16,ER,PR \\
\hline 2 & $864 \mathrm{~B}$ & Impregnated DCB & Hobic & $7-1 / 4 \times 2.312$ & N/A & $1 \mathrm{HI} 432$ & 0 & 0.6 & 2.75 & $1,1, P, A, X, I, P N, P R$ \\
\hline 3 & $864 \mathrm{~B}$ & C-7 3-cone & RBI & $7-1 / 4$ & $3-\# 14$ & BD203 & 6.7 & 7.1 & 3.5 & $2,2, \mathrm{CT}, \mathrm{H} 1, \mathrm{E}, 2 / 16, \mathrm{SD}, \mathrm{BHA}$ \\
\hline 4 & $864 \mathrm{~B}$ & C-7 3-cone & RBI & $7-1 / 4$ & $3-\# 14$ & BD203 & 0 & 0 & 2.5 & 2,2,BT,H1,E,3/32,SD,BHA \\
\hline 5 & $864 \mathrm{~B}$ & Impregnated DCB & Hobic & $7-1 / 4 \times 2.312$ & N/A & $1 \mathrm{HI} 432$ & 0.2 & 7.3 & 2.5 & 3,3,P,A,X,I,NO,PR \\
\hline 6 & $864 B$ & Mod. drag & Longyear & $6-3 / 4 \times 4.05$ & N/A & L84064 & 0 & 0 & 1.25 & N/A \\
\hline 1 & $864 \mathrm{~B}$ & C-7 1-cone & RBI & 4 & $2 \# 16$ & BD132 & 0.6 & 0.6 & 2.5 & $0,0, \mathrm{NO}, \mathrm{X}, \mathrm{E}, \mathrm{I}, \mathrm{NO}, \mathrm{PR}$ \\
\hline 1 & $864 \mathrm{C}$ & SS diamond & Longyear & $7-1 / 4 \times 4.05$ & N/A & L84063 & 6.9 & 6.9 & 8.5 & $4,6, \mathrm{SD}, \mathrm{S}, \mathrm{X}, 1 / 32, \mathrm{TD}$ \\
\hline 1 & $864 C$ & $\mathrm{H} 100 \mathrm{~F}$ & Security & 4 & $2-\# 16$ & 499265 & 6.9 & 6.9 & 8.5 & $2,2, \mathrm{SD}, \mathrm{E}, 1 / 16, \mathrm{NO}, \mathrm{TD}$ \\
\hline
\end{tabular}

Notes: $\mathrm{SS}=$ surface set diamonds bit; $\mathrm{DCB}=$ diamond core barrel; $\mathrm{RBI}=$ Rock $\mathrm{Bit}$ Industries.

"Key to IADC grades: $\mathrm{O}=$ outer one-third of bit; $\mathrm{JD}=$ junk damage; $\mathrm{TD}=$ total depth; $\mathrm{LT}=$ lost teeth/cutters; $\mathrm{H}=$ heel rows; $\mathrm{E}=$ bearing seals effective; $\mathrm{ER}=$ erosion; $\mathrm{LC}=$ lost cone; $\mathrm{I}=$ in gage; $\mathrm{N}=$ nose rows; $\mathrm{NO}=$ no dull/no other wear; $\mathrm{BT}=$ broken teeth/cutters; $\mathrm{A}=$ all rows; $\mathrm{SD}=$ shirttail damage; $\mathrm{ND}=$ nose damage; $\mathrm{CT}=$ chipped teeth; $\mathrm{M}=$ middle row; $\mathrm{RO}=$ ring out; $\mathrm{R}=$ row; $\mathrm{PR}=$ penetration rate; $\mathrm{P}=$ polished; $\mathrm{X}=$ chisel tooth; $\mathrm{PN}=$ plugged nozzle; $\mathrm{A} 3=$ all rows, 3 -cone; $\mathrm{Hl}=$ heel rows, 1 -cone; $\mathrm{BHA}=$ change bottom-hole assembly. 


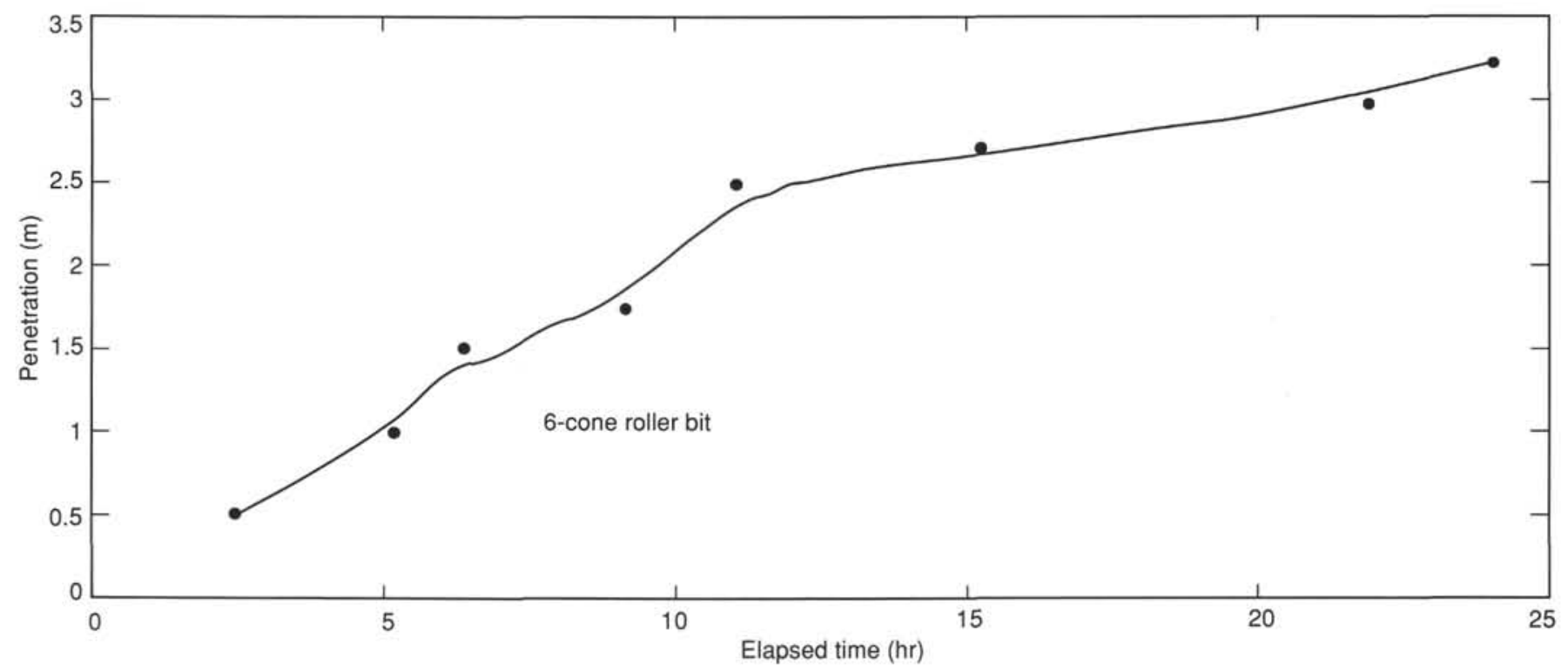

Figure 32. Penetration below seafloor vs. elapsed time (6-cone roller bit). (Note: $2-2.5 \mathrm{~m}$ of heave; massive flow unit.)
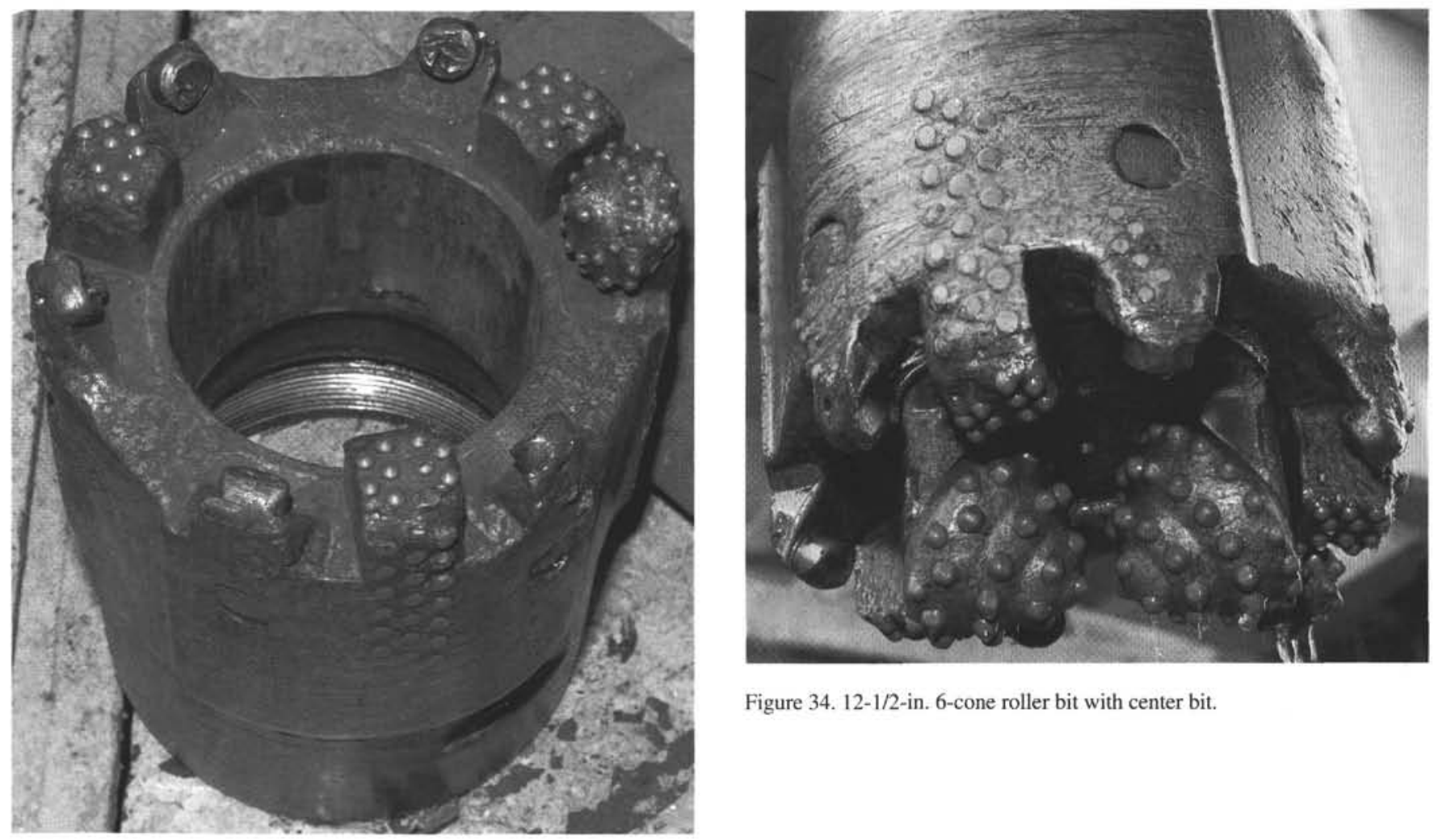

Figure 34. 12-1/2-in. 6-cone roller bit with center bit.

Figure 33. 12-1/2-in. 6-cone roller bit (after $24 \mathrm{hr}$ of rotation). 


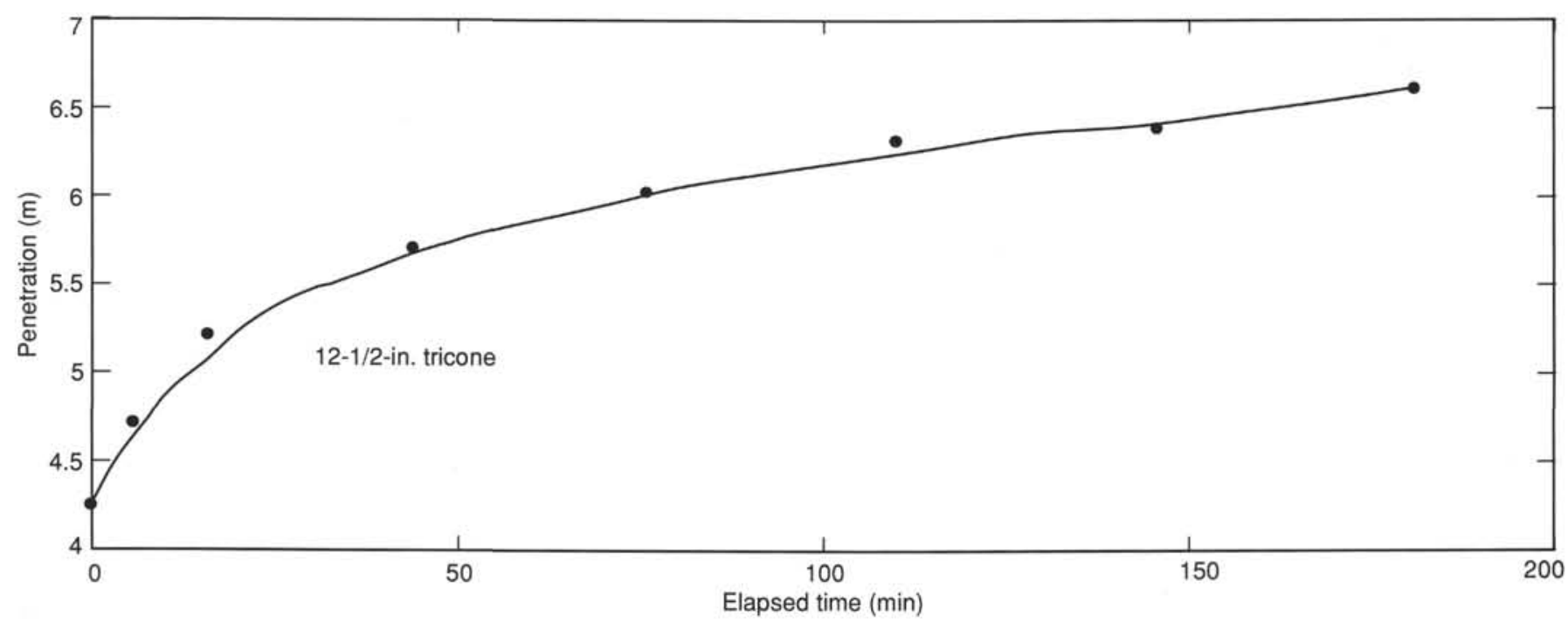

Figure 35. Penetration below seafloor vs. elapsed time (12-1/2-in. tricone). (Note: Heave less than $1 \mathrm{~m}$; broke out of massive flow at $4.2 \mathrm{mbsf}$.)

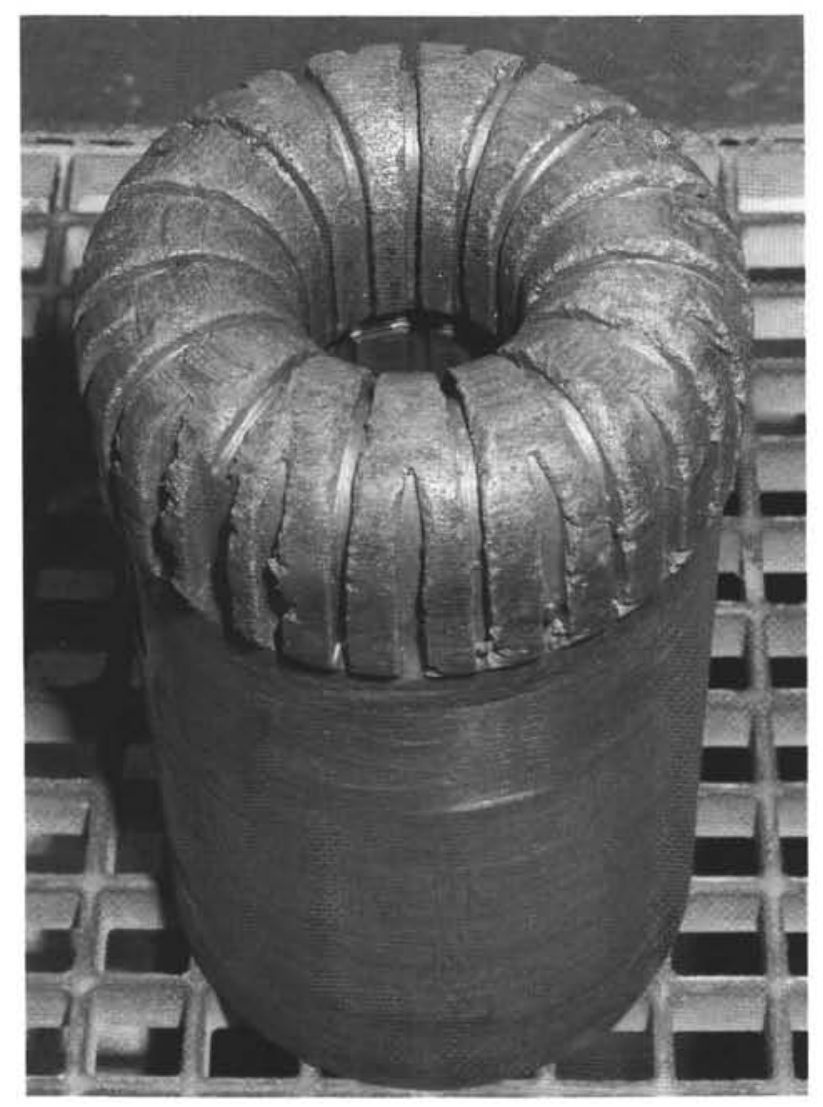

Figure 36. 7-1/4-in. impregnated DCB bit. 


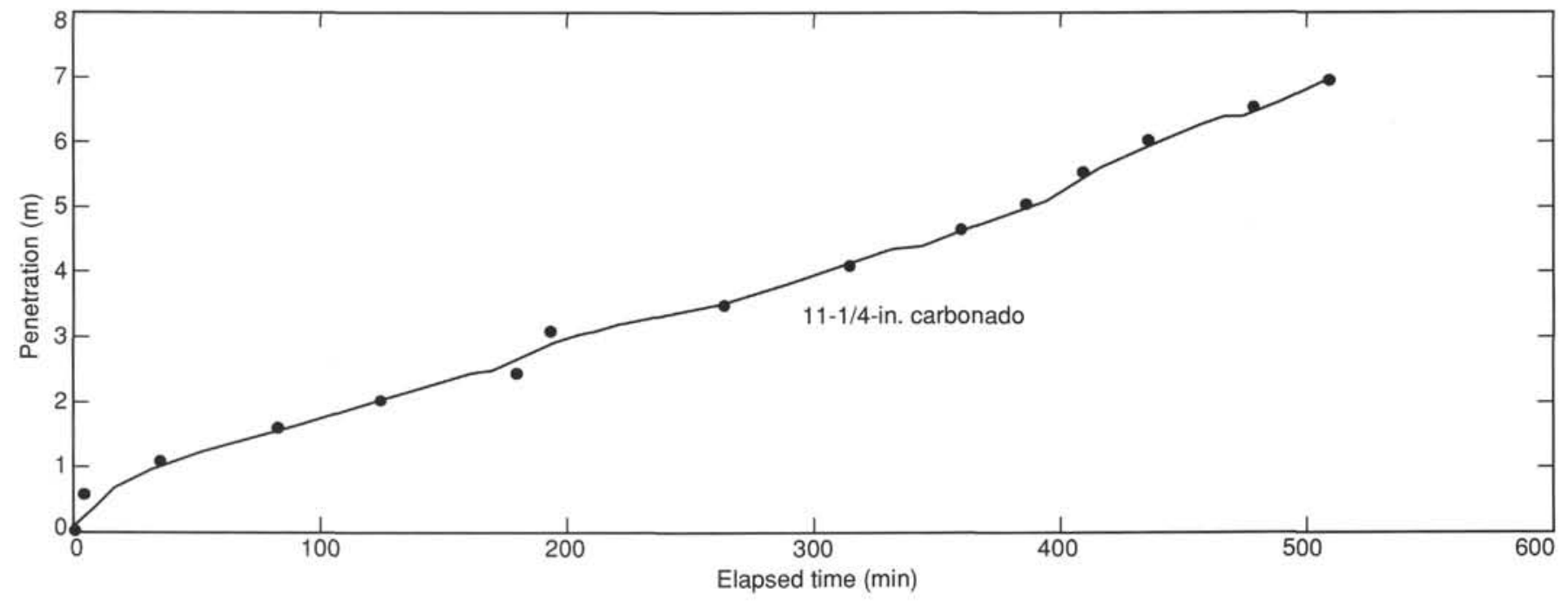

Figure 37. Penetration below seafloor vs. elapsed time (7-1/4-in. carbonado). (Note: Carbonado bit was run with a 4-in. 2-cone center bit.)
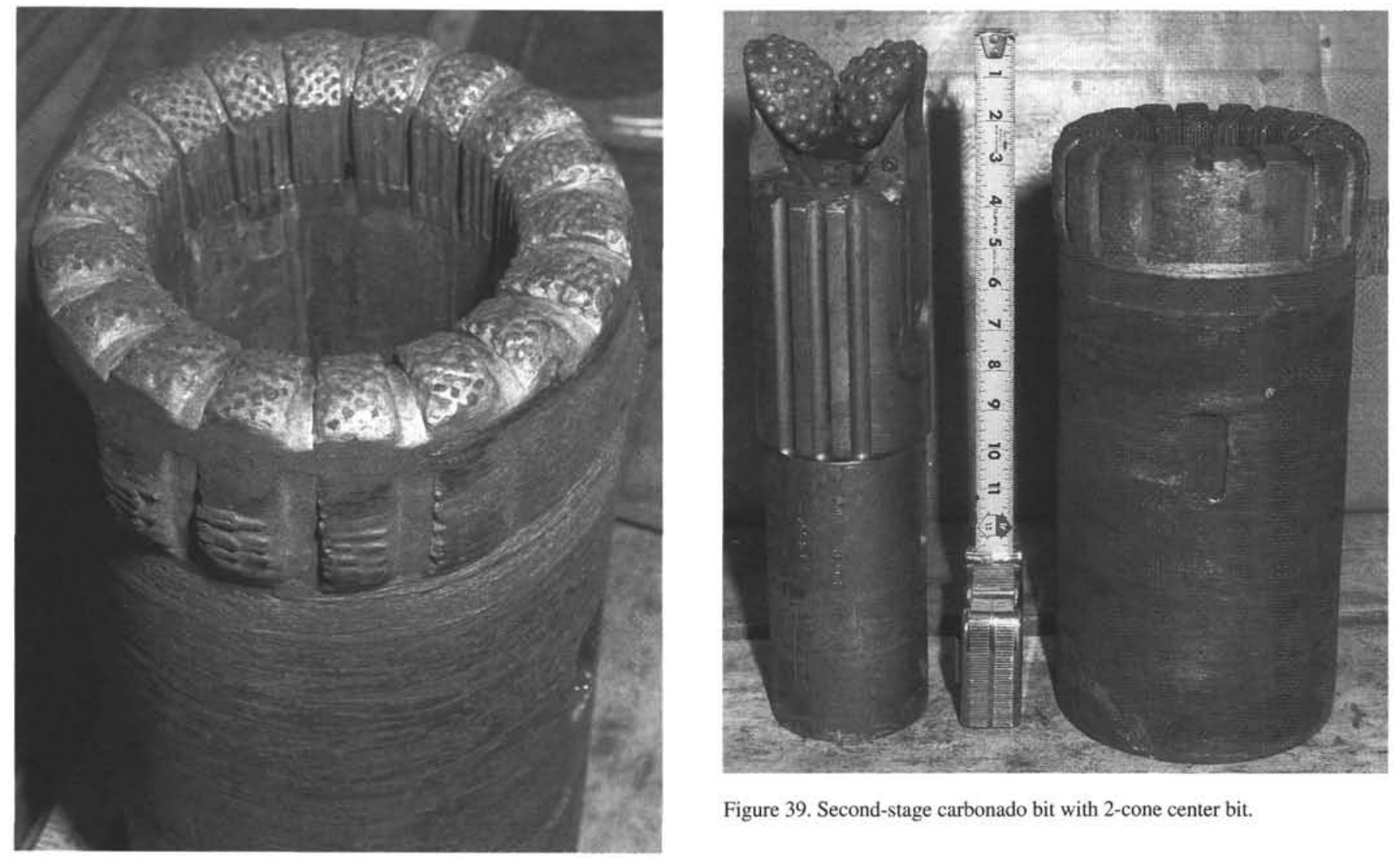

Figure 39. Second-stage carbonado bit with 2-cone center bit.

Figure 38. 7-1/4-in. second-stage drill-in BHA carbonado bit. 


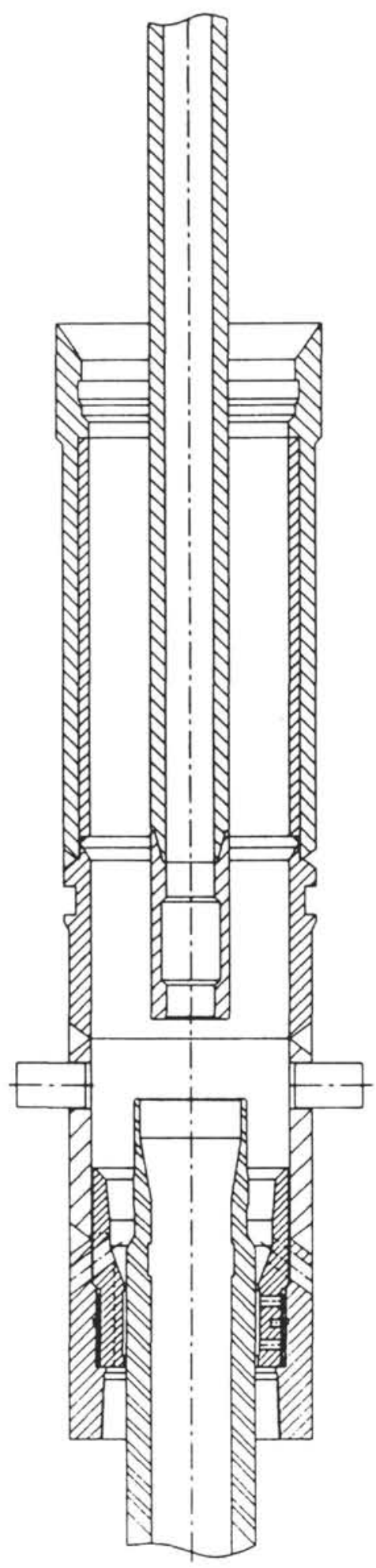

1

Reenter casing hanger with 6-3/4-in. drill collar attached to lower latch sleeve

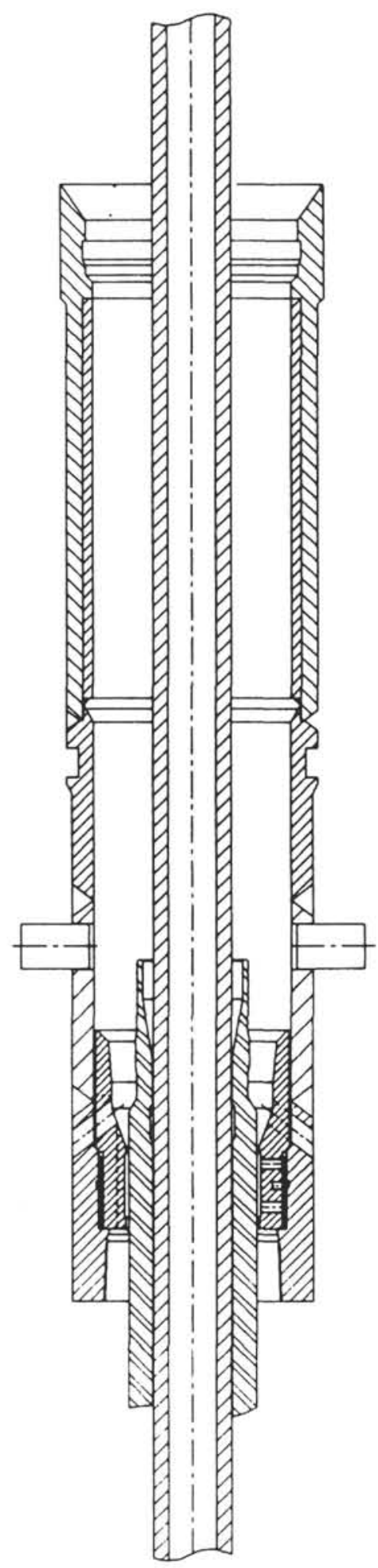

2

Lower latch sleeve inside10-3/4-in. drill collar latch on overshot

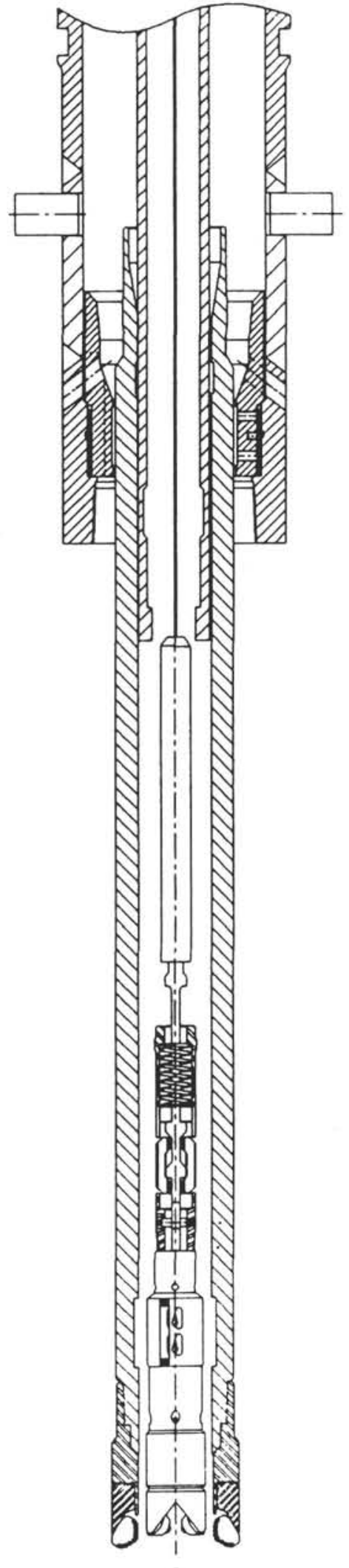

3

Lower overshot assembly onto center bit latch to retract upper dogs

Figure 40. Alternative 7-1/4-in. center-bit latch recovery method. 

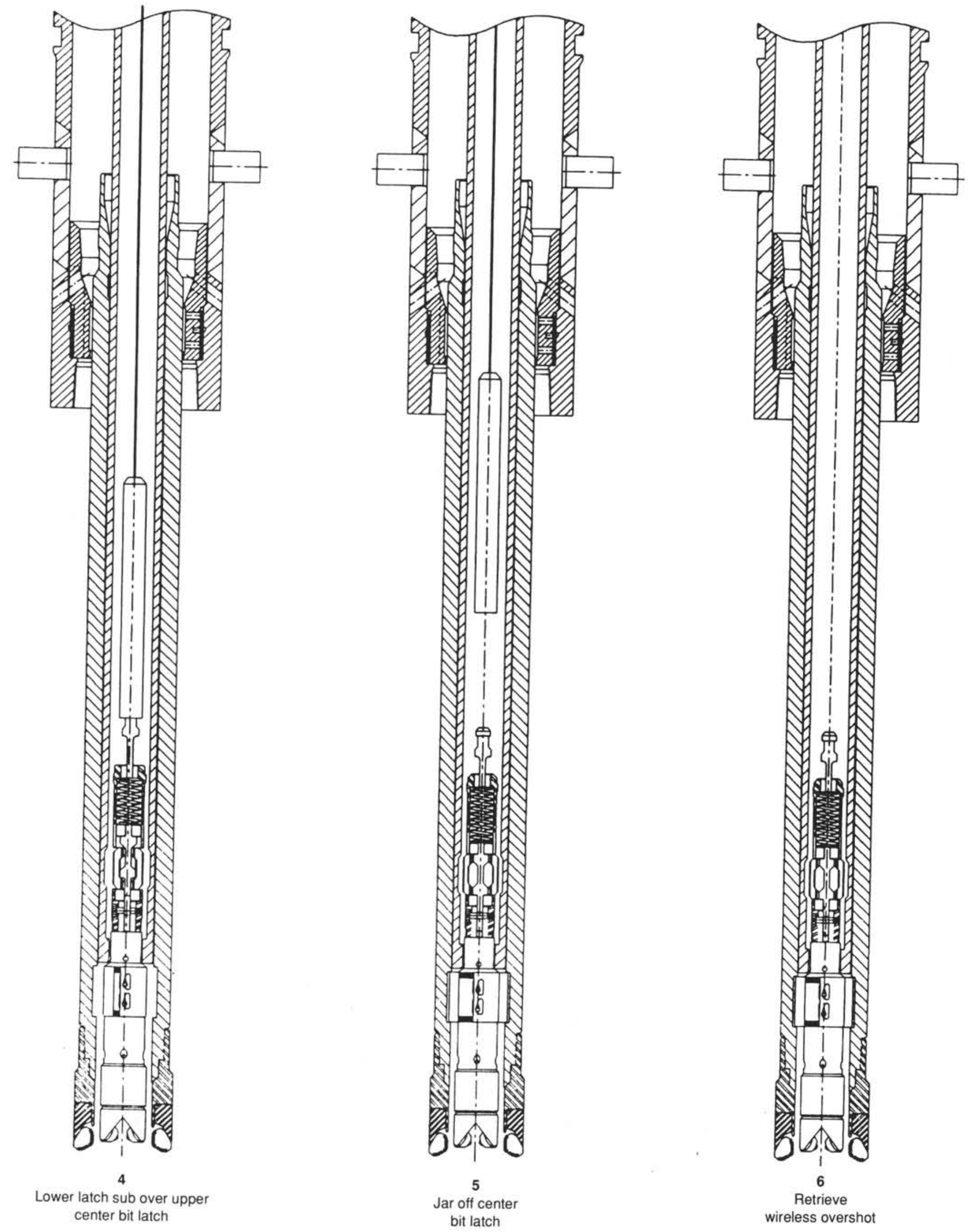

Figure 40 (continued). 


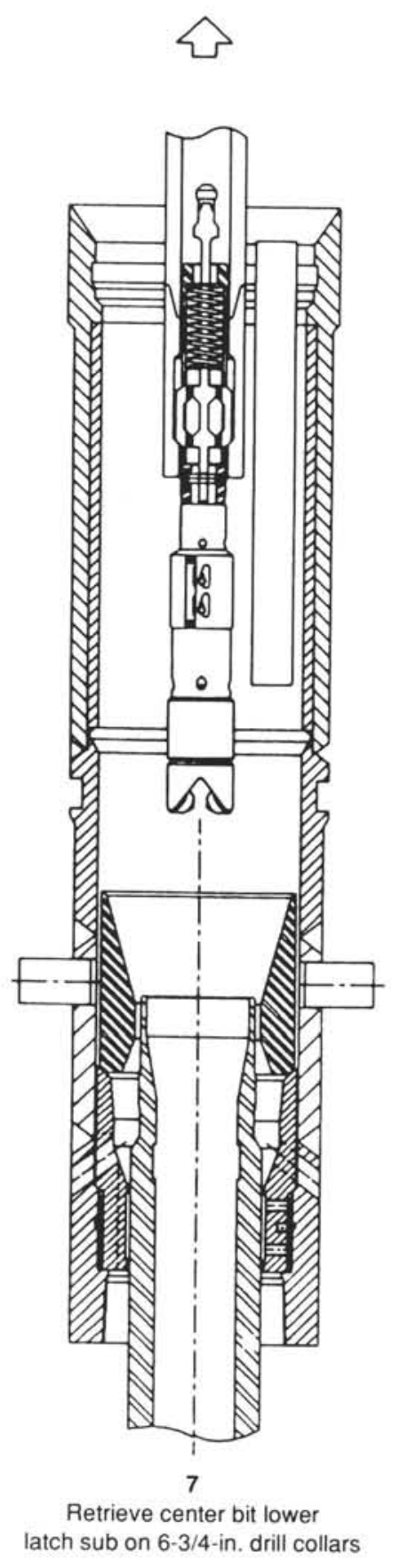

atch sub on $6-3 / 4$-in. drill collars

Figure 40 (continued).

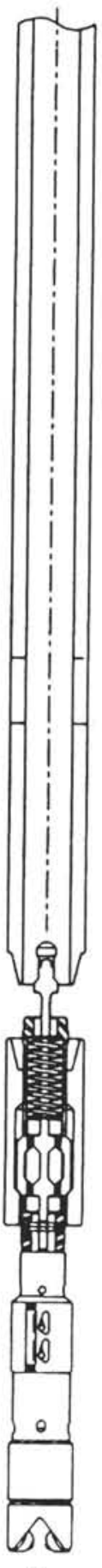

8

Remove lower latch sub from 6-3/4-in. drill collar

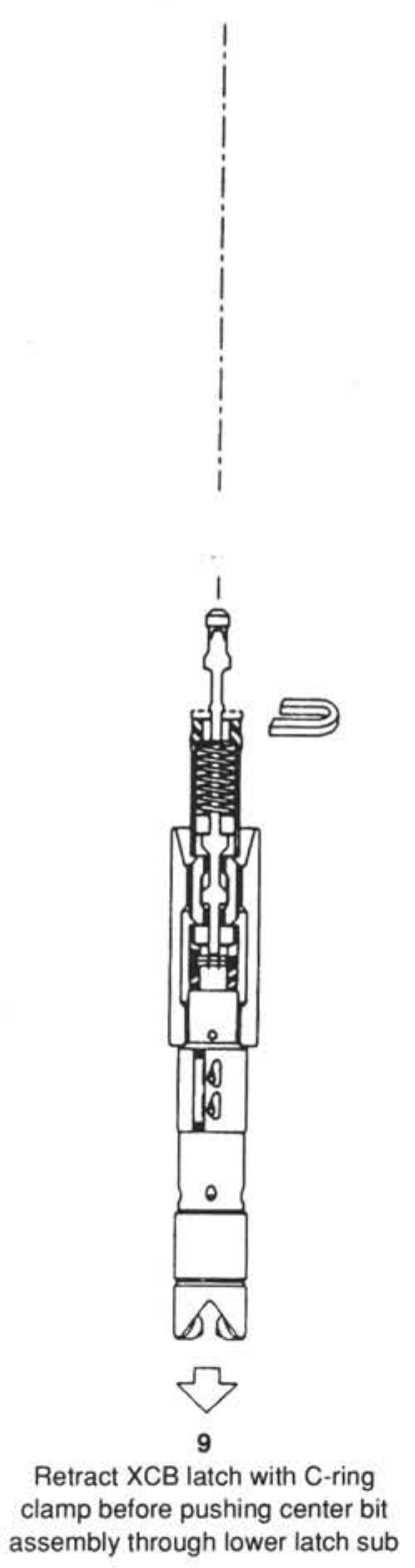

